\title{
Determinants of Emotion Work
}

\author{
Dissertation \\ zur Erlangung des Doktorgrades \\ der Mathematisch-Naturwissenschaftlichen Fakultäten \\ der Georg-August-Universität zu Göttingen
}

vorgelegt von

\section{Andrea Fischbach}

aus Montabaur

Göttingen 2003 
D 7

Referent: Prof. Dr. G. Lüer

Korreferent: Prof. Dr. U. Lass

Tag der mündlichen Prüfung: 
Meinem Vater Karl Fischbach in Liebe und Anerkennung 


\section{Acknowledgments}

I would like to thank Prof. Dr. Gerd Lüer and Prof. Dr. Uta Lass for supervising this dissertation and their helpful comments that helped develop this paper into its present version.

Special thanks are due to Prof. Dr. Dieter Zapf who encouraged my research in emotion work, shared his ideas, and provided support throughout many problems. Discussing the subject with him was always fruitful and inspiring.

I would also like to thank the many students who were involved in collecting data and developing research ideas: first, my students from the experimental courses in the last four years; and second, Dipl.-Psych. Kerstin Kielhorn, Dipl.-Psych. Katrin Meyer, Dipl.-Psych. Juliane Retzlaff, and Dipl.Psych. Astrid Selke who did their theses on emotion work and helped collect data for this dissertation as well as shared their ideas. Research with these students was always fun and I can not imagine this dissertation without their help.

Margarita Neff-Heinrich assisted in the preparation of this dissertation by proofreading and offering helpful suggestions for improving its readability. She was also a real friend in stressful times and available any time I needed hermotivating me with her "we will make it" in times I couldn't imagine it at all. Thank you.

And lastly, a heartfelt "thank you" to my men on the home front-husband Werner and two boys Till and Falk-who spent many weekends without me surviving on more pizza dinners than usual—which probably bothered me more than them. 


\section{Content}

List of Tables and Figures

Research Note

The Redefinition Self-Regulation Model of

The Hackman framework for assessing the effects of tasks

Emotion work external tasks

Emotion work task redefinition process

Results—Field Study Part 1

Method-Experiment 1

Results-Experiment 1

Discussion-Experiment 1

Method-Experiment 2

Results-Experiment 2

Redefinition Determinants of Emotion 
How study findings relate to other emotion work research 


\section{List of Tables and Figures}

\section{Tables}

Table 1

Main Occupational Differences

Table 2 Correlations among Study Variables and

Descriptive Statistics (Field Study Part 1)

Table 3

Multiple Mean Comparisons of FEWS

Table 4

Professional Identity Scales

Table 5

Correlations among Study Variables and

Descriptive Statistics (Field Study Part 2)

Table 6

Organizational Socialization and Professional Identity as Determinants of Emotion Work

\section{Figures}

Figure 1

Hackman Framework for Assessing the Effects of Tasks

Figure 2

Redefinition Self-Regulation Model of Emotion

Work (RS Model)

Figure 3

First part of the RS Model

Figure 4

Simplified RS Model: Effects of External Tasks on Self-Regulation, Task Behavior, and Consequences

Figure 5

Job profiles in Emotion Work Scales

Figure 6

Effect of Display Rule on Effort (Experiment 1)

Figure 7

Effect of Display Rule on State Negative Affect (Experiment 1)

Figure 8

Effect of Display Rule on Emotional Dissonance (Experiment 2)

Figure 9

Effect of Display Rule on State Negative Affect

(Experiment 2) 


\section{Figures (continued)}

Figure $10 \quad$ Effect of Display Rule on Emotional Dissonance (Experiment 3)

Figure 11 Effect of Display Rule on SERVQUAL (Experiment 3)

Figure 12

Simplified RS Model: Effects of External Tasks and Personal Determinants on Task Redefinition 


\section{Research Note}

In Field Study Part 1 and Field Study Part 2, teachers and travel agents data were surveyed by students as part of their thesis. The reported experiments were accomplished by students within three practical courses for course credits, supervised by the author of this dissertation.

Results of Experiments and Field Study Part 1 and 2 were presented at several conferences. 


\section{Emotion Work}

Imagine that you are a police officer policing a demonstration. Suddenly a demonstrator spits on you. How would you instinctively behave in this situation? How should you behave in this situation? Would these behaviors match? Typically there are implicit or explicit organizational expectations regarding how to behave emotionally, such as police officers remaining neutral and objective when interacting with citizens (Fischbach, 2000; Fischbach \& Zapf, 2002). Emotion work (emotional labor) can be defined as emotional job demands and psychological strategies necessary to regulate these demands. Emotional job demands can be summarized into five requirements and one stressor. These five job requirements are the display of positive emotions, negative emotions, neutrality, sensitivity, and sympathy. The job stressor, emotional dissonance, is demanded when these emotional job requirements are not actually felt. This definition allows for a broad, inclusive understanding of emotion work from an organizational perspective, extending beyond efforts and labor limited to the worker.

This study focuses on how emotion work can be understood as a job demand-particularly how emotional dissonance can be understood as a job stressor, and distinguishes emotional demands from strategies applied to fulfill 
these job demands as well as from the consequences of emotion work. Several authors discuss aspects of emotion work concepts as job demands (Brotheridge \& Lee, 1998; Grandey, 2000; Zapf, Vogt, Seifert, Mertini, \& Isic, 1999) but questions remain regarding how to distinguish emotion work job demands from individual work behavior. Controversial views exist, especially regarding the job stressor, emotional dissonance, which was proposed from the onset of emotion work research to affect negative individual consequences (Abraham, 1998; Brotheridge \& Grandey, 2002; Hochschild, 1983; Morris \& Feldman, 1996, 1997; Zapf, Seifert, Schmutte, Mertini, \& Holz, 2001). The innate feelings of the police officer in the above situation probably do not match the organizationallyrequired neutrality, requiring the officer to master (ignore or suppress) an inner conflict in order to comply with his or her job demands. Such situations highlight whether emotional dissonance is limited to a question of individual strategies of self-regulation (Bandura, 1977, 1986; Kanfer, 1990), what emotions are individually triggered by the work situation, what kind of emotional task behavior is displayed, and to what extent this behavior is in line with inner feelings. In contrast to the organizational-focused perspective of this study, some emotion work research takes a more worker-focused perspective regarding emotional dissonance and its negative consequences on individual well-being. Studies that are worker-focused (Brotheridge \& Grandey, 2002; Brotheridge \& Lee, 1998, 2002; Totterdell \& Holman, 2003) consider emotional dissonance as a self-regulation strategy with regard to affective events theory (Weiss \& Cropanzano, 1996). These studies propose that emotions triggered by situations such as spitting at a police officer have to be regulated by hiding, faking, and/or modifying feelings - leading to different, individual-determined consequences. 
Studies that are organizational-focused consider emotional dissonance an organizational job demand independent of individual strategies to regulate this demand - a job stressor leading to predictable negative consequences (Zapf, 2002; Zapf et al., 2001).

This study is based on emotion work literature, theoretical concepts, and empirical findings to date (for an overview see Zapf, 2002) and draws from Hackman's $(1969,1970)$ concept of work behavior and his theoretical framework for studying consequences of organizational tasks. In chapter 2, several conceptualizations and perspectives in emotion work research are integrated into a framework entitled Redefinition Self-Regulation Model of Emotion Work (RS Model). The RS Model attempts to distinguish emotion work demands (job requirements and the stressor emotional dissonance) from strategies in dealing with these job demands and their consequences. In emotion work research, this study is the first to investigate the role of redefinition processes specific to emotion work, redefinition being the cognitive processes involved in transforming an external-assigned task into one's understanding of what one ought to do (Hackman). The RS Model illustrates how this emotion work conceptualization is in concert with general work psychological perspectives. Within the framework of integrated conceptualizations and perspectives in emotion work research, several propositions are deduced from the RS Model about both the antecedents as well as the consequences of emotion work demands and strategies. In an attempt to demonstrate the validity of the majority of these propositions, three pivotal research topics in understanding emotion work are derived from the RS Model and empirically tested in this study: (1) organizational variables affect the definition of emotion work job demands, (2) 
emotional dissonance is a stressor in service work, affected by organizational variables as any other job demand would be, and (3) socialization strategies as an organizational determinant and professional identity as a personal determinant are important variables in understanding the redefinition of emotion work job demands. The first and second research topics are covered in chapter 3-External Task Determinants (external task (Hackman) refers to the external-assigned aspect of emotion work job demands). For the first research topic regarding organizational variables defining emotion work demands, a field study of three highly diverse occupations (police, teachers, and travel agents) is applied to show predictable differences in emotion work job requirements and the stressor, emotional dissonance. The hypotheses regard the differences in the major tasks (organizational-defining tasks) and primary tasks (goal-defining tasks) of these three occupations, which include differences in service- and interdependence characteristics (e.g., customer/client demands, status of service workers, customer/client control parameters). The second research topic-emotional dissonance as a stressor in service work-includes an experimental paradigm to test the proposition that emotional dissonance as an external task is, among the other variables, particularly defined by organizational display rules (organizational expectations regarding emotions; Ekman \& Friesen, 1975) and customer event intensities and qualities (Morris \& Feldman, 1996). Given intensely rude customer behavior where an average person spontaneously feels disgust or anger, emotional dissonance should predictably be evoked by the experimental display rule to be friendly (customer oriented in all circumstances); whereas the display rule to be authentic (be natural and show your true 
personality in all circumstances) should evoke less emotional dissonance. Three experiments are applied to test this experimental paradigm and hypothesized consequences of display rule manipulation. The third research topic regarding socialization strategies and professional identity is the subject of chapter 4 -Redefinition Determinants (redefinition (Hackman) refers to the individualunderstanding aspect of emotion work job demands). The predicted effects of socialization strategies (how organizations communicate their display rules) and professional identity (self-imposed professional role expectations) on reported emotion work requirements and emotional dissonance in police, teacher and travel agent samples are analyzed by means of hierarchical regression analysis. In chapter 5, the findings of this study are discussed with respect to conclusions and suggestions regarding emotion work job design/redesign and management. In chapter 6 , the entire study is summarized. 


\section{The Redefinition Self-Regulation Model of Emotion Work (RS Model)}

In 1983, Arlie Russell Hochschild published the seminal emotion work/emotional labor book, The Managed Heart. Commercialization of Human Feeling. The emotion work research this book set in motion differs in focus regarding how emotion work (a) is defined and identified as a job requirement and/or job stressor, (b) is coped with (strategies) by employees, and/or (c) impacts organizational consequences. The integrative framework of this study is based on these three themes of emotion work and stress literature and models of antecedents and consequences of emotion work (Grandey, 2000; Schaubroeck \& Jones, 2000; Zapf, 2002) as well as Hackman's $(1969,1970)$ seminal framework for assessing stress effects of tasks. The Redefinition Self-Regulation Model of Emotion Work (RS Model) presented in this study is an attempt to integrate diverse conceptualizations and perspectives in emotion work. The RS Model is not intended to be a formal model (direct hypotheses-testing model) of emotion work nor inclusive of every emotion work principle and nuance. The intention of the RS Model is to present a possibly useful understanding of emotion work aspects, sorting out variables which might be important in understanding emotion work antecedents and consequences, applying findings of emotion work research 
to these variables, and deriving new propositions and hypotheses about antecedents and consequences of emotion work.

\subsection{The Hackman framework for assessing the effects of tasks}

The Hackman $(1969,1970)$ framework for assessing the effects of tasks differentiates (a) the input-stage - where an external task is perceived and interpreted by individuals (redefinition process) into an internal task; which in turn affects, (b) the strategy-stage-includes internal processes (personal approaches to carrying out a task and personal evaluations of trial outcomes) as well as actual task behavior; which in turn affects (c) the final outcomestage — consequences of the Hackman-proposed task execution process. Figure 1 (p. 9) is a simplified illustration of this three-stage framework presented by Hackman (1970, p. 213). For purposes of the present study-to show how emotion work might be understood as a job demand and particularly how emotional dissonance might be understood as a stressor - the focus of Figure 1 is on the input-stage elements (external task, task redefinition process, and internal task) and salient constitutional and influencing variables of these elements. Consequently, Hackman's $(1969,1970)$ multiple effects of personal factors in the strategy stage as well as the outcome stage are simplified.

Task definition. External task is defined by Hackman as: "... assigned to a person (or group) by an external agent or is self-generated, and consists of a stimulus complex and a set of instructions which specify what is to be done visà-vis the stimuli. The instructions indicate what operations are to be performed by the performer(s) with respect to the stimuli and/or what goal is to be 
achieved." (Hackman, 1970; p. 210). According to Hackman (1969, 1970), external agent/self-generated determinants affecting the external task are goal instructions, operation instructions, and stimulus material. This definition serves the organizational focus vs. worker focus of the RS Model as it defines the sources of external tasks as being independent of individual work behavior, making it possible to systematically vary objective parameters in experimental situations and investigate their consequences.

Task redefinition process. The second element of Hackman's framework is related to his proposition that an external task is perceived and interpreted by the task performer, who cognitively redefines the task ("what ought I to do?"). Hackman called this process task redefinition, and the outcome variable of this task redefinition, internal task. According to Hackman, personal determinants affecting the task redefinition process involve the individual's understanding of the external task (either adequately or inadequately); acceptance of the task; idiosyncratic needs, values, attitudes, etc.; previous experience with the same or similar tasks; ability; performance motivation; and level of arousal. Consideration of these personal determinants may help to explain why the same external task is often represented and executed differently by different people. Once again this Hackman definition serves the RS Model as it makes clear that the same external task can lead to differences in internal tasks with respect to personal determinants, making it possible to investigate both external task input and personal determinant input and identify their consequences.

Task performance strategies and outcomes. According to Hackman, the input-stage (external tasks redefined into internal tasks) leads to cognitive processes of the task performer, who develops personal approaches relevant to 
the strategy of performance and relevant to actual behavior (internal processes).

This leads to actual task behavior strategies, which in turn has trial outcomes, which in turn affect new strategies of performance (internal processes). This process leads to certain outcomes (consequences). Once again this serves the RS Model as it makes clear that the strategies (internal cognitive processes and task behavior) affect work outcome variables (consequences), making it possible to investigate these strategies and identifying their consequences.

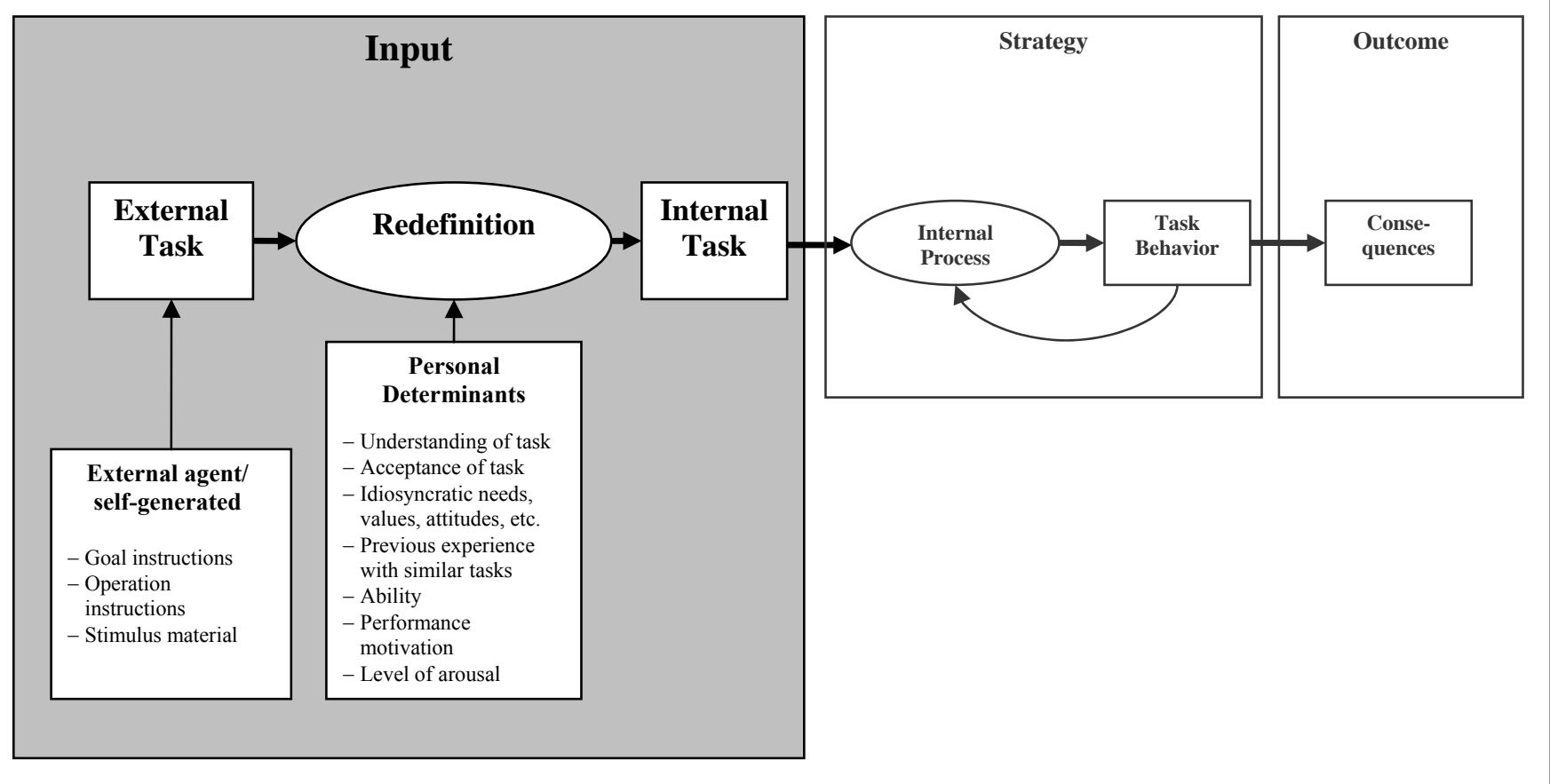

Figure 1. Hackman Framework for Assessing the Effects of Tasks (1970, p.213). 


\subsection{Emotion work external tasks}

Emotion work tasks and service. Emotion work occurs in jobs where serviceworker interactions with customer/clients are required. In service occupations, there are explicit and/or implicit organizational expectations regarding management of emotions, that is: how one's own emotions and the emotions of the interaction partners (customers/clients) should be handled. Hochschild (1983) suggests that there are organizational display rules that specify which emotions (if any) to express in each type of customer interaction. The Hochschild conceptualization is that emotion work is an organizational job demand specific to people work, where emotions have to be displayed and managed by employees in an organizationally-defined manner. An application of this concept is where, in order to close a sale, a salesperson displays friendliness and concern or a doctor might calm a child by joking during the examination (Nerdinger, 2001).

It is important to note that emotion work is not equivalent to service work-there are employees of service occupations without customer/client contact and there are occupations which are not considered service occupations in the economic science definition of service occupations but nevertheless require customer/client interactions (Nerdinger, 1994; Zapf, 2002). The current study applies a psychological interpretation of service (referred to as people work or person-related tasks in emotion work literature) and therefore a psychological use of the terms service organization as well as service worker. In this study, police and teachers are referred to as service occupations even though from an economic science point of view neither police nor teachers qualify as service sector occupations (Nerdinger, 1994). In economic science, a customer or client 
who requests and pays for service is fundamental to service industry definitions - yet in neither of these occupations is a customer paying for service (police and teachers are paid by the society). It is also most likely that under many circumstances, the recipients of police and teacher service do not request said service (e.g., being cited for exceeding speed limit; learning differential math equations). However, police as well as schools are characterizing themselves more and more as service organizations. From an emotion work point of view, these occupations consist of relevant person-related tasks and serviceand interdependence characteristics.

Determinants of external tasks in emotion work. According to Hackman (1969, 1970), an external task can be defined either by an external agent or self generated and is greatly influenced by goal instructions, operation instructions, and stimulus material. In emotion work, the external agent that defines external tasks is the service organization (organizations engaged in people work) with the attendant goal- and operation instructions, and stimulus material (termed organizational determinants in the RS Model). Hochschild has set in motion a body of psychological conceptualizations (Ashforth \& Humphrey, 1993; Grandey, 2000; Morris \& Feldman, 1996; Nerdinger, 1994; Zapf, 2002) and empirical research on emotion work (Abraham, 1998; Brotheridge \& Grandey, 2002; Kruml \& Geddes, 2000; Schaubroeck \& Jones, 2000; Zapf et al., 1999; Zapf et al., 2001; Zerbe, 2000). Summarizing these emotion work conceptualizations and empirical findings relative to external tasks, the framework proposed in this study applies the Hackman perspective of external tasks involving multiple determinants, organizing the emotion work external task determinants under the heading of organizational determinants with the three 
categories of: (a) occupational determinants relative to the type of service organization, (b) inner organizational determinants relative to organizationspecific attributes, and (c) customer event determinants relative to serviceworker-customer/client interactions (Figure 2, p. 37, RS Model).

Occupational determinants of external tasks in emotion work. Based on the major tasks and adherent major goals of the service organization, objectrelated primary tasks (Rice, 1963) and person-related primary tasks and/or subtasks can be derived. Organizational-defining major tasks differ according to occupations. In sales services, a major task might be to sell a certain product and to reach the adherent goals. Object-related primary tasks (e.g., purchasing, stock keeping) are derived and person-related subtasks (e.g., describing aspects of products to customers, giving customers advice) are derived from primary tasks. For doctors, a major task would be health care and a derived person-related primary task would be the diagnosis of a patient. To reach the goals of personrelated primary tasks (e.g., acquire a patient's medical background), social interaction subtasks also have to be achieved (Strauss, Farahaugh, Suczek, \& Wiener, 1980; Zapf, 2002). The present study presumes, in accordance with Zapf (2002), that emotion work is a subtask of a person-related task. Qualitative studies have shown that service occupations have discrete emotional job demands according to occupational-specific tasks (Rafaeli, 1989a; 1989b). The organizational major tasks relate to the Hackman concept that goal instructions define the external task (Figure 1, p. 9). This study postulates that occupational differences in major tasks affect the definition of external tasks in emotion work.

In psychological approaches to service research, there are three well acknowledged service characteristics: intangibility, heterogeneity and 
inseparability (Bowen \& Schneider, 1988; Maister, 1982; Nerdinger, 1994; Parasuraman, Zeithaml, \& Berry, 1988; Schneider \& Bowen, 1984). Intangibility pertains to the issue that service is a construct and that the quality of service can be evaluated only by subjective experiences. Heterogeneity relates to the issue that service encounters are never identical with different customers or even with the same customer at different times. Inseparability describes the phenomenon whereby the production and consumption of service occurs simultaneously. Occupations can differ in the complexity of these service characteristics: the quality of service in a restaurant is easier to evaluate than the quality of a medical diagnosis (Zeithaml, 1981, citation according to Nerdinger, 1994). Heterogeneity is most likely less intense in a shop where single, short interactions between strangers follow behavioral scripts than in a hospital with patients remaining an entire week or longer. Inseparability is typically high for direct person-related service (human services) where the customer/client is the direct object of service (e.g., services provided by nurses, physicians, teachers, and social workers) and low for indirect person-related service where something pertaining to the customer/client is the object of service (e.g., services provided by repair persons, salespersons, tellers), or the arrangement of consumption of a product (e.g., services provided by insurance administrators, investment brokers) (Gross, 1983; Nerdinger, 1994). The organizational service characteristics relate to the Hackman concept that the stimulus material defines the external task (Figure 1, p. 9). This study postulates that occupational differences in service characteristics affect the definition of external tasks in emotion work.

There are many typologies of service occupations (Nerdinger, 1994). One considers the nature and intensity of interdependence between the service worker 
and customer/client. Interdependence involves the dynamic of service workers expressing emotions to influence customer/clients (Kruml \& Geddes, 2000), customer/clients doing the same to influence service workers (Rafaeli, 1989a, 1989b), and that in different occupations, influence strategies and influence possibilities can differ on both sides of the dynamic (Nerdinger, 1994). The first of three aspects of this interdependence concept is the quality of the interaction. Based on Gutek (1997), Holman (2003) classified the quality of service interactions in call centers as encounters vs. relationships. Encounters can be characterized as single, short interactions between strangers, following behavioral scripts where both interaction partners are presumed to not show authentic emotional expression. Service interactions classified as relationships are where the interaction partners typically know each other, have a shared history, and interactions have relatively more leeway where both interaction partners are presumed to show authentic feelings involving trust and loyalty. Zapf, Isic, Bechtoldt, and Blau (2003) argue according to Gutek (1997) and Holman (2003) that direct person-related services can be classified more as relationship interactions whereas indirect person-related services can be described more as encounter interactions, and that different emotion work display rules can be expected according to the different qualities of interactions. The second aspect of interdependence is customer demands. For most service organizations, customer demands are essential to defining organizational goals. For instance, hospital patients expect service based more on the relationship interaction (e.g., the nurse calls him/her by name and shows sympathy); whereas a fast food customer most likely expects service according to the encounter interaction (e.g., standardized greeting asking for food order). Rafaeli and Sutton 
(1990) showed in a structured observation study how customer demands affect actual display of positive emotions of supermarket cashiers (e.g., eye contact, smiling, pleasantness, thank-yous). In sales and other service organizations, high standards in service quality and high customer satisfaction are often explicit goals (Zeithaml \& Bitner, 2000). The third aspect of interdependence is the status and control of service workers relative to customer/clients (Nerdinger, 1994). Doctors have high status and interaction control compared to their patients. It can be assumed that in the context of this interdependence aspect, emotion work demands of doctors and other high status/high interaction control professionals differ from a cashier in a supermarket (Rafaeli, 1989a). The organizational interdependence characteristics relate to the Hackman concept that the stimulus material defines the external task (Figure 1, p. 9). This study postulates that occupational differences in interdependence characteristics affect the definition of external tasks in emotion work.

Taken together, it can be proposed that an external task in emotion work is determined by the occupational major tasks, service characteristics, and interdependence characteristics (Proposition 1).

Inner organizational determinants of external tasks in emotion work. During face-to-face or voice-to-voice interactions, service workers are required to express appropriate emotions as a job demand to help achieve organizational goals and enhance the bottom line. In line with the Goffman (1959) role concept of social interaction, Hochschild (1983) used the metaphor of a drama-where the work setting is seen as a stage, the customer/client is the audience, and the employee is the actor with explicit and/or implicit display rules governing how to 
interact with the customer/client (Ekman \& Friesen, 1975). The concept of display rules exists in much of the emotion work literature. This study relates display rules in emotion work to the Hackman variables goal-and operation instructions (Figure 1, p. 9). Flight attendants are generally required to show positive emotions (Hochschild, 1983); bill collectors (Sutton, 1991) and detectives (Stenross \& Kleinman, 1989) are required to show situationaldetermined negative, positive or neutral emotions; and nurses are particularly required to show sympathy (Buessing \& Glaser, 1999; James, 1989, 1992). There is a body of literature that deals with the question of how, in different corporate cultures, display rules are communicated and how service workers are influenced by various socialization strategies (e.g., Ashforth \& Humphrey, 1993; Hochschild, 1983; Rafaeli, 1989a, 1989b; Rafaeli \& Sutton, 1987; Van Maanen \& Kunda, 1989). Sutton (1991) describes how organizations use socialization strategies such as personnel selection, written materials, supervisor and peer observations, training, and rewards and punishments to manage the emotion norms regarding their bill collector interactions with debtors. Tsai (2001) showed that the psychological climate for service friendliness in a corporate culture was positively related to positive emotions displayed by service workers. This study relates socialization strategies and corporate culture in emotion work to the Hackman variable stimulus material (Figure 1, p. 9). These conceptualizationsdisplay rules, socialization strategies, and corporate culture-are listed as innerorganizational variables in the RS Model (Figure 2, p. 37).

Taken together, it is proposed that an external task in emotion work is determined by inner organizational display rules, socialization strategies, and corporate culture (Proposition 2). 
Customer event determinants of external tasks in emotion work. Most emotion work empirical studies consider the frequency of emotional display as an important aspect of emotion work (Adelmann, 1995; Brotheridge \& Lee, 1998, 2002; Morris \& Feldman, 1996, 1997; Zapf et al., 1999). When a call center agent speaks with 60 to 250 customers per eight-hour shift (Dieckhoff, Freigang-Bauer, Schröter, \& Viereck, 2002), these high numbers of service encounters can be expected to lead to higher frequencies of emotional displays compared to a therapist who might treat a maximum of eight patients per day. It is also plausible that the intensity and duration of emotional display requirements are further aspects of emotion work, suggested by Morris and Feldman (1996) to require attentiveness to display rules. Regarding the quality of customer events, call center agents often report interactions with rude and impolite customers (Dormann, Zapf, \& Isic, 2002), whereas therapists presumably have less negative interactions with clients. The required variety of emotions to be expressed can also differ. A call center agent is most likely expected to express only favorable emotions, but a kindergarten teacher might be expected to express a high variety of emotions ranging from kindness to strictness, depending upon the situation. These factors related to customer events - frequency, intensity, duration, quality, and variety-are listed as customer event parameter values in the RS Model. This study relates customer events to the Hackman external task determinant, stimulus material.

Taken together, it is proposed that an external task in emotion work is determined by customer event frequency, intensity, duration, quality, and variety (Proposition 3). 
Interrelations of organizational determinants. This summarization of the emotional work literature dealing with what in this study is termed occupational, inner organizational, and customer event determinants of external emotion work tasks are proposed to affect the definition of an actual task. Variables referred to as inner organizational determinants (display rules, socialization strategies, and corporate culture) are presumed to be more similar within and more dissimilar among service occupations. It is also presumed that previously discussed customer event parameter values can be expected to be affected by occupational and inner organizational variables as well.

Thus, customer event determinants of external emotion work tasks are expected to be more similar within an organization and more dissimilar among organizations and more similar within an occupation and more dissimilar among occupations; and inner organizational determinants of external emotion work tasks are expected to be more similar within an occupation and more dissimilar among occupations (Proposition 4).

Emotional Dissonance as an external task in emotion work. According to Proposition 1 regarding occupational determinants of external tasks, Proposition 2 regarding inner organizational determinants of emotion work, and Proposition 3 regarding customer event determinants of emotion work, an external task in emotion work is proposed to be defined by a combination of these three aspects and their parameter values (Figure 2, p. 37, RS Model). It is suggested in the literature that display rules requiring the display of specific emotions are associated with situational cues which determine the external emotion work task (Rafaeli \& Sutton, 1987, 1990). Given the display rule to be friendly toward customers in a situation where a customer is complaining in a very rude manner 
(a common work experience in call-center work-Dormann et al., 2002), or given the display rule in police work to be neutral and professional in a death situation (Fischbach, 2000; Fischbach \& Zapf, 2002), it is probably true in both cases that the evoked feelings are not in line with the display rule demands of such situations. As previously mentioned in this study, emotional dissonance occurs when an employee is required to express emotions which are not genuinely felt in the particular situation (Hochschild, 1983). This could be thought of as a person-role conflict in which a person's innate emotional response is in conflict with role expectations regarding the display of emotions (Abraham, 1998; Rafaeli \& Sutton, 1987). Some see emotional dissonance more as a dependent variable (Adelmann, 1995; Ashforth \& Humphrey, 1993), others refer to it as occurring in the emotion work self-regulation process (Brotheridge \& Grandey, 2002; Brotheridge \& Lee, 1998, 2002; Totterdell \& Holman, 2003). Zapf (2002) proposes with regard to action theory and stress research (Frese \& Zapf, 1988, 1994; Zapf et al., 1999) that emotional dissonance is a built-in aspect of the work role and job design, or more specifically a job stressor leading to predictable negative individual consequences (Hochschild, 1983). According to Zapf (2002), the aforementioned propositions regarding external task definition in emotion work, and the application of an external task definition with respect to the Hackman framework $(1969,1970)$, this study proposes that emotional dissonance can more comprehensively be defined as an external work task rather than a personal psychological reaction to emotional display or a personal behavioral strategy. It is contended by this study that as a job demand (stressor), emotional dissonance occurs as a predictable, external task in customer events where the service worker will most likely either feel an emotion which is not in 
line with the emotion required to be expressed (organizational display rule) or feel nothing. As an external task, emotional dissonance is subject to the same determinants, processes, strategies, and consequences as any other external task (Figure 2, p. 37, RS Model).

Thus, Proposition 5 suggests that emotional dissonance is an external emotion work task (Proposition 5).

\subsection{Emotion work task redefinition process}

The RS Model (Figure 2, p. 37) illustrates the redefinition of external tasks as being affected by two sources of input: the emotion work external task and personal determinants. Of all the organizational determinant variables influencing an emotion work external task, it can be argued that display rules and socialization strategies probably play the most important roles. It is generally agreed in emotion work literature that there are expectations of the organization regarding how service workers should behave when interacting with customers/clients (Hochschild, 1983; Schneider \& Bowen, 1984; Zapf, 2002). It is also generally agreed that, compared to manufacturing work, it is much more difficult in service occupations to define specific organizational tasks (external tasks) which can be unambiguously redefined into internal tasks. What exactly does it mean to display role- and situation-appropriate emotions as part of one's job? It is the exception from the rule if a company has documented, explicit display rules governing how to behave in interactions with customers (e.g., Ash, 1984). Display rules (listed as an inner organizational variable in the RS Model) are more often part of the organizational culture and are learned through explicit and implicit processes of organizational socialization (Bauer, Morrison, \& 
Callister, 1998). This complicated nature of communicating and governing service worker display rules limits the possibilities of an organization to directly control not only how tasks are carried out but also organizational and individual consequences, and leads to an increased relevance of indirect organizational control mechanisms as well as individual personal determinants in the employee task redefinition process (Bowen \& Schneider, 1988; Schneider \& Bowen, 1984). As mentioned in section 2.1 and illustrated in Figure 1 (p. 9), Hackman postulates an extensive list of personal determinants that affect the task redefinition process. Regarding emotion work, four of these personal determinants are considered especially relevant: (a) understanding of taskconsidered to be mostly affected by socialization strategies; (b) acceptance of task - which in the context of emotion work is postulated to be mostly a question of individual professional identity; (c) ability — which in the context of emotion work is considered to be mostly a question of emotional competence; and (d) idiosyncratic needs, values, attitudes, etc.- - which in the context of emotion work are expected to be mostly a question of personality factors and gender.

Socialization strategies as an organizational determinant. In accordance with the literature regarding behavior expectations (Hochschild, 1983; Schneider \& Bowen, 1984; Zapf, 2002), the challenges of defining and communicating these display rules (e.g., Ash, 1984), and the Hackman claim that external task understanding in the redefinition process is dependent upon the clarity of the task, it is postulated that the pivotal aspect regarding the success of display rules is if and how service workers learn them. In job roles involving customer interactions, organizational display rules are important as they are presumed to define what the appropriate and expected job behavior is for a particular job. 
Constituent for social roles is that they are sometimes difficult to pin down because individual opinions can differ over what one's role should be (Scott, Mitchell, \& Birnbaum, 1981). The professional role-making/role-taking process (Mead, 1934) is important to organizational socialization and can be mapped out into stages - beginning with group expectations for a particular position, communication processes about these expectations, perceived expectations about the role, actual role behavior, and the feedback of this role behavior compared to group expectations. The goal of socialization strategies is to adapt the employee values, attitudes and skills to the specific job requirement (Scott et al., 1981). It is assumed that the more socialization strategies an employee perceives, the more aware the employee will be regarding role expectations, and theoretically the greater influence the organization display rules will have in the task redefinition process regarding emotion work. Some examples set forth by the present study in which socialization strategies and sources of display rules can be defined and communicated explicitly are by: (1) explanations of superiors; (2) educational courses; (3) vocational training. Examples in which socialization strategies can be communicated implicitly are by: (4) perceived, unspoken part of the company culture; (5) individual job experiences; (6) individual beliefs about norms and values of a profession; and (7) perceived societal expectations of a profession which are typically communicated by the customer or client (Sutton, 1991). It can be contended that the more aware an individual is of explicit- or implicitimparted role expectations (display rules) relative to their job, the more likely they are to redefine their imposed external tasks within the context of organizational expectations. 
It is proposed in this study that socialization strategies as an organizational determinant of external emotion work tasks influence the redefinition process of emotion work (Proposition 6).

Professional identity as a personal determinant. In several studies, display rules are considered more or less conciliative to the individual professional ethos (Ashforth \& Humphrey, 1993; Ashforth \& Tomiuk, 2000; Briner, 1995; Rafaeli \& Sutton, 1987). In a qualitative study, Ashforth and Tomiuk revealed that the interviewed service agents generally believed that their professional task behavior reflect their true selves. They also generally reported that they had to be good actors and fake emotions toward customers/clients in order to do their job well. This seemingly contradictory phenomenon was discussed in the emotion work literature as internalized role playing (Hochschild, 1983; Morris \& Feldman, 1996; Rafaeli \& Sutton, 1987). Ashforth and Tomiuk described this phenomenon as deep authenticity where a required emotion (display rule) is in line with the display rules of a specific identity, internalized and displayed as a reflection of self regardless of whether genuinely felt. They related the concept of authenticity to the service worker question (more likely posed intuitively, holistically and automatic), "do I identify with the role?"professional identity. More clarity to the concept of professional identity can be derived from Stryker's Identity Theory (1987). Identity Theory is based on Symbolic Interactionism (Cooley, 1902; Mead, 1934), which postulates that individuals are members of several social categories (e.g., husband/wife, father/mother, sport-team-member/volunteer, police-officer, etc.). People learn role expectations and role demands primarily through interactions with others. 
Each role produces distinct components of self, generally referred to as role identities. Role identities can usually be defined as self-conceptions, self-referent cognitions, or self-definitions according to the role(s) individuals occupy. Identity, in turn, can usually be defined as the internalized set of these several role identities. Some aspects of a role identity have more self-relevance than others. The commitment to certain aspects of role identities (Foote, 1951) helps to explain the identity salience of that person. An important aspect of Stryker's Identity Theory is that identity seeks validation: the more salient an aspect of an identity, the more receptive one is to behavioral opportunities that confirm that aspect of identity. In service occupations, there are role expectations of the organization and of the customers. By interactions with members of the organization (management, staff, colleagues, and training groups) and with customers, service workers build a sense of who they are as a service professional — what their professional values, goals and beliefs are-and what ought to do and how they ought to behave on the job. According to Stryker, some aspects of the service role can become personally central, salient and valued (e.g., quality-service orientated); others can be discounted as personally unimportant and valueless (e.g., fast-service oriented). It is proposed that, in line with Stryker's Identity Theory, the most salient professional identity aspects of the individual will be evoked in service work situations, and are more likely to lead to redefinitions of external tasks into internal tasks that the individual considers important. It is postulated that awareness of the salient professional identity aspects of the service worker will aid in understanding how individuals redefine external emotion work tasks, and also aid in predicting consequences of emotion work tasks on said individuals. Again citing Stryker's Identity Theory, 
within the same profession it can be expected that there are most likely a multitude of professional identity aspects, and that there are individual differences in the salience of these aspects. These individual differences in professional identity salience, in turn, lead to individual differences in the task redefinition process within the same occupation. The current study argues that in emotion work, professional identity (the internalized set of professional role expectations in one's job) is the fundamental aspect in task acceptance and relates to Hackman's acceptance of task personal determinant in task redefinition. The RS Model lists professional identity as the first of four personal determinants affecting the emotion work external task redefinition process.

It is proposed that professional identity as a personal determinant influences the redefinition process of emotion work (Proposition 7).

Emotional competence as a personal determinant. The Riggio (1986) model of basic social skills proposed that the perception of the emotions of interaction partners and the expressing and controlling of one's emotions in a nonverbal and verbal manner are fundamental social skills. The concept of emotional intelligence was conceptualized by Salovey and Mayer (1989) and popularized by Goleman (1996). Salovey and Mayer distinguished four psychological processes involving emotional information: (a) appraising; (b) expressing emotions in self and others; (c) using emotions adaptively to achieve one's goals; and (d) regulating emotions in self and others. The term competence rather than intelligence is preferred in this study because there are theoretical problems in calling these competences intelligence when distinguishing them from common psychological intelligence concepts (Davies, Stankov, \& Roberts, 
1998; Schuler, 2002). These competences (and the experiences in applying them in customer relations) affect the personal choice of which emotion display is demanded/appropriate in a given situation. A kindergarten teacher perceiving as naughtiness an outburst of fury from a child over an unsolved puzzle will redefine what emotion display is required in this situation more in the manner of strictness and punishment compared to a kindergarten teacher perceiving the outburst as frustration and will more likely redefine the task in a sympathetic, calming manner. Or the experience that children often calm down faster when outbursts are ignored rather than positively reinforced with attention might lead to other task redefinitions such as remaining neutral. This study proposes that in the context of personal determinants influencing the emotion work task redefinition process, emotional competence relates to the Hackman ability variable of personal determinants. The RS Model lists emotional competence as the second of four personal determinants affecting the emotion work task redefinition process.

It is proposed that emotional competence as a personal determinant influences the redefinition process of emotion work (Proposition 8).

Personality and gender as personal determinants. The emotion work literature and empirical research treats other important aspects which fit into the RS Model framework of affecting the redefinition of emotion work external tasks-specifically personality traits and gender (Grandey, 2000; Hochschild, 1983; Schaubroeck \& Jones, 2000). The malleability of aspects affecting emotion work leads to what is termed a weak situation in personality research. It is proposed in this study that emotion work can be assumed to be an organizational 
job demand where many weak situations governed by individual differences occur, and therefore inter-individual behavior differences should be detectible. Schutte, Kenrick, and Sadalla (1985) found that weak situations are often associated with behavioral variance between individuals, one explanation being that individual personality differences influence behavioral variance. Personality traits are known to have a stronger impact on behavior in settings where appropriate activity is not clearly defined (Stewart, Carson, \& Cardy, 1996). In a recent paper, Fischbach and Zapf (2003) proposed that personality traits are crucial to the redefinition process of emotion work because of the leeway of emotion work interpretation. However, the empirically tested effects of personality traits on the redefinition process of emotion work revealed that the influence of personality existed but was less than expected for the redefinition of the work role within a single occupational group. Nevertheless, the body of research on this aspect merits the inclusion of personality as a personal determinant factor influencing the emotion work task redefinition process. The RS Model lists personality as the third of four personal determinants affecting the emotion work task redefinition process.

Gender is also a widely-accepted integral aspect of emotion work (Grandey, 2000; Hochschild, 1983; Schaubroeck \& Jones, 2000) and is therefore included in the RS Model. However, it is doubtful whether theoretical conceptualization and associated empirical support for hypotheses regarding gender in the context of the emotion work redefinition process exists. Presumably, gender influences the redefinition process of an external task, as gender-biased differences in needs and wishes are often considered in the gender and work literature, including the Hackman claim that idiosyncratic needs and 
wishes affect task redefinition. It has been proposed that aspects associated with positive emotional behavior such as friendliness and agreeableness are prototypically female; and that aspects of competitiveness and enforcement behavior are prototypically male (Bakan, 1966; Eagly, 1987; Powell, 1999). One explanation offered in the literature for gender differences is that prototypic male and female work role perception and work role behavior arise from the traditional distribution of men and women in specific occupational roles such as physician (prototypically a male work role) vs. nurse (prototypically a female work role). The RS Model lists gender as the fourth of four personal determinants affecting the emotion work task redefinition process. In this instance, it is proposed that personality and gender relate to the idiosyncratic needs, values, attitudes, etc. variable of the Hackman framework personal determinants component. The RS Model lists personality and gender as two of the four personal determinants affecting the emotion work task redefinition process.

It is proposed that personality and gender as personal determinants influence the redefinition process of emotion work (Proposition 9).

\subsection{Strategies of emotion work}

The second part of the RS Model uses the heading Emotion Work-Strategy to group emotion work conceptualizations dealing with self-regulation processes and variables leading to actual task behavior, emulating the second part of Hackman's (1969, 1970) framework (Figure 1, p. 9). Accordingly, the present study places the Hochschild (1983) claim that several self-regulation processes are typically triggered by emotion work demands in this RS Model Emotion 
Work—Strategy stage comprised of a self-regulation process, task behavior, and feedback of task behavior (Figure 2, p. 37). Hochschild focused on these selfregulation processes as necessary to comply with emotion work job demands. Hochschild defined emotional labor as, "the management of feeling to create a publicly observable facial and bodily display" (p. 7). In cases where the actual emotions of a service worker toward a customer/client are not in line with the display rule (how one should interact with clients), Hochschild proposed that there are two strategies used in order to fulfill the display rules: either surface acting by which only the emotional expression is manipulated in order to fulfill the job demands; or active deep acting by which the feelings of the service worker are actively manipulated in order to fulfill the job demands. The RS Model (Figure 2) lists surface acting and deep acting as two of four strategies evoked by emotional demands involved in emotion work. Ashforth and colleagues (Ashforth \& Humphrey, 1993; Ashforth \& Tomiuk, 2000) described the phenomenon of authenticity in service where a required emotion is spontaneously felt and displayed by the service worker-what is referred to in the literature as surface authenticity_and what was termed by Hochschild as passive deep acting and later termed automatic emotion regulation by Zapf (2002). Surface authenticity, passive deep acting, and automatic emotion regulation are referred to in this study as automatic regulation-listed in the RS Model as the third of four strategies evoked by emotional demands involved in emotion work. Rafaeli and Sutton (1987) defined a fourth emotion work strategy where the employee does not express the job-required emotions and termed this option emotional deviance. Emotional deviance is included in the RS Model as the fourth emotion work strategy. Grandey (1998) and Kruml and Geddes (1998) 
distinguished two high correlating dimensions of emotion work strategies: emotional dissonance and emotional effort. Emotional dissonance refers to Hochschild's concepts of surface acting and active deep acting; and emotional effort refers to the degree to which employees actively try to change their inner feelings in order to match the feelings they are expected to express. The notion of emotional dissonance, high correlating with the concept of emotional effort, is applied in several studies (Brotheridge \& Grandey, 2002; Brotheridge \& Lee, 2002; Grandey, 2000) and positive effects of effort on burnout are shown.

This leads to the proposition that emotional demands affect selfregulation efforts (Proposition 10).

Furthermore, emotional demands affect actual task behavior (Proposition11).

Organizational determinants of emotion work strategies. In the selfregulation literature (Bandura, 1977, 1986; Kanfer, 1990) and stress literature (Zapf \& Semmer, in press), feedback is suggested and empirically tested as an important determinant in the self-regulation/task behavior dynamic. Feedback can be provided by the customer event, where the service worker learns how task performance strategies either promote or hinder goals ("am I successful with this strategy or should I change my strategy to reach my goal?"). The RS Model lists the organizational determinants of customer event feedback as a variable affecting the self-regulation strategies leading to emotion work task behavior. The recursive arrow from task behavior to self-regulation (Figure 2, p. 37, RS Model) illustrates the feedback influence of task-behavior in the self-regulation process. Supervisors and colleagues can also be sources of feedback, supporting 
service-worker development of more efficient and less stressful emotion work strategies. According to action theory and stress research (Frese \& Zapf, 1994; Hacker, 1973, 1998; Zapf, 2002), job autonomy (leeway in decision-making), and supervisor- and coworker support as well as their feedback promote performance of the service worker. Thus, job autonomy, supervisor- and coworker support, and feedback are predicted to have moderator effects in the relationship between emotional dissonance and negative emotion work consequences. The RS Model lists the organizational determinants of inner organizational job autonomy, supervisor-, and coworker support as well as feedback as variables affecting the self-regulation strategies leading to emotion work task behavior.

It is proposed that organizational determinants of customer event feedback and inner organizational extents of job autonomy, supervisor and coworker support, including feedback, affect self-regulation efforts and task behavior of emotion work (Proposition 12).

Personal determinants of emotion work strategies. In her paper dealing with emotion regulation in the workplace, Grandey (2000) suggested that emotional expressivity and emotional intelligence (presumed in the present study to be components of emotional competence), positive/negative affectivity (widely accepted as personality factors), and gender are included in aspects that influence self-regulation. Emotional competences such as masking true feelings, regulating emotions in self and others, and use of emotions in persuading customers/clients are involved in the emotion work strategy process and affect both the success of this process and employee consequences. The effect of personality (particularly positive or negative affectivity) on negative individual 
consequences might be that persons high in negative affectivity respond more intensely to negative events (Weiss \& Cropanzano, 1996) and therefore have a greater probability of suffering burnout. In the empirical study of emotion work/emotional labor and burnout by Brotheridge and Grandey (2002), negative affectivity was positively correlated to all three of the burnout dimensions (emotional exhaustion, depersonalization and reduced personal accomplishment). Grandey (2000) also discussed that women might be more concerned with getting along whereas men might be more concerned with getting by, suggesting different gender-biased emotion work strategies. Influence of personal determinants on emotion work strategies were recently tested by a diary study of Totterdell and Holman (2003), who found that emotional intelligence (measured by a scale of Schutte et al., 1998) was only weakly positively related to deep acting strategies, and that women engaged in both higher levels of negative affect regulation and the faking of emotions (surface acting strategies). Performance, measured by self-description scales (good vs. bad service), was positively related to deep acting strategies but not to surface acting strategies. Emotional exhaustion consequence was positively related to surface acting strategies but not to deep acting strategies. In the self-regulation literature (Bandura, 1977, 1986; Kanfer, 1990) and stress literature (Jex \& Bliese, 1999; Jex, Bliese, Buzzell, \& Primeau, 2001; May, Schwoerer, Reed, \& Potter, 1997; Zapf \& Semmer, in press), self-efficacy is suggested and empirically tested as a further important personal determinant in the self-regulation process and a moderator in the relationship of the stressor emotional dissonance and negative emotion work consequences in the RS Model. Self-efficacy as a personal determinant seems to exert positive emotion work consequences as self-efficacy influences cognitive 
appraisal differences in resources ("am I okay or in trouble?" and "what can I do about this stressful event?") according to the transactional stress model (Lazarus \& Folkman, 1984) and demand resource models (Frese \& Zapf, 1994; Karasek, 1979; Oesterreich \& Volpert, 1999). The four personal determinant variables discussed in this section-emotional competence, personality, gender, and selfefficacy - are listed as personal determinant components in the strategy stage (second part) of the RS Model.

It is proposed that personal determinants of emotional competence, personality, gender and self-efficacy affect self-regulation efforts and task behavior of emotion work (Proposition 13).

\subsection{Consequences of emotion work}

This study proposes that several emotion work consequences need to be considered: employee consequences (negative or positive, short-term and/or long-term); customer satisfaction; and inner organizational success (Figure 2, p. 37, RS Model). Once again emulating the Hackman $(1969,1970)$ input-strategyoutcome framework (Figure 1,p. 9), the RS Model uses the consequence heading to group propositions and findings in the emotion work literature regarding positive and negative consequences of emotion work.

Employee consequences were a pivotal claim of Hochschild's book (1983). She described various negative psychological consequences of emotion work and maintained that showing emotions not felt at the moment (emotional dissonance) leads to the alienation of one's feelings, negative affective states, and eventually causes long-term psychological ill health. Most empirical studies have analyzed relationships between aspects of emotion work and long-term 
consequence of emotion work, especially the burnout dimensions (emotional exhaustion, depersonalization and reduced personal accomplishment) and have found correlations between emotional dissonance and emotional exhaustion (Abraham, 1998; Brotheridge \& Lee, 1998; Grandey, 1998; Kruml \& Geddes, 1998; Morris \& Feldman, 1997; Nerdinger \& Röper, 1999; Zapf et al., 1999, 2001), as well as correlations between emotional dissonance and depersonalization (Kruml \& Geddes, 1998; Zapf et al., 1999). Correlations have also been found between emotional dissonance and reduced personal accomplishment (Abraham, 1998; Morris \& Feldman, 1997; Zapf et al., 1999), supporting Hochschild's view that emotion work is likely to have negative employee consequences. This study expands the concept of emotion work and attempts to present it as a multi-dimensional construct. This inclusive approach allows the incorporation of positive correlations that have been found between several aspects of emotion work and job satisfaction (Adelmann, 1995; Morris \& Feldman, 1997; Rutter \& Fielding, 1988; Wharton, 1993; Zapf et al., 1999) as a long-term emotion work consequence and corresponding positive affective states as an immediate consequence of emotional regulation and task performance.

In the context of emotion work where the service encounter can be viewed as intrinsic to the job, the criteria for the assessment of task behavior is service quality and includes the quality of the interaction (e.g., SERVQUAL instrument of Parasuraman et al., 1988). In the RS Model it is proposed that an external task redefined to an internal task leads to self-regulation and actual task behavior describable in this example as good vs. bad service quality, and this in turn leads to the inner organizational success or failure and customer satisfaction or dissatisfaction. The RS Model lists organizational consequences as including 
consequences impacting the employee, customer satisfaction, and inner organizational success.

This leads to the proposition that employee consequences, customer satisfaction, and inner organizational success are consequences of emotion work- depending on the external task, task redefinition, internal task, self-regulation strategy, and actual task behavior (Proposition 14).

\subsection{Summary of the RS Model}

The Redefinition Self-Regulation Model of Emotion Work (RS Model) attempts to integrate diverse emotion work conceptualizations and empirical research, applying an organizational focus to emotion work. This organizational focus is especially useful in demonstrating that the emotion work job stressor, emotional dissonance, can be understood as an external task and is subject to the same determinants, strategies, and consequences as any other external task.

The first part of the RS Model entitled "Emotion Work-Job Demand" attempts to illustrate that emotion work job requirements (displays of positive emotions, negative emotions, neutrality, sensitivity-, and sympathy requirements) and the emotion work job stressor, emotional dissonance, are external tasks which are redefined into internal tasks. These emotion work external tasks are defined and influenced by organizational determinants (occupational, inner organizational, and customer event) and this body of organizational determinants, working together with personal determinants (professional identity, emotional competence, personality, and gender), are involved in the redefinition process that redefines external tasks into internal tasks. 
The second part of the RS Model is entitled "Emotion Work-Strategy" and is characterized by strategies (surface acting, deep acting, automatic regulation, or emotional deviance) evoked by emotional demand. These strategies require different degrees of effort of self-regulation and actual task behavior. Self-regulation is influenced by organizational determinants of customer event feedback and inner organizational extents of job autonomy, supervisor- and coworker support including their feedback. Self-regulation is also influenced by personal determinants of emotional competence, personality, gender, and self-efficacy. The self-regulation process leads to actual task behavior-providing recurrent customer event feedback that influences the selfregulation process.

Emotion work task behavior leads to the third and final part of the RS Model entitled "Consequences." Three categories of organizational consequences are: various employee consequences, various levels of customer satisfaction, and various levels of inner organizational success. Employee consequences are characterized by ranges of negative or positive, short-term and/or long-term, and are listed as negative affect, performance, burnout, positive affect, and job satisfaction. Figure 2 illustrates the Redefinition Self-Regulation Model of Emotion Work. 


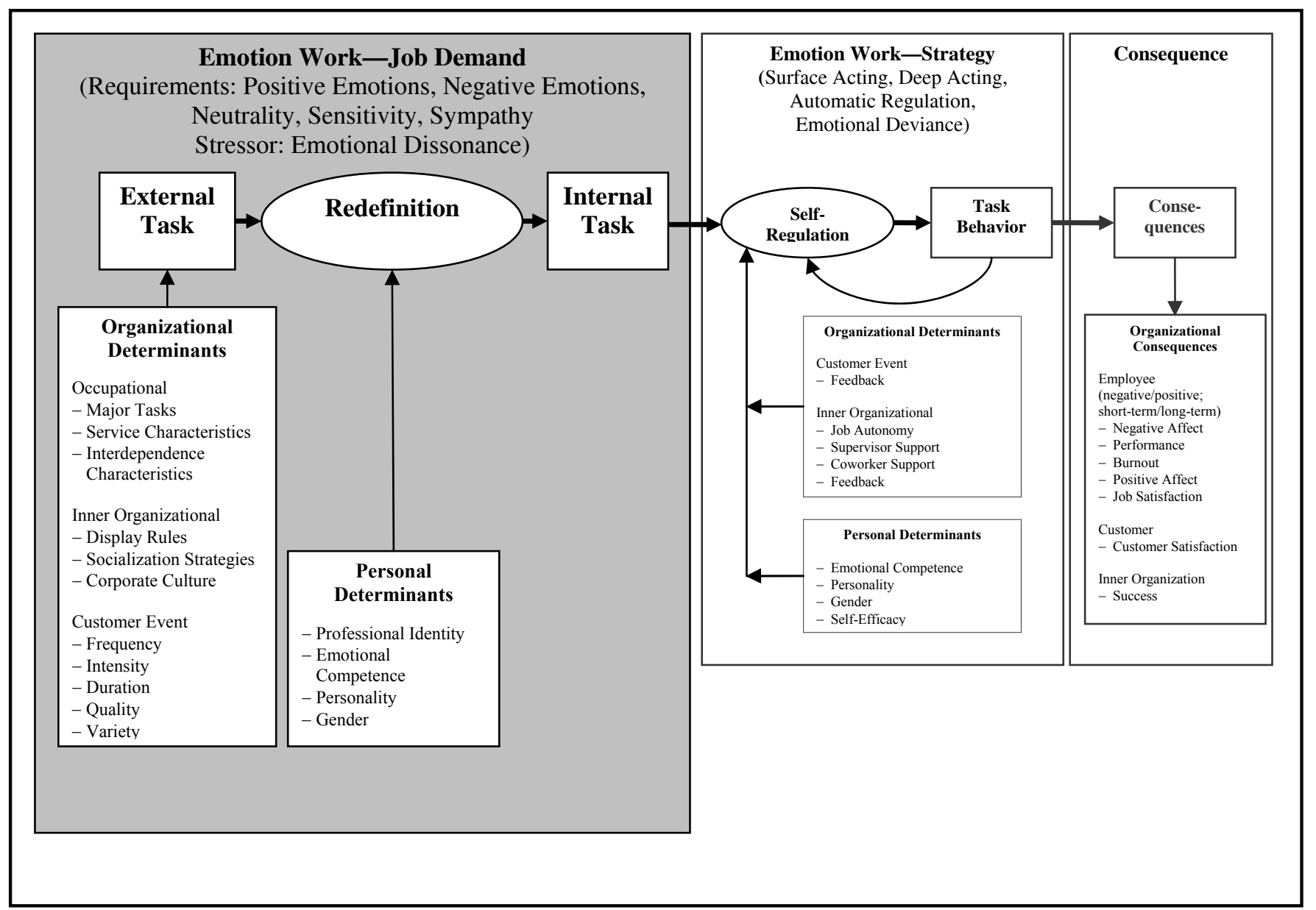

Figure 2. Redefinition Self-Regulation Model of Emotion Work (RS Model).

\subsection{Summary of propositions}

Proposition 1: An external emotion work task is determined by the occupational major tasks, service-, and interdependence characteristics.

Proposition 2: An external emotion work task is determined by inner organizational display rules, socialization strategies, and corporate culture. 
Proposition 3: An external emotion work task is determined by customer event frequency, intensity, duration, quality, and variety.

Proposition 4: Customer event determinants of external emotion work tasks are expected to be more similar within an organization and more dissimilar among organizations and more similar within an occupation and more dissimilar among occupations; and inner organizational determinants of external emotion work tasks are expected to be more similar within an occupation and more dissimilar among occupations.

Proposition 5: Emotional dissonance is an external emotion work task.

Proposition 6: Socialization strategies as an organizational determinant of external emotion work tasks influence the emotion work redefinition process.

Proposition 7: Professional identity as a personal determinant influences the emotion work redefinition process.

Proposition 8: Emotional competence as a personal determinant influences the emotion work redefinition process.

Proposition 9: Personality and gender as personal determinants influence the emotion work redefinition process.

Proposition 10: Emotional demands affect self-regulation efforts.

Proposition 11: Emotional demands affect actual task behavior.

Proposition 12: Organizational determinants of customer event feedback and inner organizational extents of job autonomy, supervisor and 
coworker support, including feedback, affect emotion work selfregulation efforts and task behavior.

Proposition 13: Personal determinants of emotional competence, personality, gender and self-efficacy affect emotion work self-regulation efforts and task behavior.

Proposition 14: Employee consequences, customer satisfaction, and inner organizational success are consequences of emotion work-depending on the external task, task redefinition, internal task, self-regulation strategy, and actual task behavior. 


\section{External Task Determinants of Emotion Work}

Investigation of external task determinants proposed in the RS Model by Field Study Part 1, and Experiments 1 through 3. The first part of the RS Model (Figure 3, p. 41) applies to the Emotion Work-Job Demand stage, and suggests that the organizational determinants (occupational, inner organizational, and customer event) define external emotion work tasks (Propositions 1-3). These determinants are proposed to be correlated, resulting in similarities within occupations and dissimilarities among occupations (Proposition 4). Important in this conceptualization is that emotion work external tasks, including emotional dissonance, are defined independently from individual approaches to task redefinition and self-regulation processes and individual task behavior (Figure 2, p. 37, RS Model). The emotional job requirements to display positive emotions, negative emotions, and neutrality, and sensitivity- and sympathy requirements and particularly the job stressor emotional dissonance (Proposition 5) are proposed to be external tasks in this model, defined by the aforementioned three categories of external task determinants. 


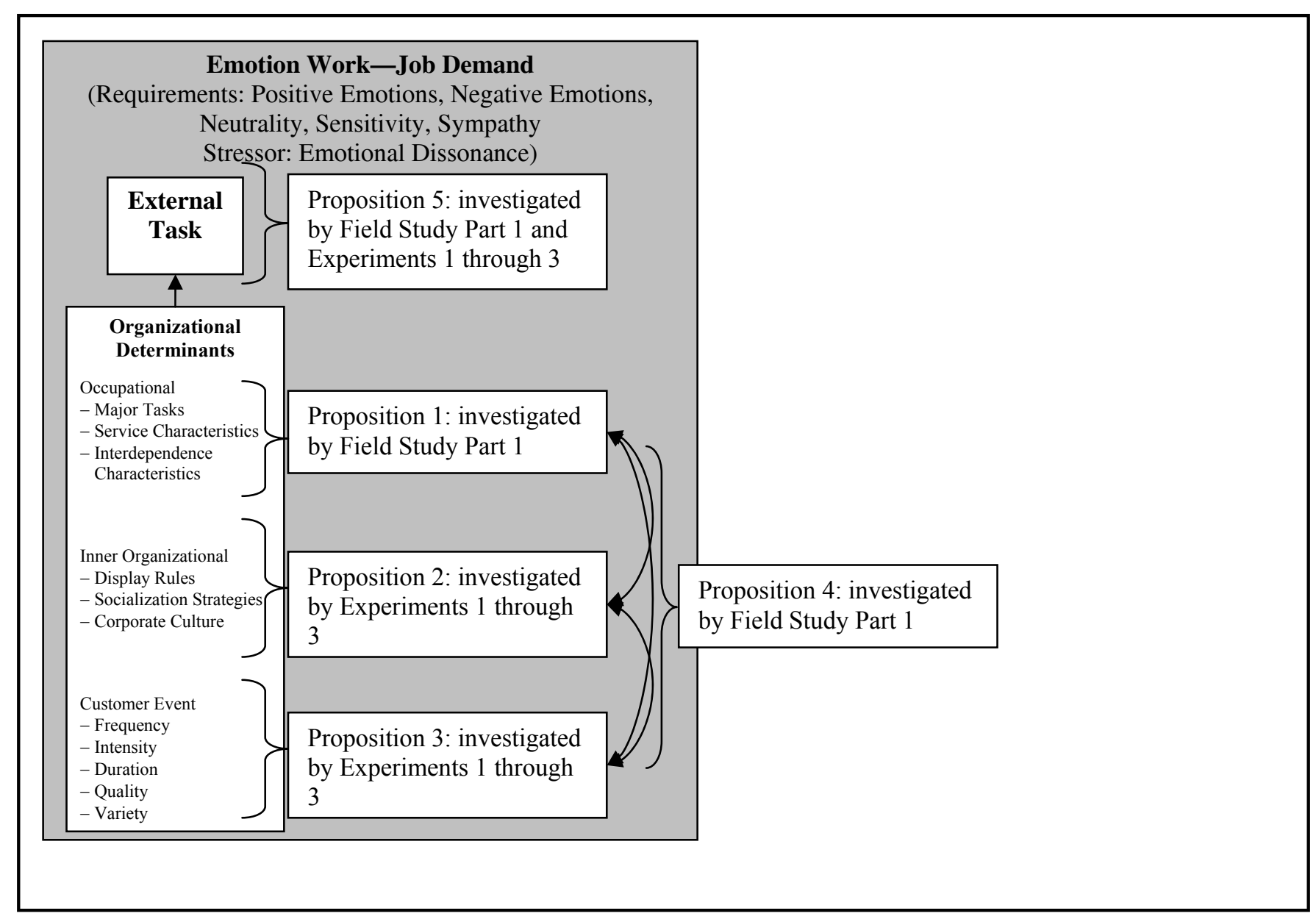

Figure 3. First part of the RS Model: Organizational determinants of external tasks of emotion work and related Propositions 1 through 5.

Strategies of Field Study Part 1-emotion work as an external task. The intention of Field Study Part 1 was to garner an empirical data base to support Proposition 1 (occupational major tasks, service-, and interdependence characteristics are determinants of external emotion work tasks). The strategy of Field Study Part 1 was to postulate the existence of similarities in occupational determinants (major tasks, service-, and interdependence characteristics) within an occupation, and dissimilarities in occupational determinants between different occupations. These similarities within and dissimilarities among occupations 
were proposed to be affected by inner-organizational and customer event determinants, and to be more similar within occupations and more dissimilar among occupations (Proposition 4). The occupational similarities and dissimilarities in service characteristics and interdependence characteristics were in turn hypothesized to affect occupational differences in emotion work external tasks - particularly occupational differences in emotional dissonance. As stated in Proposition 5, emotional dissonance is an external task, affected as any other emotion work external task by occupational differences in requirements to display positive emotions, negative emotions, and neutrality, and sensitivity- and sympathy requirements. There are some methodological issues in the study of emotion work as an external task regarding: (a) using self-ratings for assessing external tasks, (b) methodology of assessing emotion work external tasks applied by the Frankfurt Emotion Work Scales (FEWS, Zapf, et. al., 1999; Zapf et al., 2000), and (c) the level of aggregation for assessing external tasks among occupations.

(a) Self-ratings for external task assessment. For Field Study Part 1, the emotion work job requirements and emotional dissonance were operationalized by the Frankfurt Emotion Work Scales (FEWS, Zapf, et. al., 1999; Zapf et al., 2000). These scales measure emotion work external tasks utilizing self-ratings of job-incumbents. In stress research and job analysis literature (Frese \& Zapf, 1988, 1994; Kasl, 1986; Semmer, 1992; Spector, 1992), the conceptual problems of operationalizing so-called objective job requirements and stressors (external tasks) using self-ratings is well documented. It can be argued that questionnaires filled out by subjects are generally subjective measures as the answers are dependent upon individual cognitive and emotional processing. Expert-ratings, 
document analysis, and physical methods are generally considered objective measures in job-analysis as they are independent of the individual cognitive and emotional processing of the job incumbent (Frese, 1982; Hackman \& Lawler, 1971; Hackman \& Oldham, 1974; Semmer, 1982). However, Frese and Zapf (1988) postulated that any questionnaire report can be rated from low to high in dependency on cognitive and emotional processing, depending on both the quality of the job-analysis construct and the item verbalizations. An item verbalized as, "I feel overwhelmed by the burden of the job" is high in dependency on cognitive and emotional processing, whereas an item verbalized as, "How many pieces of work do you complete in a shift?" is low in dependency. Frese and Zapf (1988) postulated and gave empirical support that self-ratings might be adequate and even more practical measures of external tasks (objective job requirements and stressors) if items are verbalized with low cognitive and emotional processing dependency. FEWS operationalize emotion work tasks using a behavior requirement approach (Hackman, 1969, 1970), quantifying how often particular emotional behavior is required in order to achieve the tasks. An example of this approach is the following FEWS item introduction statement, asking for the specific emotions required to be displayed: "In order to meet the demands and expectations about how to deal with clients, it is often necessary to display very specific emotions towards the clients. For each of the emotions listed in the following table, please mark how often you are required to display them when working with clients [followed by scale-ratable item selections]." It is the supposition of this study that self-ratings in FEWS items can be interpreted as measurements of emotion work external task because 
items are presumed to be verbalized with low cognitive and emotional processing dependency.

(b) Assessment methodology of external tasks used by the Frankfurt Emotion Work Scales (FEWS). In 1996, Morris and Feldman conceptualized emotion work as a multidimensional construct. The FEWS builds on this concept, differentiating and measuring the frequency of expression of six organizationally-required emotional expressions: positive emotions; negative emotions; neutrality; sensitivity; sympathy; and emotional dissonance. For the first two (positive and negative), Zapf et al. (1999) developed separate scales to accommodate the vast range of requirements to display these divergent emotions (Stenross \& Kleinman, 1989; Zapf, 2002). It is plausible that in service-worker occupations such as sales, the occupation-specific expression of emotions is onedimensional, requiring a single, dominant emotion such as positive, customerfocus display at all times. In other service-worker occupations such as kindergarten teacher, there is a vast variety of occupation-specific emotion display requirements (e.g., expressing happiness towards a child who presents a nice painting, strictness towards children hurting each other, sympathy towards a child with a scraped knee, etc.) — and these occupation-specific emotion display requirements can also be inner organizationally determined, differing within the same occupation depending on, in this example, the pedagogy of the kindergarten. The aspect of neutrality was added to a subsequent version of the original FEWS 3.0 based on qualitative research regarding job requirements in police work (Fischbach \& Zapf, 2002) and is included in FEWS version 4.0 (Zapf et al., 2000). Police workers are often required to show neither positive nor negative emotions in interactions with citizens, suspects or witnesses. The same 
could hold true for judges who have to hear an accusation and give a judgment about said statement. In FEWS, sensitivity requirements are expected to positively correlate with both the frequency to display positive and the frequency to display negative emotions because the expression of an emotion during an interaction is often influenced by the emotion of the interaction partner and by the requirement to be aware of their emotions. Only in rare, short and less intense interactions (e.g., greeting guests at a tavern) is it not important to sense the emotions of the interaction partner. The requirement to show sympathy with the sorrows and problems of clients can be expected of a pediatric doctor-calming a hurt child in order to administer treatment. Emotional dissonance occurs when a service worker is required to express emotions which are not felt in the job situation. Emotional dissonance could be thought of as any situation in which the innate response of a person is in conflict with emotional role expectations (Abraham, 1998; Rafaeli \& Sutton, 1987). Much emotion work research has involved the development of instruments to quantify aspects of emotion job demands, using self-ratings of job holders (e.g., Brotheridge \& Lee, 1998; Buessing \& Glaser, 1999; Schaubroeck \& Jones, 2000; Zapf et al., 1999). Although these instruments are not identical, they overlap to a large extent with the FEWS - surveying job holders regarding frequency, duration and variety of their emotion work job demands. According to the external task-redefinitioninternal task process illustrated in the RS Model, it follows that the answers reported by job holders surveyed by FEWS are a measurement of their internal, redefined tasks — which are affected by both (a) the external task assigned and (b) personal determinants. This requires that individual differences be taken into account when interpreting FEWS-scaled scores. It is the supposition of this study 
and the RS Model (Figure 2, p. 37) that the variance in FEWS scaled scores can be explained by organizational- as well as personal determinants, as the elemental constructs of these determinants influence the reported internal tasks.

(c) Level of aggregation. In the applied field study, FEWS surveys were administered to service workers of three highly diverse occupations (police, teacher, travel agent) in a variety of organizations within these occupations. The level of aggregation of FEWS scales can be applied to specific tasks (e.g., advising customers as a travel agent task), positions (e.g., the sum of travel agent tasks), workplaces (e.g., the sum of tasks within the same travel agency), or occupations (e.g., the sum of travel agent tasks among several travel agent organizations). For the purpose of Field Study Part 1, the FEWS were aggregated to an occupational level by computing mean scaled scores within one occupation. It should be stated that the greater the level of abstraction (i.e., occupations), the broader and more general the potential conclusions (Frieling, 1977). Therefore, at an occupational aggregate, specific inner organizational and customer event determinants cannot be taken into account. An example of this would be the inability to take into account the different organizationally-required emotion display rules (e.g., sensitivity and sympathy) and customer event frequency and duration factors for nurses in a children's hospital as those for nurses in a seniorcare facility. Both groups of nurses are likely to have similar organizationallyrequired emotional display rules but the nurses in the senior home are likely to experience more client events where an average person innately feels disgust or anger-leading to a higher required and expected job demand for emotional dissonance (Zapf, 2002). It was hypothesized that regardless of these potential 
differences within an occupation, differences among the occupations surveyed for this field study would be possible to demonstrate.

Strategies of Experiments 1 through 3, including the development of an experimental paradigm in the study of emotion work as an external task. In Experiments 1 through 3, the intention was to get experimental evidence in support of Proposition 5: emotional dissonance is an external task and as such is considered to be independent of a particular worker and actual task behavior (Figure 3, p. 41). Emotional dissonance is most poignantly evoked by the display rule to show an emotion not innately felt by a service worker (Hochschild, 1983). The experiments of the present study include the development of an experimental paradigm to test the hypothesis that emotional dissonance is, among other variables that define and influence an external task, particularly defined by display rules (Proposition 2) and event qualities (Proposition 3). Given intensely negative (e.g., rude and impolite) customer behavior (a customer event quality), where an average person innately feels disgust or anger, emotional dissonance should predictably be evoked by the display rule to be friendly (customer oriented in all circumstances); whereas the display rule to be authentic (be natural and show your true personality in all circumstances) should evoke less emotional dissonance. In the authentic condition, it is conceivable that the service situation itself and/or individual social socialization experiences could define a self-initiated requirement to be friendly even though the customer behaves unfriendly.

A simplified RS Model is presented in Figure 4 (p. 48). In order to deduce empirically-testable hypotheses about the effects of the two display rules (friendly vs. authentic), predictions were made in the context of the RS Model 
regarding effects of these display rules on the definition of emotional dissonance as an external task (Proposition 5); the effects of emotional dissonance on selfregulation (Proposition 10: external tasks affect self-regulation efforts); the effects of emotional dissonance on task behavior (Proposition 11: external tasks affect the task behavior); and the predicted negative short-term consequence (state negative affect) of the display rule- and customer event-generated emotional dissonance (Proposition 14: external tasks have employee, and/or customer satisfaction, and/or organizational success consequences).

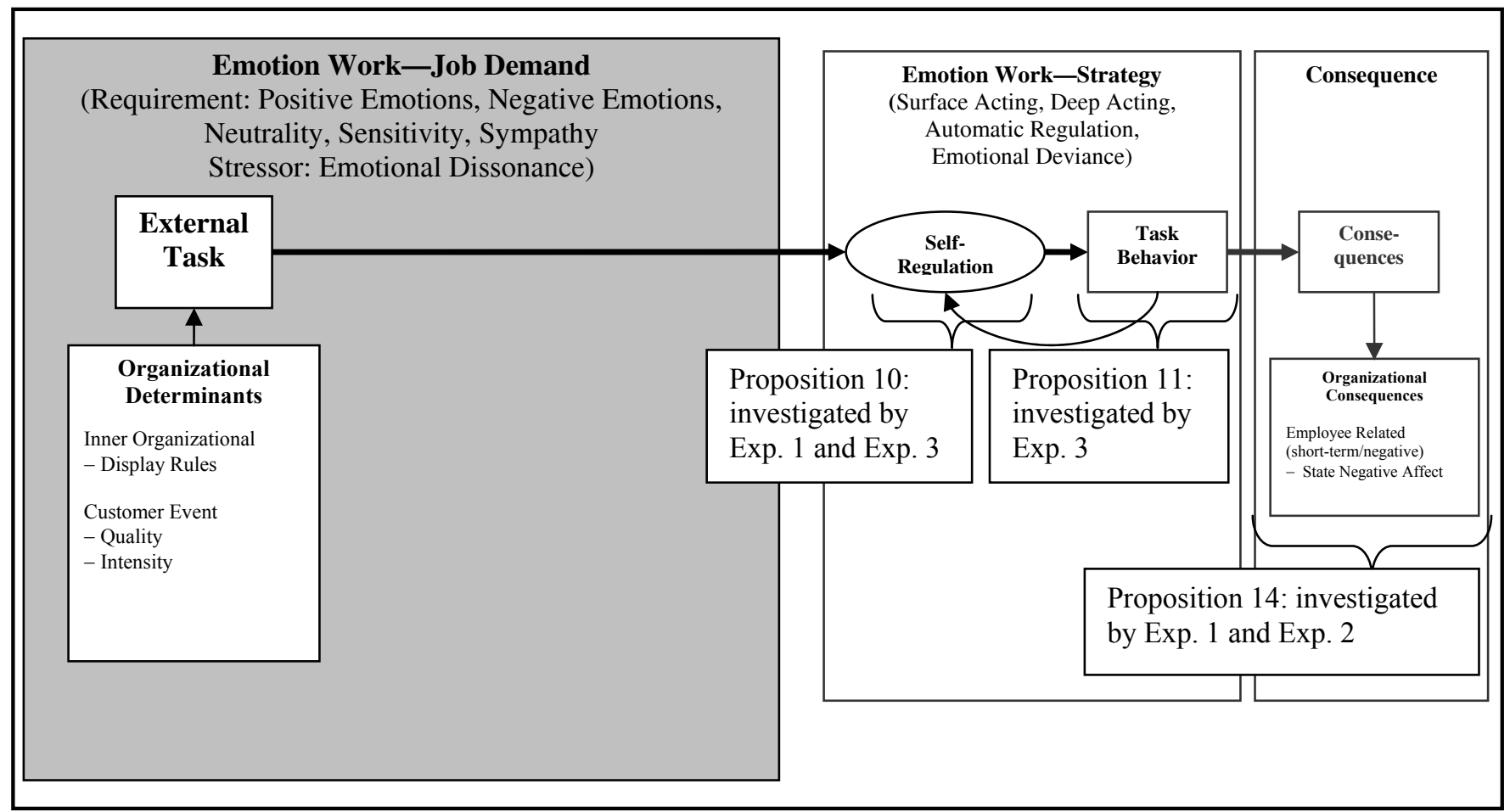

Figure 4. Simplified RS Model: Effects of External Tasks on Self-Regulation (Proposition 10), Task Behavior (Proposition 11), and Consequences (Proposition 14). 


\subsection{Field Study Part 1-Occupational Determinants of External Emotion Work Tasks}

Effects of occupational similarities and dissimilarities on emotion work. In Field Study Part 1, police, teachers and travel agents were surveyed to demonstrate occupational differences in emotion work requirements and the stressor, emotional dissonance-affected by differences in major tasks, service-, and interdependence characteristics. Part of the intent of these surveys was to give some empirical base for the first part of the RS Model and the derived Proposition 1 (an external task in emotion work is determined by occupational major tasks, service-, and interdependence characteristics). These three occupations were chosen because they were assumed to be highly diverse in the categories of occupational major tasks, service-, and interdependence characteristics. The major tasks of police are danger-assessment and prevention (Fischbach, 2000, Fischbach \& Zapf, 2002). This leads to many diverse primary and derived subtasks, including dealing with diverse so-called customers/encounter partners (citizens, victims, or suspects) and often providing unsolicited service (writing a speeding ticket; making an arrest). Some police service-worker tasks could be classified as executing direct person-related tasks (e.g., interrogating or arresting); others could be classified more as indirect person-related tasks (e.g., protocol tasks of handling an accident). The service characteristics of the police occupation can generally be described as intangible because of the nature of the product (danger assessment and prevention). Depending on the task, the service characteristics can be highly inseparable while executing a direct person-related task, or can be low while executing indirect 
person-related tasks. As the heterogeneity of their encounter partners (citizens, victims, or suspects) is comparatively high, police-citizen interactions can be described more in terms of an encounter (Gutek, 1997) where single, more or less short interactions, usually between strangers, predominant. A highly diverse customer base can also lead to highly diverse customer demands, ranging from requesting or anticipating help to absolutely no demand whatsoever for so-called police service (see mention of unsolicited service above). Police authority is high and consequently accompanied by a wide range of possibilities to control encounters with citizens, victims, or suspects (Nerdinger, 1994; Rafaeli, 1989a). Their authority is reinforced by the payment of their services from society, making them financially independent from their encounter partners and making it possible to carry out tasks where it is often important to assert actions and demands against the wishes of their encounter partners.

The major task of the teaching profession is to directly affect the cognitive, emotional, or motivational states of their students. Teachers can therefore be classified as executing direct person-related tasks or more specifically_human services (Nerdinger, 1994; Zapf, Isic, Fischbach, \& Dormann, 2003). The service characteristics of the teaching occupation can be described as highly intangible because of the nature of the product (teaching, educating and advising) and highly inseparable as there is no teaching without learning students. The heterogeneity of their so-called customers (students) is comparatively high, as dissimilarities in interactions with students can be presumed depending on idiosyncratic differences in abilities, needs and wishes of students. Teacher-student interactions can be described more in terms of a relationship (Gutek, 1997) as presumably teacher and students know each other 
and share a common history due to protracted time spent together. However, student (and parent) demands on teachers can be highly diverse, ranging from morale support for personal problems to no demands whatsoever for teaching and educating (unsolicited service, e.g. teaching non-elective, required courses). As with the police profession, teacher authority is high and is also accompanied by many possibilities to control teacher-student interactions (Nerdinger, 1994; Rafaeli, 1989a). Payment from society also makes teachers more independent from their so-called customers (students) than those typically classified as service workers and their teach task can also be against their so-called customer wishes.

Travel agents can be classified as an indirect person-related service occupation (Nerdinger, 1994). The major task of travel agents is to sell travel or more precisely to arrange for the consumption of travel for their customers. The service characteristics of the travel agent occupation can be described (according to Zeithaml, 1981, citation according to Nerdinger, 1994, p. 48) as both tangible and intangible, as journeys can be evaluated by relatively objective criteria (e.g., construction noise; timeliness), and by rather subjective criteria (e.g., the service in the hotel restaurant). The travel agent inseparable service characteristic is low as the product (travel) can be separated from the product delivery. The relative heterogeneity of travel agent customers can be considered low, as high similarities in customer situations can be presumed; and the customer-service interactions can be described more as encounters (Gutek, 1997) where single, relatively short interactions with more or less strangers predominant. In spite of these sales interaction realities, travel agent customer relationship management often attempts to emulate relationship characteristics of human services in order to affect sales (Gutek, 1997; Holman, 2003; Zapf, Isic, Bechtoldt, \& Blau, 2003) 
and customer demands are high (quality tangibles, reliability, responsiveness, assurance and empathy; Parasuraman et al., 1988). Travel agent status compared to police and teacher is low and is therefore accompanied with greater possibilities for customers to control the service-interaction (Nerdinger, 1994; Rafaeli \& Sutton, 1987). There is no travel agent business without customers, and this makes them directly dependent on both the existence of customers and the satisfaction of customer needs and wishes, which have already been described as intensely demanding. Table 1 summarizes the main occupational differences in major tasks, service-, and interdependence characteristics for police, teachers and travel agents.

\section{Table 1}

Main Occupational Differences for Police, Teachers and Travel Agents

\begin{tabular}{|c|c|c|c|}
\hline & Police & Teachers & Travel Agents \\
\hline Major Tasks & $\begin{array}{l}\text { danger- assessment } \\
\text { and prevention }\end{array}$ & education & sales \\
\hline $\begin{array}{l}\text { Service Characteristics } \\
\text { 1. intangibility } \\
\text { 2. heterogeneity } \\
\text { 3. inseparability }\end{array}$ & $\begin{array}{l}\text { high } \\
\text { high } \\
\text { diverse: high/low }\end{array}$ & $\begin{array}{l}\text { high } \\
\text { high } \\
\text { high }\end{array}$ & $\begin{array}{l}\text { diverse: high/low } \\
\text { low } \\
\text { low }\end{array}$ \\
\hline $\begin{array}{l}\text { Interdependence } \\
\text { Characteristics } \\
\text { 1. interaction } \\
\text { 2. customer demands } \\
\text { 3. status and control of service } \\
\text { worker }\end{array}$ & $\begin{array}{l}\text { encounter } \\
\text { diverse } \\
\text { high }\end{array}$ & $\begin{array}{l}\text { relationship } \\
\text { diverse } \\
\text { high }\end{array}$ & $\begin{array}{l}\text { encounter/ } \\
\text { emulated relationship } \\
\text { high service quality } \\
\text { low }\end{array}$ \\
\hline
\end{tabular}

Police officers are frequently assigned to indirect person-related tasks (low inseparability; e.g., protocol tasks of handling an accident; Fischbach, 2000). Police officers often cite neutrality as an important strategy to avoid 
prejudice or inequity and to be successful in dealing with indirect person-related tasks (Fischbach \& Zapf, 2002). This aspect of neutrality implies that a high requirement to display neither positive nor negative emotions toward citizens, suspects, and victims can be expected for police work. However, there are also direct person-related tasks in police work (high inseparability)—with situations requiring diverse emotional displays such as positive (calming a victim), negative (arresting a person who resists), or sympathy (delivering an advise of death to a relative). Nevertheless, police officers assigned to direct person-related tasks are in most cases expected to show detached concern and learn to be internally neutral while displaying, for example, anger or sympathy. The reasoning behind this complex emotion work demand is that police officers need to be prepared for deliberative decision making and action, conceivably involving life or death decisions. The two main emotion work differences between police work and that of teachers are that teachers are engaged almost solely in direct person-related work, and their service-worker interactions are more relationship- than encounter-oriented. Teachers often know their students and share a common history. Trust and loyalty are usually important elements of the teacher-student relationship, and regarding emotion work, the display of positive emotions and sympathy are likely to be frequently required in this type of human service work (Gutek, 1997; Holman, 2003; Zapf, Isic, Bechtoldt, \& Blau, 2003). In contrast to the police detached concern (neutrality) emotional demand, teachers are expected to be engaged and involved in an emotional loaded situation (e.g., being sensitive to emotions of students and displaying sympathy) as well as displaying authenticity (positive or negative emotion 
displays)_expressing felt emotions toward students as pedagogic principle to show students how their behavior and emotional display affect the emotions of others. In contrast to the neutrality nature of police emotion work and the authentic nature of teacher emotion work, travel agents are generally expected to display only positive emotions - a consequence of low status and control relative to their customers (Nerdinger, 1994; Rafaeli \& Sutton, 1987). "Customer is king" is the expected emotion work guideline in situations such as those of travel agents who compete for customers and collect payment only after sales are closed. Travel agent customer-relationship management is predicted to require the expression of only positive emotions and sympathy in order to compel trust and loyalty from the customer. This leads to the following hypotheses derived from the first part of the RS Model (Figure 3, p. 41) in reference to Proposition 1 (an external emotion work task is determined by occupational major tasks, service-, and interdependence characteristics) and Proposition 2 (an external emotion work task is determined among other factors, by display rules):

Hypothesis 1: The frequency of positive emotion display requirements is hypothesized to be lower for police compared to teacher and travel agent.

Hypothesis 2: The frequency of negative emotion display requirements is hypothesized to be lower for travel agent compared to police and teacher; and lower for police compared to teacher.

Hypothesis 3: The frequency of sympathy requirements is hypothesized to be lower for police compared to teacher and travel agent.

Sensitivity can be expected to be part of the emotion work requirements for police, teachers and travel agents. There are tasks in police work where 
knowledge of encounter partner(s) emotions is a requisite for determining their job-required emotional reaction (e.g., evaluating the state of a suspect for threat of danger). Teachers need to sense the emotions of students in order to support student learning and personal problems and as a prerequisite for engagement and authenticity requirements described above. It is important for travel agents to sense customer emotional characteristics as this would likely help them ascertain sales approaches and travel suggestions in order to lead to a sale. Sensing emotional preferences of customers-showing interest, reliability, and concern for their wishes and needs - might also help in getting customers to commit to the agency (Nerdinger, 2001). As all three occupations were predicted to have job related sensitivity requirements, no differentiating hypothesis regarding sensitivity requirements was made.

Because of the interdependence characteristics of police work (encounter interactions, variety of customer demands, and high authority and control compared to their encounter partners), coupled with the broad breadth of organizationally required and acceptable emotional displays, emotional dissonance for police is expected to be low. Emotional dissonance is also expected to be low for teachers as there are emotional display rules in place to encourage reciprocal interaction in instances of negative student events, diminishing the probability of emotional dissonance. It is also likely that negative events occur in police and teacher work where even an emotionally detached, experienced police officer or teacher could feel insulted, disgusted, angry or compassionate beyond the legal and professional limits of reciprocity. Because of these imposed limits in displaying these feelings, it can also be expected that emotional dissonance is an external emotion work task in police and teacher 
work. It can also be assumed that negative customer events (such as impatient or complaining customers) are likely to occur in travel agent work, as in any indirect person-related occupation (Rafaeli, 1989a; Zapf, Isic, Fischbach, \& Dormann, 2003). As these negative events can become intense, evoking disgust and anger-combined with the predominant requirement for travel agents to express only positive emotions - a high requirement of emotional dissonance is predicted. This leads to the following hypothesis derived from the first part of the RS Model (Figure 3, p. 41) and references Proposition 1 (an external task in emotion work is determined, among other occupational factors, by occupational interdependence characteristics):

Hypothesis 4: The frequency of emotional dissonance requirements is hypothesized to be higher for travel agents compared to police and teachers.

\subsubsection{Method—Field Study Part 1}

Subjects-Police sample. The first sample consists of German police officers $(N$ $=221$ ). The proportion of male subjects was considerably larger than the proportion of females ( $95 \%$ vs. $5 \%$ ). The average age was 39 years, with a range from 23 to 59 years $(S D=7.37)$. The mean work experience was 20 years, with a range of work experience from 3 to 41 years $(S D=8.28)$. Seventy percent of the sample were officers in the upper grade of civil service; the remainder were in the lower grade. Overall, $52 \%$ held a supervisory position; the others were nonmanagement police officers. All of the participants held full-time positions and worked with clients providing service on the street, working on day and night shifts with a variety of tasks ranging from controlling car drivers to tracking 
thieves and even bank robbers. There were 723 questionnaires dispersed to two police departments in the northern German state of Lower Saxony (Niedersachsen) - both with police stations ranging from 6 to 100 officers. Participation in the study was voluntary and the police departments were requested to participate in the survey and to fill out the questionnaires via an explanatory cover letter from the university. The questionnaires with explanatory cover letters were distributed to the police officers by members of department leadership. A total of 221 questionnaires (response rate: $30.43 \%$ ) were sent back to the university in a sealed envelope, collected first by the police leadership department. The police officers were given the option to use post mail to return their questionnaires directly to the university.

Subjects-Teacher sample. The second sample consists of German teachers $(N=209)$. The proportion of female subjects was considerably larger than the proportion of males $(74.6 \%$ vs. $25.4 \%)$. The average age was 47 years, with a range from 25 to 64 years $(S D=9.91)$. The mean work experience was 20 years, with a range of work experience from 1 to 41 years $(S D=10.68)$. Ninety percent were regular schoolteachers; the remaining nine subjects held positions as headmaster (1) and trainee teacher (8). Half of the subjects taught full-time, the other half part-time, and most of the subjects had a pupil contact of 4 to 6 hours per day. Nearly $30 \%$ taught at the elementary school level (Grundschulen), $17 \%$ taught at the basic high school level (Hauptschulen), 22\% taught at middletrack high school level (Realschulen), and 15\% taught at the college-prep high school level (Gymnasien). The remaining 16\% taught at other school types such as vocational schools. The average number of teachers per school was 37; 
ranging from 8 to 82 teachers per school. Seventy percent taught at schools located in cities with more than 100,000 citizens, most of them located in the northern German states of Schleswig-Holstein, Lower Saxony (Niedersachsen), and Hamburg. Participation in the study was voluntary and 480 questionnaires were dispersed. Schools were requested to participate in the survey and to fill out the questionnaires via a visit by a research assistant at the schools or when more practical, by a contact teacher. As in the police survey, questionnaires were accompanied by an explanatory cover letter from the university. The questionnaires and the cover letters were distributed to the teachers by headmasters or contact teachers. A total of 221 questionnaires (response rate: $30 \%$ ) were collected by the headmasters or contact teachers in a sealed envelope and fetched by a research assistant from the university. The teachers were given the option to use post mail to return their questionnaires directly to the university. Two returned questionnaires were dropped from the sample because they contained more than two unanswered pages.

Subjects-Travel Agents sample. The third sample consists of German travel agents $(N=202)$. The proportion of female subjects was considerably larger than the proportion of males ( $81 \%$ vs. $19 \%)$. The average age was 33 years, with a range from 18 to 68 years $(S D=9.81)$. The mean work experience was 10 years, with a range of work experience from 0.5 to 42 years $(S D=7.81)$. Twenty-one percent held a company management position, 3\% held a department management position, 58\% held a senior agent position, and $13 \%$ were entry-level trainees. The remaining $5 \%$ held other positions such as reentry re-training positions. Sixty-eight percent of subjects worked full-time, the remaining worked part-time, and most of the subjects had a customer contact of 4 
to 8 hours per day. The average employees per agency was seven, ranging from the smallest agency with only one travel agent to the biggest agency with 25 travel agents; and $32 \%$ of the subjects worked in specialized departments of the agency (flight, train, tourist) vs. the remaining who worked in non-specialized departments and/or non-specialized agencies. Most worked at agencies located in cities with more than 100,000 citizens, located in the northern German states of Niedersachsen and Hessen. Participation in the study was voluntary and questionnaires were sent to 350 travel agents in 87 different agencies. Questionnaires were distributed to travel agents via a visit by a research assistant at the agencies or when more practical, were dispersed first to contact travel agents who in turn distributed them to fellow agents. As in the other two samples, questionnaires included an explanatory cover letter from the university. A total of 202 questionnaires (response rate: 58\%) were collected in a sealed envelope by a research assistant from the university. The travel agents were given the option to use post mail to return their questionnaires directly to the university.

Instruments - FEWS. In the police sample, emotion work was measured using the Frankfurt Emotion Work Scales-FEWS version 3.0 (Zapf et al., 1999). For the purpose of this study, five aspects of emotion work were measured with the following five scales: positive emotions-three items measured frequency of requirement to display positive emotions (e.g., "How often in your job do you have to display pleasant emotions towards your clients?"); negative emotions — three items measured frequency of requirement to display and handle negative emotions (e.g., "How often in your job do you have to display unpleasant emotions towards your clients?"); sensitivity 
requirements - three items measured frequency of requirement to sense the emotion of the interaction partner (e.g., "How often is it of importance in your job to know how the clients are feeling at a given moment?"); requirement to show sympathy-two items measured the frequency of requirement to show sympathy regarding the sorrows and problems of the clients (e.g., "How often do you have to express sympathy towards clients?"); and emotional dissonance-four items measured the frequency of dissonance between felt and displayed emotions (e.g., "How often in your job do you have to display emotions that do not agree with your true feelings?"). Each item was rated on a five-point scale ranging from very rarely/never [1] to very often/several times an hour [5]. An item analysis was applied to FEWS 3.0 and showed that four of the five scales reached coefficient alpha from .76 to .89 and fell comfortably above the 0.70 minimum for reliability recommended by Nunnally and Bernstein (1994). Only the positive emotions scale failed to reach this criteria (coefficient alpha $=.57)$.

For the teacher and travel agent samples, FEWS version 4.0 was usedan enhanced version of FEWS 3.0 as a result of issues identified in the police survey and other previous studies. Beyond other improvements, which will be described in chapter 4, FEWS version 4.0 also included improvements to linguistic concerns of items (e.g., "while performing your duties, do you have to express negative emotions towards your clients, for example strictness or anger, when laws are disobeyed?" was changed to "how often does it happen while performing your duties that you have to express negative emotions towards your clients, for example strictness or anger, when laws are disobeyed?"). For Field Study Part 1, the proximate equivalent items which were used in the police 
survey FEWS 3.0 were selected from the teacher and travel agent survey FEWS 4.0 in order to measure the five Emotion Work Scales and optimize comparability of the three occupations. This lead to FEWS 3.0 proximate equivalent scales FEWS 3.1 for the teacher and travel agent surveys. An item analysis was applied to FEWS 3.1 items and showed that three of the five scales (positive and negative requirement scales and showing sympathy requirement scale) in the teacher and the travel agent samples reached coefficient alpha from .53 to .65 , falling below the recommended .70 minimum for reliability recommended by Nunnally and Bernstein (1994). Only sensitivity requirement and emotional dissonance in the teacher and travel agent samples reached coefficient alpha from .78 to .86 and fell above the .70 criterion for reliability. 


\subsubsection{Results—Field Study Part 1}

The descriptive data and correlations of all study variables are shown in Table 2 .

\section{Table 2}

Correlations among Study Variables and Descriptive Statistics for Police, Teacher and Travel Agent

\begin{tabular}{|c|c|c|c|c|c|c|c|c|c|}
\hline Variable name & Mean & S.D. & 1 & 2 & 3 & 4 & 5 & 6 & 7 \\
\hline \multicolumn{10}{|l|}{ 1. Age (years) } \\
\hline police & 39.44 & 7.37 & - & & & & & & \\
\hline teacher & 46.59 & 9.91 & - & & & & & & \\
\hline travel agent & 33.47 & 9.81 & - & & & & & & \\
\hline \multicolumn{10}{|l|}{ 2. Gender $(1=$ male $2=$ female $)$} \\
\hline police & - & - & .33 & - & & & & & \\
\hline teacher & - & - & -.19 & - & & & & & \\
\hline travel agent & - & - & -.23 & - & & & & & \\
\hline \multicolumn{10}{|l|}{ 3. Positive Emotions } \\
\hline police $_{(\text {FEWS 3.0) }}$ & 2.10 & 0.77 & .00 & .01 & .57 & & & & \\
\hline 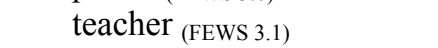 & 3.85 & 0.62 & -.06 & -.28 & .65 & & & & \\
\hline travel agent (FEWS 3.1) & 3.97 & 0.60 & .03 & .10 & .59 & & & & \\
\hline \multicolumn{10}{|l|}{ 4. Negative Emotions } \\
\hline police $_{(\text {FEWS 3.0) }}$ & 2.64 & 0.81 & -.21 & -.04 & .43 & .76 & & & \\
\hline teacher (FEWS 3.1) & 2.90 & 0.55 & -.09 & -.12 & .20 & .56 & & & \\
\hline travel agent & 1.66 & 0.50 & -.17 & -.09 & -.20 & .53 & & & \\
\hline \multicolumn{10}{|l|}{ 5. Sensitivity Requirement } \\
\hline police $_{(\text {FEWS 3.0) }}$ & 3.19 & 0.88 & -.25 & -.08 & .47 & .47 & .89 & & \\
\hline teacher $_{\text {(FEWS 3.1) }}$ & 9.98 & 0.71 & .04 & -.15 & .47 & .07 & .86 & & \\
\hline travel agent (FEWS 3.1) & 3.79 & 0.73 & .02 & .02 & .42 & -.11 & .78 & & \\
\hline \multicolumn{10}{|l|}{ 6. Showing Sympathy } \\
\hline police $($ FEWS 3.0) & 2.51 & 0.73 & -.20 & -.06 & .55 & .54 & .63 & .75 & \\
\hline teacher ${ }_{(F E W S ~ 3.1)}$ & 3.61 & 0.65 & .14 & -.23 & .43 & .15 & .59 & .63 & \\
\hline travel agent $($ FEWS 3.1) & 3.15 & 0.77 & -.05 & .15 & .36 & .02 & .31 & .60 & \\
\hline \multicolumn{10}{|l|}{ 7. Emotional Dissonance } \\
\hline police $_{(\text {FEWS 3.0) }}$ & 2.77 & 0.75 & -.23 & -.01 & .40 & .59 & .59 & .47 & .82 \\
\hline teacher $_{(\text {FEWS 3.1) }}$ & 2.57 & 0.77 & -.08 & -.13 & .15 & .37 & .02 & .10 & .82 \\
\hline travel agent (FEWS 3.1) & 3.02 & 0.79 & -.19 & .06 & .28 & .15 & .20 & .41 & .84 \\
\hline
\end{tabular}

Police: $N(210,219) ; p<.01$ at $\mathrm{r} \geq .18$; Teacher: $N(208,209) ; p<.01$ at $\mathrm{r} \geq .18$; Travel Agent: $N(201,202) ; p<.01$ at $\mathrm{r} \geq .20$. Coefficient $\alpha$ in italic.

For the purpose of comparing the Hypotheses 1 through 4 predicted differences in the FEWS mean scaled score between the three occupations, a onefactorial analysis of variance was applied with occupation (police, teacher, travel 
agent) as the independent variable and the five FEWS 3.0/3.1 scales (positive, negative emotions, sensitivity requirements, requirement to show sympathy and emotional dissonance) as dependent variables. Mean differences were evaluated by Scheffé post hoc analyses. Corresponding results of Scheffé tests (Table 3) show 12 of 15 significant differences in means of emotion work scales of police vs. teacher vs. travel agent professions, supporting Hypothesis 1 that the frequency of positive emotion is lower for police compared to teacher and travel agent; supporting Hypothesis 2 that the frequency of negative emotions is lowest for travel agent, next lowest for police, and highest for teacher; supporting Hypothesis 3 that sympathy is lower for police compared to teacher and travel agent; and supporting Hypothesis 4 that emotional dissonance is highest for travel agent. Furthermore, the multiple mean comparison of FEWS 3.0 with FEWS 3.1 emotion work scales revealed no significant differences in emotion work requirements only for both positive emotions and sensitivity requirements between teacher vs. travel agent professions, and for emotional dissonance between police vs. teacher professions. Figure 5 shows the corresponding three, discrete occupational profiles for the emotion work job demands of the police vs. teacher vs. travel agent professions. 
Table 3

Multiple Mean Comparisons of FEWS 3.0 (Police) and FEWS 3.1 (Teacher and Travel Agent) Emotion Work Scales (Scheffé test ${ }^{\mathrm{a}}$ )

\begin{tabular}{lllllll}
\hline & Sample & Positive & Negative & Sensitivity & Showing & Emotional \\
& Emotions & Emotions & Requirements & Sympathy & Dissonance \\
$A$ & $B$ & $\Delta M$ & $\Delta M$ & $\Delta M$ & $\Delta M$ & $\Delta M$ \\
\hline Police & Teacher & $-1.75^{* *}$ & $-0.26^{* *}$ & $-0.80^{* *}$ & $-1.10^{* *}$ & 0.20 \\
Police & Travel Agent $-1.87^{* *}$ & $0.98^{* *}$ & $-0.60^{* *}$ & $-0.64^{* *}$ & $-0.25^{* *}$ \\
Teacher & Travel Agent & -0.12 & $1.24^{* *}$ & 0.19 & $0.46^{* *}$ & $-0.45^{* *}$ \\
\hline
\end{tabular}

Note: adjusted mean of sample sizes (n): 209,770; $\Delta M=$ mean differences in samples $A, B ; * *<.01$.

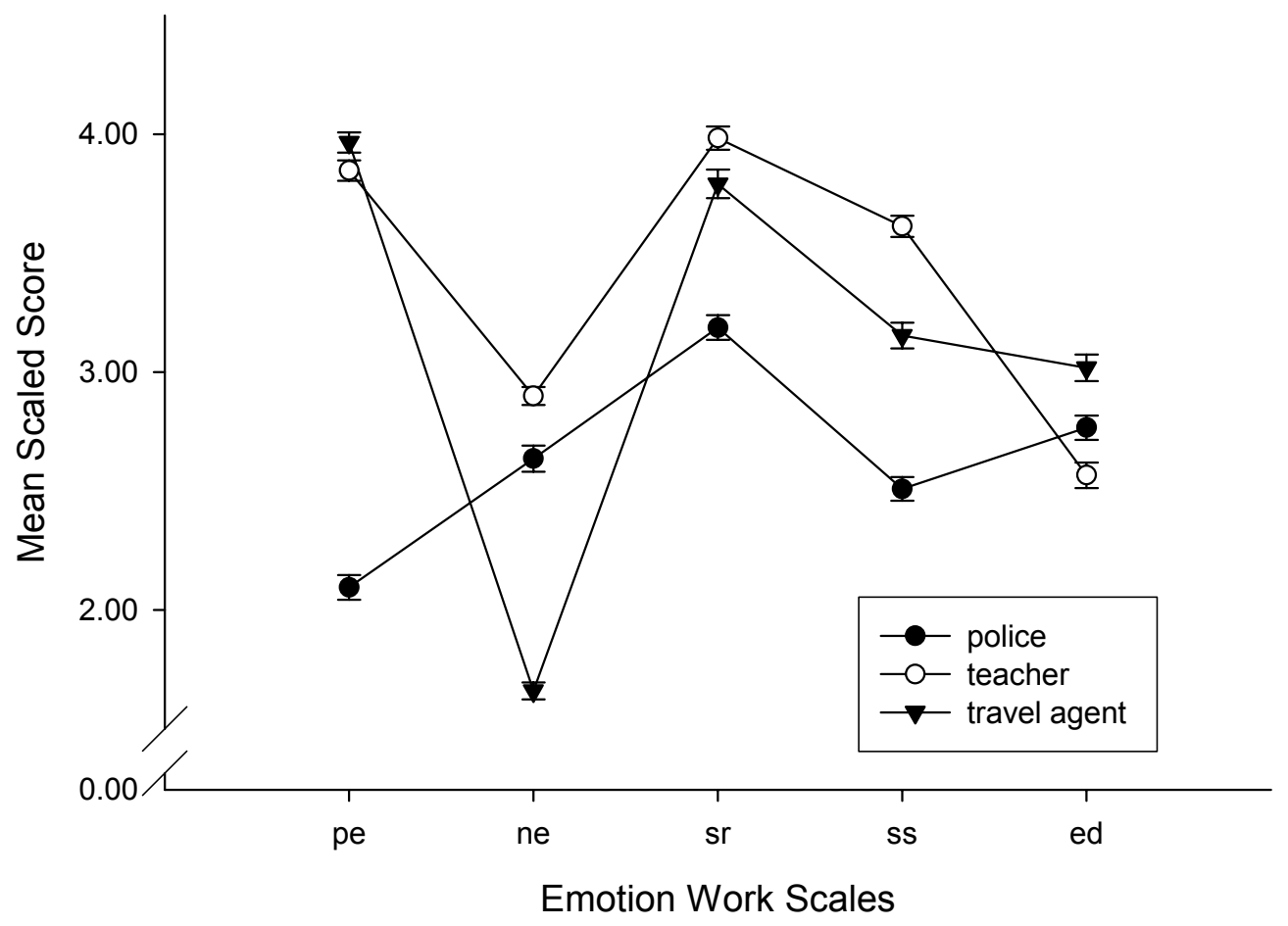

Figure 5. Job profiles in Emotion Work Scales for police, teacher and travel agent (pe: positive emotions, ne: negative emotions, sr: sensitivity requirements, ss: showing sympathy, ed: emotional dissonance). 


\subsubsection{Discussion—Field Study Part 1}

In the teacher survey, a high level of all emotion work job requirements and the lowest level of emotional dissonance in comparison to the other two occupations were reported-supporting the tenets of Hypotheses 1 through 4. The police profile was most distinct from those of the teacher and travel agent surveys, with the lowest level of favorable emotion work job requirements (positive emotions, sensitivity and sympathy) in comparison to the teacher and travel agent surveys, a significantly lower level of negative emotion work job requirements in comparison to the teacher survey, and a significantly higher level of negative emotion work job requirements in comparison to the travel agent surveysupporting the tenets of Hypotheses 1 through 3. As predicted, the police survey revealed a significantly lower level of emotional dissonance in comparison to the travel agent survey. The travel agent profile could be characterized as reporting high levels of favorable emotion work job requirements (positive emotions, sympathy and sensitivity) associated with the lowest level of negative emotion work job requirements - supporting the tenets of Hypothesis 1 through 3-and the highest level of emotional dissonance in comparison to the other two occupations-supporting Hypothesis 4. The clear, distinct, and interpretable FEWS profiles for police, teacher and travel agent work support the assumption that the FEWS can be used as a job analysis instrument to assess service interactions, describing organizational job requirements and stressor, emotional dissonance, independent of individual workers. Occupational dissimilarities between organizations of distinct occupations and the occupational similarities between organizations of the same occupations were shown by FEWS profiles to 
affect emotion work external tasks in hypothesized directions, supporting the tenets of the first part of the RS Model and Proposition 1 (Figure 2, p. 37; Figure 3, p. 41).

The present study has strengths and limitations. One of the strengths is the reasonable sample size in all of the three surveyed occupations. However, participation in this study was voluntary rather than participants being randomly drawn. Therefore, biases (e.g., social desirability) might be considered to weaken the interpretation of results. However, social desirability biases can not explain the shown systematical occupational differences; this bias might only have increased the error variance in any occupation and decreased the probability to show systematical occupational effects, because this error should have weaken the results independently from occupations. A further limitation of this study is that FEWS versions 3.0 was applied to police vs. FEWS version 4.0 was applied to teacher and travel agent surveys. The FEWS version 4.0 is an optimized equivalent version of FEWS 3.0. Similar items build mean scaled score in FEWS 3.0 and FEWS 3.1, in order to optimize equivalence for the purpose of Field Study Part 1. However some of FEWS 4.0 items were changed in wording to address linguistic concerns of FEWS 3.0., and are therefore not identical to their counterpart FEWS 3.0 item. Moreover, the FEWS version 3.1 scales show lower reliabilities, seven of eighteen coefficients alpha falling below the minimum for reliability recommended by Nunnally and Bernstein (1994). This might be influenced by concerns of item homogeneity and number of items, which were attempted to be improved by enhancements in FEWS 4.0, and perhaps an issue of variance restrictions within occupations. This can be expected regarding hypothesis of occupational similarities in emotion work. Moreover, the increased 
error variance by lower scale reliability would only have decreased the probability to detect the hypothesized differences like argued for the social desirability bias above and would have worked against the hypothesis. Nevertheless, systematical occupational differences were shown.

It was the intent of Field Study Part 1 to present some empirical data to support the first part of the RS Model - that organizational determinants define external tasks in the context of emotion work (i.e., requirements to display positive, or negative, or neutral emotions, requirements to be sensitive for the emotions of the customers, requirements to show sympathy; and the stressor emotional dissonance, Figure 2, p. 37; Figure 3, p. 41). A general concern in emotion work field studies is that customer event organizational determinants (frequency, intensity, duration, quality, and variety) are difficult for researchers to keep completely constant. Therefore, in Field Study Part 1 it was not intended to identify all of the particular inner organizational and customer event determinants (Figure 2, RS Model); but rather to identify occupational determinants—similarities in organizations within one occupation and dissimilarities in organizations between different occupations in major tasks, service-, and interdependence characteristics. To find support for the postulated influence of other specified organizational determinants of emotion work/external task (RS Model Figures 2 and 3 and related Proposition 2 regarding inner organizational determinants of external tasks; and Proposition 3 regarding customer event determinants of external tasks), laboratory studies should be applied. These considerations aside, experiments were applied in this 
study as several possible effect variables could be kept constant or controlled and specific variables with predictable consequences could be manipulated.

\subsection{Experiment 1}

According to the RS Model (Figure 2, p. 37) and related Propositions 10, 11, and 14 (Figure 4, p. 48), it is postulated that an emotion work job requirement or stressor affects the individual emotion work strategies, including self-regulation and task behavior, and in turn leads to emotion work consequences, including individual negative short-term consequences. The varying display rules under the constant of intensely negative event quality define the amount of emotional dissonance (an external task). According to Proposition 10 it is proposed that emotional dissonance (an external task) affects the effort of the emotion work self-regulation. This should lead to differences in the self-regulation according to the different display rule conditions, and implies that more effort in the selfregulation process is needed under the friendly display rule condition where more emotional dissonance is demanded. According to Proposition 14 it is proposed more precisely for the stressor emotional dissonance (an external task) that emotional dissonance has negative organizational consequences (employee consequences, customer satisfaction, and inner organizational success). That implies that negative short-term consequences (state negative affect) of the experimental work situation are higher in the case of emotional dissonance. On the basis of this discussion, the following is predicted:

Hypothesis 5: Display rule friendly (higher requirement of emotional dissonance) will lead to more expended effort in emotion work self- 
regulation than display rule authentic (lower requirement of emotional dissonance).

Hypothesis 6: Display rule friendly (higher requirement of emotional dissonance) will lead to a higher amount of negative short-term consequences than display rule authentic (lower requirement of emotional dissonance).

\subsubsection{Method-Experiment 1}

Overview. The study was characterized as an effort to examine the effects of several selling strategies on customer satisfaction. Subjects were instructed to play the role of a student who works as a call center agent in an internet access firm. All subjects were asked to make two telephone calls to customers to sell internet access. All subjects were supported by documentation listing advantages of the company internet access (e.g., enrollment prize, no base charge, etc.). The so-called customers were role-played by research assistants and were instructed to give standard harsh answers to all of the arguments the subjects stated (e.g., "I don't understand what you're talking about—couldn't you explain this comprehensibly?"). After completing their first telephone call, each subject was asked to fill out a postexperimental questionnaire. The experiment concluded without a second telephone call and the subjects were informed of the true purpose of the study, thanked, and dismissed.

Subjects. Eighty students of the Institute of Psychology, University of Göttingen, Germany (age ranged from 19 to $52, M=23.15$ years, $S D=4.4$ years; sample consisted of 31 males and 49 females) participated for course credits. 
Participants (callers) were randomized into two experimental groups described below.

Display rule manipulation. After presenting the cover story and some general instructions to all of the participants, the display rule of the company was varied in the instructions. Half of the subjects were told that the guiding belief of the company is "The customer is king" and that employees should be extremely courteously, friendly and obliging in order to comply with the positive image of the company (friendly condition). The other half were told that the latest findings in customer service research showed that the guiding belief "The customer is king" is out-people who are authentic and communicate with their true personality to customers are seen to be more credible and capable. Therefore, the company was choosing only students for the selling task because they are unbiased and the company wanted them to behave during the phone calls very natural and authentic (authentic condition).

Test planning. Because of pragmatic constraints in recruiting and testing participants, it was not practicable to follow the recommendations derived from a priori power analyses (Cohen, 1988). For this experiment and the two following experiments, the significance level was fixed a priori to a one-tailed level alpha of .10. Additionally the compromise method for power analysis recommended for such cases (Hager, 1987) was applied to estimate a criteria for level alpha, given a restricted sample size, to be able to decide against the null-hypothesis, if a hypothesized effect actually exist (one-hypothesis). The desired effect to detect was fixed to $d=0.5$ (medium effect size of arithmetic mean differences). According to a beta/alpha ratio of 1 (considering both types of errors equally serious), the power analysis with GPOWER (Erdfelder, Faul, \& Buchner, 1996; 
Faul \& Erdfelder, 1992) revealed for the sample size realized in this study $(N=$ $\left.80 ; n_{1}=n_{2}=40\right)$ that it should be decided against the null-hypothesis regarding the compromise method at one-tailed level alpha of .13.

Dependent variables. In the postexperimental questionnaire, a three item scale was developed to measure the expended effort in the emotion work selfregulation process. Three statements were followed by a six-point scale (coded from not at all [0] to completely agree [5]). The first item asked if deep acting strategies were used during the role play ("during the conversation, I tried to suppress my inner feelings."). The second and third items measured the intensity of the felt emotions during the role-play ("I felt anger during the role-play."; and "I felt personally attacked by my conversational partner during the role playing."). Scale scores ranged from 0.00 to $5.00(M=2.54, S D=1.26)$; item scale correlation ranged from .51 to .63; and Cronbach's Alpha $=.73$-all indicating good scale properties according to the suggestions of Nunnally and Bernstein (1994).

To measure the state negative affect of participants after the telephone calls, the individual short-term consequence of emotional dissonance (state negative affect), a fourteen-item bipolar-adjective list was applied. The items were selected from larger scales of Zerssen (1970). A sample item would be bright vs. unhappy as end anchors of a 6-point rating scale without numerical anchors. State negative affect scale score was computed by mean of item-scores and each item was coded from 0 to 5 , with higher values indicating stronger state negative affect. Scale scores ranged from .43 to $4.14(M=2.08, S D=0.77)$; item scale correlation ranged from .34 to .76 ; and Cronbach's Alpha $=.91$-all 
indicating good scale properties according to the suggestions of Nunnally and Bernstein (1994).

Manipulation check. On the postexperimental questionnaire, subjects also completed a manipulation check item. They were asked to rate the extent to which they were committed to this role-playing experiment using the same sixpoint scale (coded from not at all [0] to completely agree [5]). Commitment mean for subjects in the friendly condition was slightly higher than in the authentic condition - but as expected, this difference was not significant (3.2 vs. $\left.3.0, t_{78}=.64, p=.26\right)$. Only three subjects answered that they were not at all committed to the role-playing experiment; $67.6 \%$ of subjects reached values equal or greater than three indicating a satisfactory commitment to the rolepaying experiment.

Summary of the design. The design of the study was a simple one factorial experiment (display rule friendly vs. authentic). Subjects were randomly assigned to one of these two display rule conditions. Except for differences due to the manipulation, the experimental materials issued to all subjects were the same, and all answered the same postexperimental questionnaire containing the one manipulation check item described above. Subjects were told to read the instructions aloud. The instructed communication partners (customers) changed randomly. The communication partners (customers) were not informed which display rule was assigned to which subject (callers). 


\subsubsection{Results-Experiment 1}

It was proposed that the two display rules (friendly vs. authentic) would lead to an increased level of emotional dissonance in the friendly condition, whereas emotional dissonance would be lower in the authentic condition. According to the RS Model (Figure 2, p. 37; Figure 4, p. 48), Proposition 10 (emotional demands affect the effort for self-regulation), and Proposition 14 (emotional demands affect consequences), emotional dissonance was predicted to demand a greater effort in self-regulation under the friendly condition (Hypothesis 5) and influence individual consequences - i.e., a negative affective state of the roleplayed employee after the telephone conversation with a rude, harsh customer (Hypothesis 6).

In Hypothesis 5, it was predicted that the display rule friendly (higher requirement of emotional dissonance) will lead to a greater effort in emotion work self-regulation than the display rule authentic (lower requirement of emotional dissonance). Subject mean scores in reported effort in the emotion work selfregulation process during the role play were analyzed by a two-group, one-tailed $t$ test for independent samples. The mean of effort for subjects in the friendly condition was higher than in the authentic condition, whereas the difference reached no significance. However, according to the compromise method, it would be appropriate to decide against the null-hypothesis $(2.70$ vs. $2.38, S D=1.32$ vs. $\left.1.20, t_{78}=1.12, p=.13, d=0.25\right)$. Figure 6 shows the corresponding differences in scale score of reported effort for the display rule friendly vs. authentic. In this and the following figures corresponding to experiment results, the independent variable is plotted on the x-axis, the dependent variable is plotted on the y-axis, and grid 
marks on the $y$-axis denote the range of total mean scale score plus/minus one standard deviation.

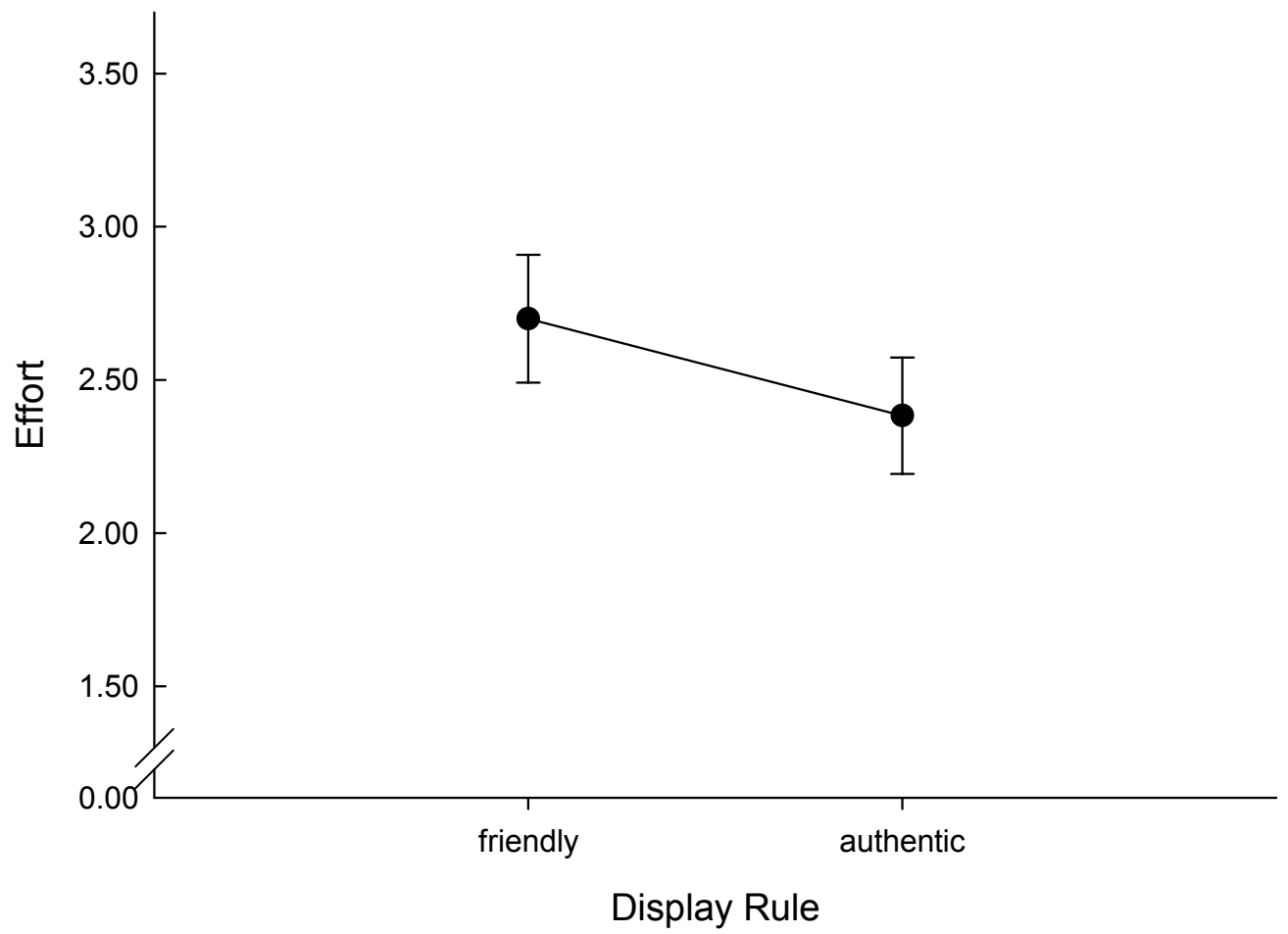

Figure 6. Effect of Display Rule on Effort in Experiment 1.

The subjects instructed to be friendly were expected to experience more emotional dissonance than the subjects instructed to be authentic because they were told to be friendly in a situation where they were personally insulted. Hypothesis 6 predicted that under the friendly display rule condition (and therefore a higher requirement of emotional dissonance), reported state negative affect would be higher than under the authentic display rule condition (and therefore a lower requirement of emotional dissonance). Subject mean scores in reported state negative affect were analyzed by a two-group, one-tailed $t$ test for 
independent samples. As hypothesized, the mean of state negative affect for subjects in the friendly condition was significant higher than in the authentic condition (2.22 vs. $1.93, S D=0.80$ vs. $\left.0.72, t_{78}=1.68, p=.05, d=0.38\right)$. Figure 7 shows the corresponding differences in scale score of reported effort for the display rule friendly vs. authentic.

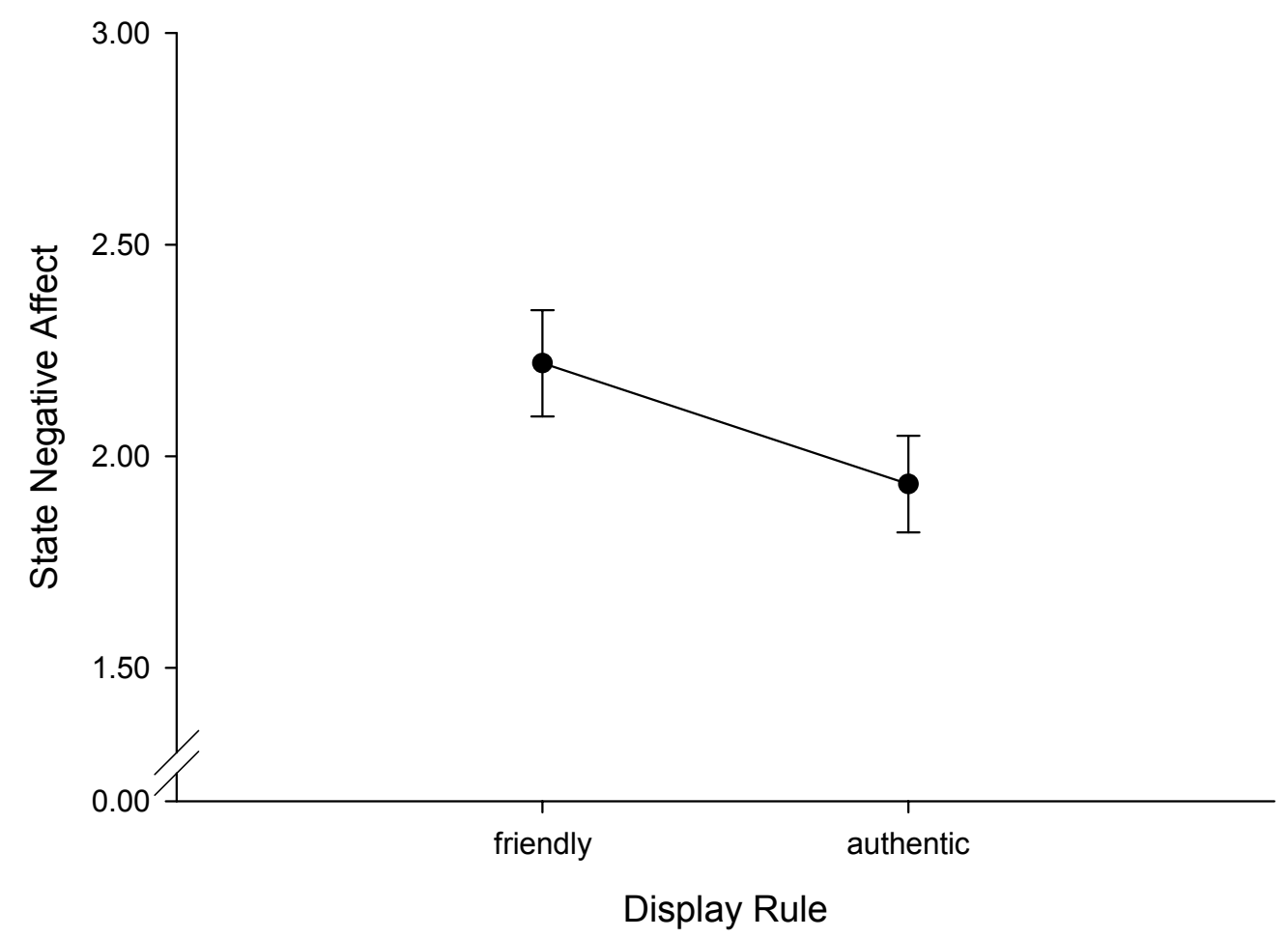

Figure 7. Effect of Display Rule on State Negative Affect in Experiment 1.

\subsubsection{Discussion-Experiment 1}

By applying the experimental paradigm, varying the display rule in a controlled situation where a customer is behaving in a very negative manner it was possible to show that the friendly display rule, which was hypothesized to constitute a high requirement of emotional dissonance (external task), affects short-term 
consequences in a predicted direction. The participants under the friendly display rule condition reported also more effort expended for the emotion work selfregulation process (what was hypothesized in Hypothesis 5) but this result reached no significance at level alpha .10 , whereas according to the compromise method, given the restricted sample size, it should be decided against the nullhypothesis. The significant higher level of state negative affect after the telephone call under the friendly display rule condition compared to the participants under the authentic display rule condition supports Hypothesis 6 . There is some evidence (given the compromise criteria) for Hypothesis 5, derived from Proposition 10, that emotional dissonance is effortful, and Hypothesis 6 derived from Proposition 14 is supported by the data. The job demand emotional dissonance has negative individual consequences—regardless of individual differences in redefinition, self-regulation, and actual task behavior triggered by the external task (Figure 4, p. 48).

A limitation regarding interpretation of results is that only small to mean effect sizes were revealed. This might be a concern associated with the fixed customer reactions (only standardized answers, and no flexible reacting to the statements of the caller), creating an artificial interaction situation. However, the manipulation check revealed that most of the participants were satisfactorily committed to the experiment. A second issue regarding interpretation of results is that although it was supposed that emotional dissonance would be defined by the experimental paradigm, emotional dissonance was not explicitly measured. However, there is indirect empirical support by the predicted and shown effects of the experimental manipulation that a friendly display rule in combination with 
negative customer behavior defines a high level of required emotional dissonance.

\subsection{Experiment 2}

Experiment 2 was designed to replicate the finding of Experiment 1 that the friendly display rule combined with intensely negative customer behavior will lead to a higher amount of negative short-term consequences than the authentic display rule (Hypothesis 6). The same experimental paradigm used in Experiment 1 was applied in Experiment 2 in order to manipulate the level of emotional dissonance. To address the concern regarding not explicitly measuring emotional dissonance in Experiment 1, the FEWS Emotional Dissonance Scale (Zapf et al., 1999) was applied in Experiment 2 to explicitly quantify this external task for the two display rule conditions. This leads to the following hypothesis:

Hypothesis 7: Display rule friendly will lead to higher emotional dissonance than display rule authentic.

To overcome the concern regarding the unnatural interaction situation in Experiment 1 and strengthen the external validity of Experiment 2, this experiment was set up to be more flexible in the role play of a rude, impolite customer. The role-player had a more flexible behavior script (including the behavior to be rude and impolite) and was given a list of example questions, answers and claims but no standard responses as in Experiment 1. To further control for role player effects and to strengthen the internal validity, the same person role-played the instructed interaction partner in all trials. In addition, a 
measurement enhancement was applied in Experiment 2. The State Negative Affect Scale of the PANAS (Watson, Clark, \& Tellegen, 1988) was used to measure the predicted individual short-term consequences of the required emotional dissonance, which is the accepted instrument for measuring emotional states in emotion work research in order to strengthen comparability of experiment and field study findings (Brotheridge \& Grandey, 2002; Grandey, 2000; Schaubroeck \& Jones, 2000; Totterdell \& Holman, 2003).

\subsubsection{Method-Experiment 2}

Overview. Subjects were instructed to play the role of a student who works as a call center agent in a recruitment agency for students. All subjects were tasked to answer calls from complaining students and deal with the complaints as a first contact point. The complaining student was role-played by a research assistant who was instructed to complain very harshly about several failings of the agency (e.g., late payment, bad working conditions, etc.). After completing one telephone conversation, each subject was asked to fill out a postexperimental questionnaire. The subjects were then informed of the true purpose of the study, thanked, and dismissed.

Subjects. Twenty students of the Institute of Psychology, University of Göttingen, Germany (age ranged from 19 to $37, M=23.00$ years, $S D=4.22$ years; sample consisted of 5 males and 15 females) participated for course credits. Participants (role-playing call center agents) were randomized into two experimental groups described below. 
Display rule manipulation. After presenting some general instructions, including the cover story to all of the participants, the display rule of the company was varied per instructions. The display rule manipulation of this experiment emulated the display rule manipulation of Experiment 1: half of the subjects received the friendly display rule and the other half received the authentic display rule.

Test planning. One-tailed level alpha was a priori fixed to .10 . Additionally the level alpha criterion regarding the compromise method was computed to evaluate the empirical effect, given the restricted number of subjects. Given a fixed effect $d=0.5$, and a beta/alpha ratio of 1 the power analysis with GPOWER (Erdfelder et al., 1996; Faul \& Erdfelder, 1992) revealed for the sample size realized in this study $\left(N=20 ; n_{1}=n_{2}=10\right)$ that it should be decided regarding the compromise method against the null-hypothesis at onetailed level alpha of .29 .

Dependent variables. In the postexperimental questionnaire, three items measured the frequency of required dissonance between felt and displayed emotions during the role play (selected and adapted from the emotional dissonance scale of FEWS 3.0, Zapf et al., 1999; e.g., "How often during the role play did you have to display emotions that did not agree with your true feelings?"). Each item was rated on a five-point scale ranging from very rarely/never [1] to very often [5]. Emotional dissonance scale score was computed by mean of item-scores with higher values indicating stronger emotional dissonance. Scale scores ranged from 1.67 to $5.00(M=3.27, S D=$ 1.09); item scale correlation ranged from .77 to .89; and Cronbach's Alpha $=$ 
.90 -all indicating good scale properties according to the suggestions of Nunnally and Bernstein (1994).

The State Negative Affect Scale of the PANAS (Watson et al., 1988) was applied to measure state negative affect reported by participants following their telephone conversations. The scale included ten items reflecting negative states (e.g., nervous) and respondents were asked to rate the extent (from not at all [0] to extremely [4]) to which the emotion was experienced at the moment. State negative affect scale score was computed by mean of item-scores with higher values indicating stronger state negative affect. Scale scores ranged from 0.00 to $1.70(M=0.72, S D=0.56)$; item scale correlation ranged from .21 to .80 ; and Cronbach's Alpha $=.84-$ all indicating good scale properties according to the suggestions of Nunnally and Bernstein (1994).

Summary of the design. The design of the study was a simple one factorial experiment (display rule friendly vs. authentic). Subjects were randomly assigned to one of these two display rule conditions. Except for differences due to the manipulation, the experimental materials issued to all subjects were the same, and all answered the same postexperimental questionnaire. Subjects were told to read the instructions aloud. The instructed communication partner (roleplaying complaining student) was the same research assistant for all participants and was not informed which display rule was assigned which subject (roleplaying call center agents). 


\subsubsection{Results-Experiment 2}

It was predicted that the two opposite display rules would define the level of required emotional dissonance (Hypothesis 7) and in turn, the reported state negative affect (Hypothesis 6) after the telephone conversation with a rude, harsh student. Hypothesis 7 predicted that subjects who were instructed to be friendly would report more emotional dissonance than subjects who were instructed to be authentic because they were told to be friendly in a situation where they were personally insulted. Hypothesis 6 predicted that the higher amount of emotional dissonance requirements for subjects under the friendly condition would lead to a higher state negative affect compared to the authentic condition. To test Hypothesis 7 and Hypothesis 6, subject mean scores in emotional dissonance and state negative affect were analyzed by two separate two-group, one-tailed $t$ tests for independent samples. As hypothesized, the mean of emotional dissonance for subjects in the friendly condition was significantly higher than in the authentic condition ( 4.20 vs. $2.33, S D=0.57$ vs. $\left.0.50, t_{18}=7.80, p=.00, d=3.55\right)$. Figure 8 shows the corresponding differences in scale score of reported emotional dissonance for the display rule friendly vs. authentic. 


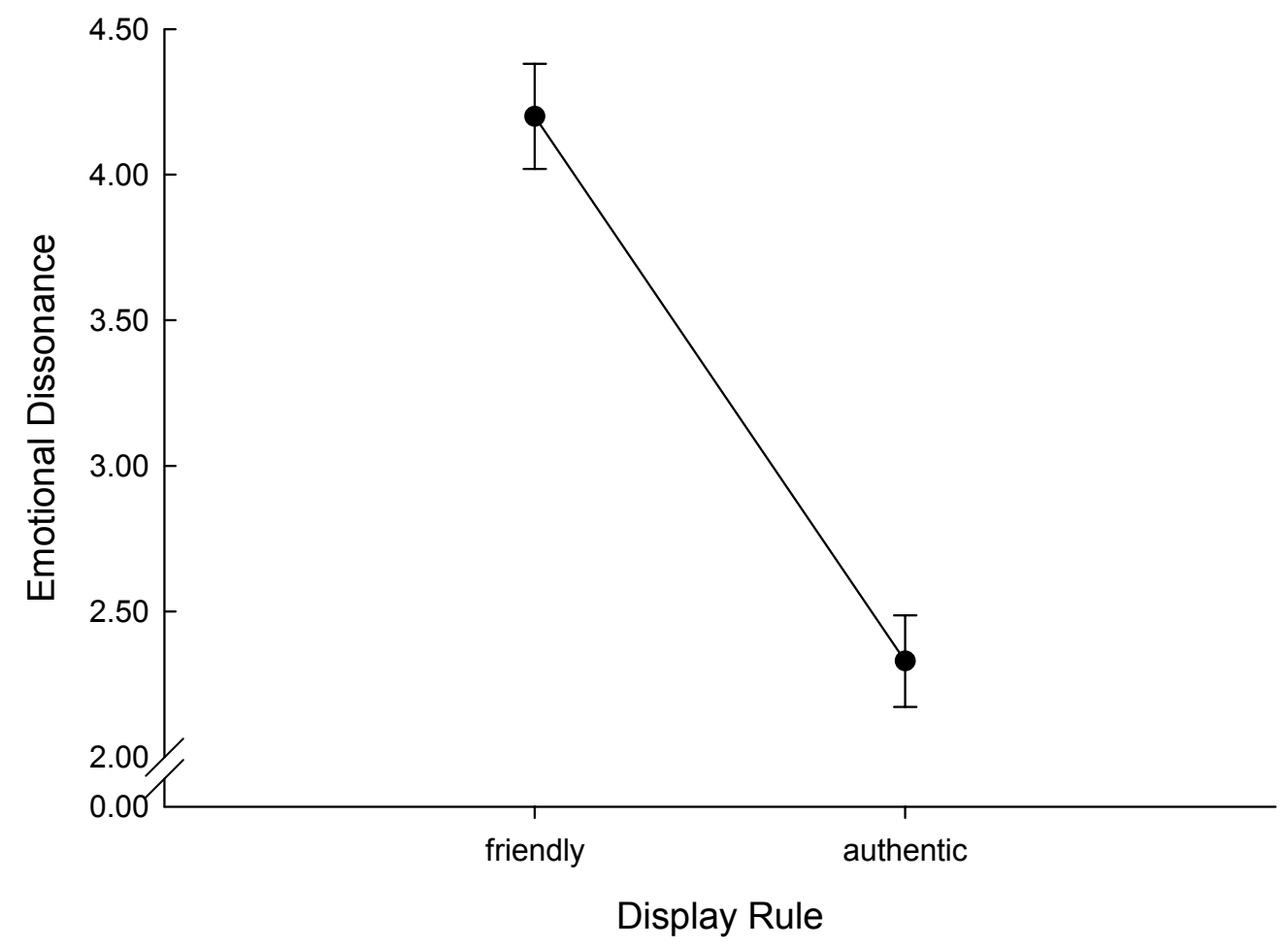

Figure 8. Effect of Display Rule on Emotional Dissonance in Experiment 2.

The mean of state negative affect for subjects in the friendly display rule condition was significantly higher than in the authentic condition (1.00 vs. 0.44 , $S D=0.56$ vs. $0.42, t_{18}=2.54, p<.00, d=1.13$ ). Figure 9 shows the corresponding differences in scale score of reported state negative affect for the display rule friendly vs. authentic. 


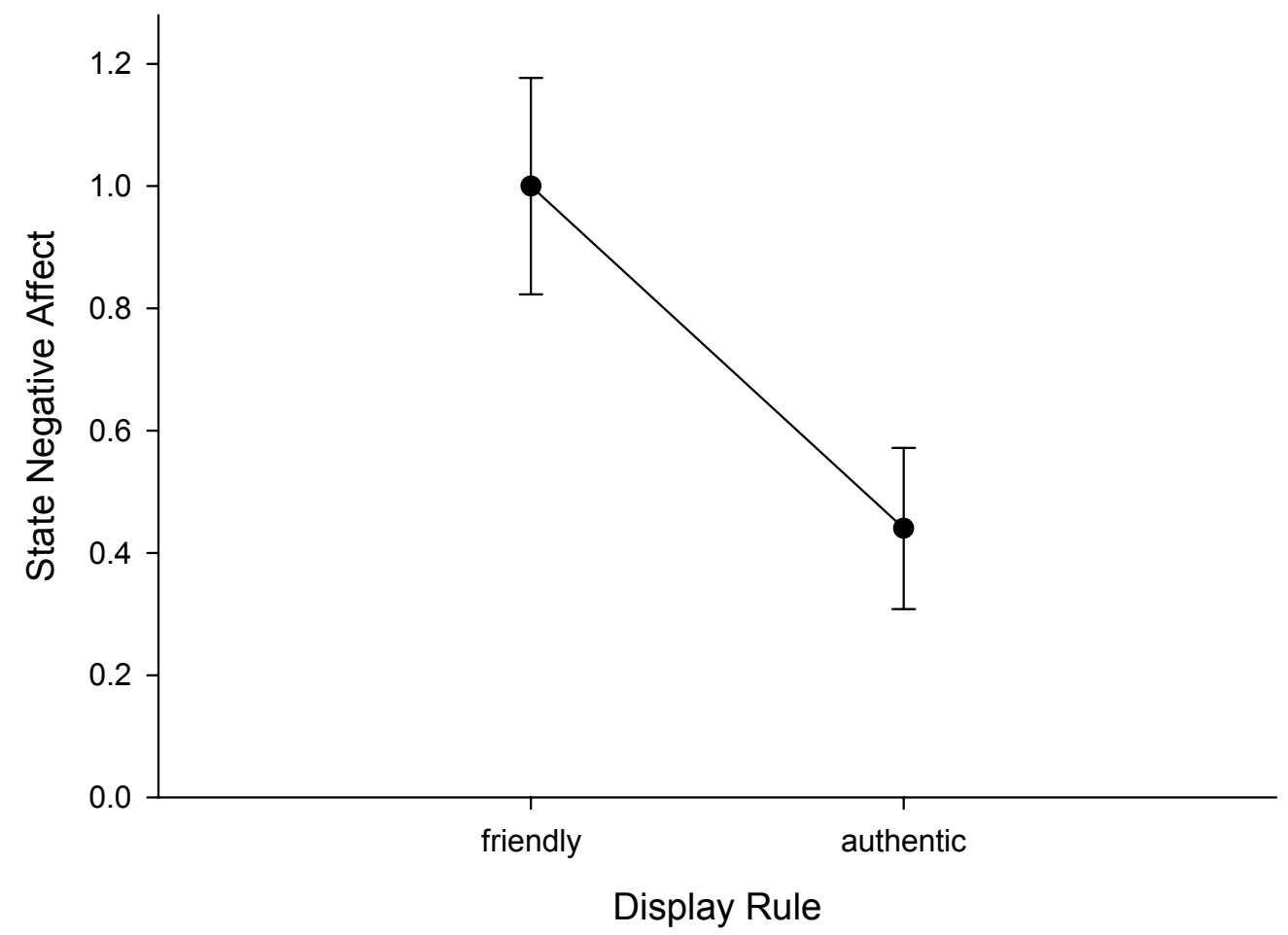

Figure 9. Effect of Display Rule on State Negative Affect in Experiment 2.

\subsubsection{Discussion-Experiment 2}

Results of Experiment 2 support the assumption that this experimental paradigm where the display rule was varied under a constant of intensely negative behaving customer would define the level of the external task emotional dissonance, as predicted in Hypothesis 7: that there is significantly more required emotional dissonance reported under the friendly compared to the authentic display rule condition. Furthermore, this experiment replicates the descriptive findings of Experiment 1, supporting the assumption that emotional dissonance affects negative individual short-term consequences. As predicted in Hypothesis 6 , there is significantly more state negative affect reported under the friendly compared to the authentic display rule condition. These findings support 
Proposition 5 that emotional dissonance is an external task as well as Proposition 14 that emotional demands has consequences, and more precise emotional dissonance has negative individual short-term consequences. Regardless of individual differences in redefinition, self-regulation, and actual task behavior, the experimental manipulation of organizational determinants (organizational display rule and intensity and quality of the customer event) affect the reported requirement of emotional dissonance and state negative affect (Figure 4, p. 48).

In contrast to Experiment 1, effect sizes in Experiment 2 are very high. This might be affected by the nonstandardized customer reactions, which were applied to this experiment to improve the external validity of the experiment. Therefore, Experiment 2 participants are expected to be more involved and committed to the role-play interaction than Experiment 1 participants. But this could have weakened the internal validity of the experiment as the experimental situation was partly defined by the dynamic of the situation, which can limit the interpretation of results. However, because of the replicated findings of Experiment 1, there is empirical evidence that the direction of the shown effects (higher emotional dissonance and state negative affect under the friendly display rule condition) is affected by the experimental manipulation and that only the magnitude of these effects might be overestimated by the dynamic of the unstandardized situation.

\subsection{Experiment 3}

In Experiment 3 the same experimental paradigm allowing manipulation of emotional dissonance as an external task was used as in Experiments 1 and 2, by 
varying the instructed display rule (friendly vs. authentic), along with role-played negative customer behavior (negative, high intensity event quality). As was hypothesized for Experiment 1 and 2, the friendly display rule was predicted to lead to a higher amount of emotional dissonance than the authentic display rule (Hypothesis 7). In this sense, the results of Experiment 3 should replicate the implicit (Experiment 1) and explicit (Experiment 2) findings regarding emotional dissonance and that emotional dissonance is an external task (as this was stated in Proposition 5). A further proposition according to the RS Model and organizational determinants of emotion work (Figure 2, p. 37; Figure 4, p. 48) is that the emotion work external task affects the individual emotion work task behavior (Proposition 11). The friendly display rule in a interaction with an intensely negative behaving customer should lead to a friendlier task behavior than the authentic display rule in a interaction with an intensely negative behaving customer, because this event should evoke negative feelings for subjects in both conditions, but under the friendly condition the external task is to suppress this inner feelings and to show friendly behavior, whereas under the authentic condition, the external task is less restrictive, and subjects are explicitly allowed to show their true feelings, if they would like to do, and therefore under this condition there is a higher probability for unfriendly behavior. It was therefore proposed that the display rule friendly would result in more positive task behavior (better service quality) than the display rule authentic (less positive task behavior; worse service quality) as a consequence of the display rule, independent from individual differences in task redefinition and emotion work self-regulation (including emotional competences). This leads to the next hypothesis: 
Hypothesis 8: Display rule friendly will lead to friendlier task behavior than the display rule authentic.

\subsubsection{Method-Experiment 3}

Overview. Subjects were asked to play the role of a German railway (Deutsche Bahn AG) employee working at the central station service office of a big city. All subjects were assigned a task to answer the phone of a complaining traveler and deal with the complaints. The complaining travelers were role-played by research assistants and were instructed to ask standardized rude questions and to give standardized harsh answers to all of the arguments that the subjects stated (e.g., "I will make you personally accountable for this delay"). After completing one telephone conversation, each subject was asked to fill out a postexperimental questionnaire. The subjects were then informed of the true purpose of the study, thanked, and dismissed.

Subjects. Thirty volunteer students from the University of Göttingen, Germany (age ranged from 20 to $27, M=23.27$ years, $S D=2.45$ years; sample consisted of 15 males and 15 females) participated. Participants role-playing train station employees were randomized into the two experimental groups described below.

Display rule manipulation. This experimental display rule manipulation emulated the display rule manipulation of Experiment 1 and 2. After presenting the general role-play instructions describing the complaint handling work task, participants were handed instructions presented as the display rule of the firm. Half of the subjects received the friendly display rule and the other half received the authentic display rule. 
Test planning. One-tailed level alpha was a priori fixed to .10. Additionally the level alpha criterion regarding the compromise method was computed to evaluate the empirical effect, given the restricted number of subjects. Given a fixed effect $d=0.5$, and a beta/alpha ratio of 1 the power analysis with GPOWER (Erdfelder et al., 1996; Faul \& Erdfelder, 1992) revealed for the sample size realized in this study $\left(N=30 ; n_{1}=n_{2}=15\right)$ that it should be decided against the null-hypothesis regarding the compromise method at onetailed level alpha of .25.

Dependent variables. In the postexperimental questionnaire, four items measured the frequency of required dissonance between felt and displayed emotions (selected and adapted from the Emotional Dissonance Scale of the FEWS, Zapf et al., 1999, described in Experiment 2). Emotional dissonance scale score was computed by mean of item-scores with higher values indicating stronger emotional dissonance. Scale scores ranged from 1.00 to $4.00(M=2.73$, $S D=0.68)$; item scale correlation ranged from .32 to .56 ; and Cronbach's Alpha $=.64-$ all indicating acceptable scale properties according to suggestions of Nunnally and Bernstein (1994). The quality of service displayed by the subjects (role-playing train station employees) during the telephone conversation was rated independently by five research assistants on 13 items of the SERVQUAL (Parasuraman et al., 1988). The items described positive service behavior expectations (e.g., "You can expect from this train station employee concern for the interests of customers") and the five research assistants functioning as observers were asked to rate the service behavior of subjects from tape-recorded telephone conversations on a six six-point scale ranging from completely agree [1] to not at all [6]. Item-scores were computed by mean of the five independent 
observation-item ratings; SERVQUAL scale score was than computed by mean of reverse coded item-scores with higher values indicating more positive service behavior expectations, and lower values indicating more negative service behavior expectations. Scale scores ranged from 2.49 to $5.68(M=4.53, S D=$ 0.79); item scale correlation ranged from .79 to .94; and Cronbach's Alpha $=$ .98 -all indicating very good scale properties according to suggestions of Nunnally and Bernstein (1994).

Summary of the design. The design of the study was a simple one factorial experiment (display rule friendly vs. authentic). Subjects were randomly assigned to the two display rule conditions. Except for differences due to the manipulation, the experimental materials issued to all subjects were the same, and all answered the same postexperimental questionnaire. Subjects were told to read the instructions aloud. The instructed communication partners (role-playing complaining travelers) changed randomly; all of them had the same standardized sentences to say during the role play, and they were not informed which display rule was assigned to which subject (role-playing train station employees). Subject behavior according to service quality was rated separately by five observers (research assistants) and each item score was computed as the mean of these five ratings to control for individual observer errors.

\subsubsection{Results-Experiment 3}

As in Experiment 2, the subjects instructed to be friendly were expected to report more emotional dissonance than the subjects instructed to be authentic because they were told to be friendly in a situation where they were personally insulted 
and where an average person would spontaneously feel disgust or anger (Hypothesis 7). To test this hypothesis, subject mean score in emotional dissonance was analyzed by a two-group, one-tailed $t$ tests for independent samples. The mean of emotional dissonance for subjects in the friendly condition was slightly higher than in the authentic condition (reaching just the level alpha criterion for rejecting the null-hypothesis if the compromise method would be applied to the data; 2.82 vs. $2.65, S D=0.69$ vs. $0.86, t_{28}=0.66, p=.25, d=$ 0.24). Figure 10 shows the corresponding differences in scale score of reported emotional dissonance for the display rule friendly vs. authentic.

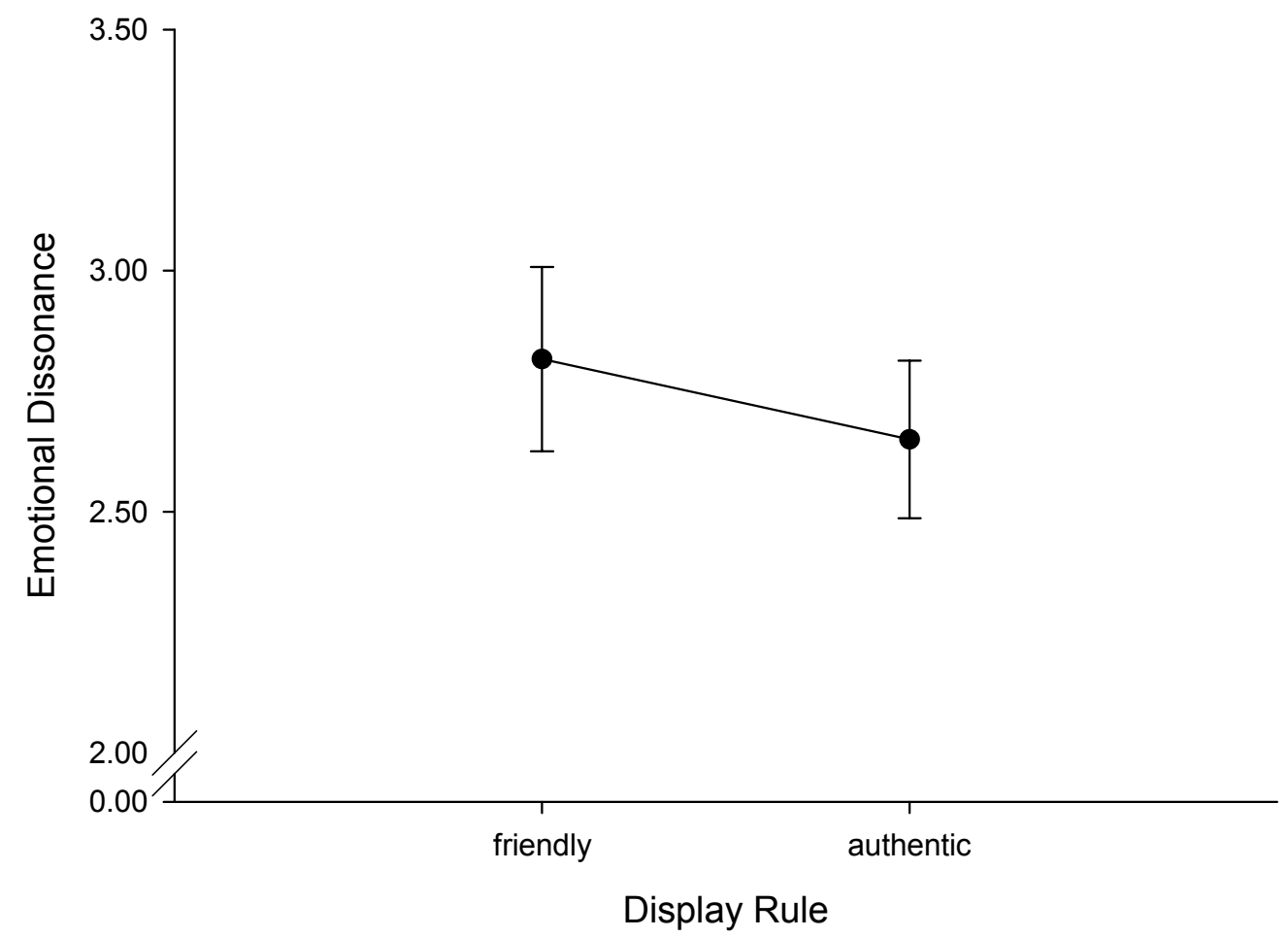

Figure 10. Effect of Display Rule on Emotional Dissonance in Experiment 3.

According to Hypothesis 8 that the display rule friendly will lead to a friendlier task behavior than the display rule authentic, subject SERVQUAL 
mean scores were analyzed by a two-group, one-tailed $t$ test for independent samples. The SERVQUAL mean score for subjects in the friendly display rule condition was significant higher than under the authentic display rule condition (4.72 vs. $4.33, S D=0.69$ vs. $\left..86, t_{28}=1.35, p=.09, d=0.50\right)$. Figure 11 shows the corresponding differences in scale score of rated service quality (SERVQUAL) for the display rule friendly vs. authentic.

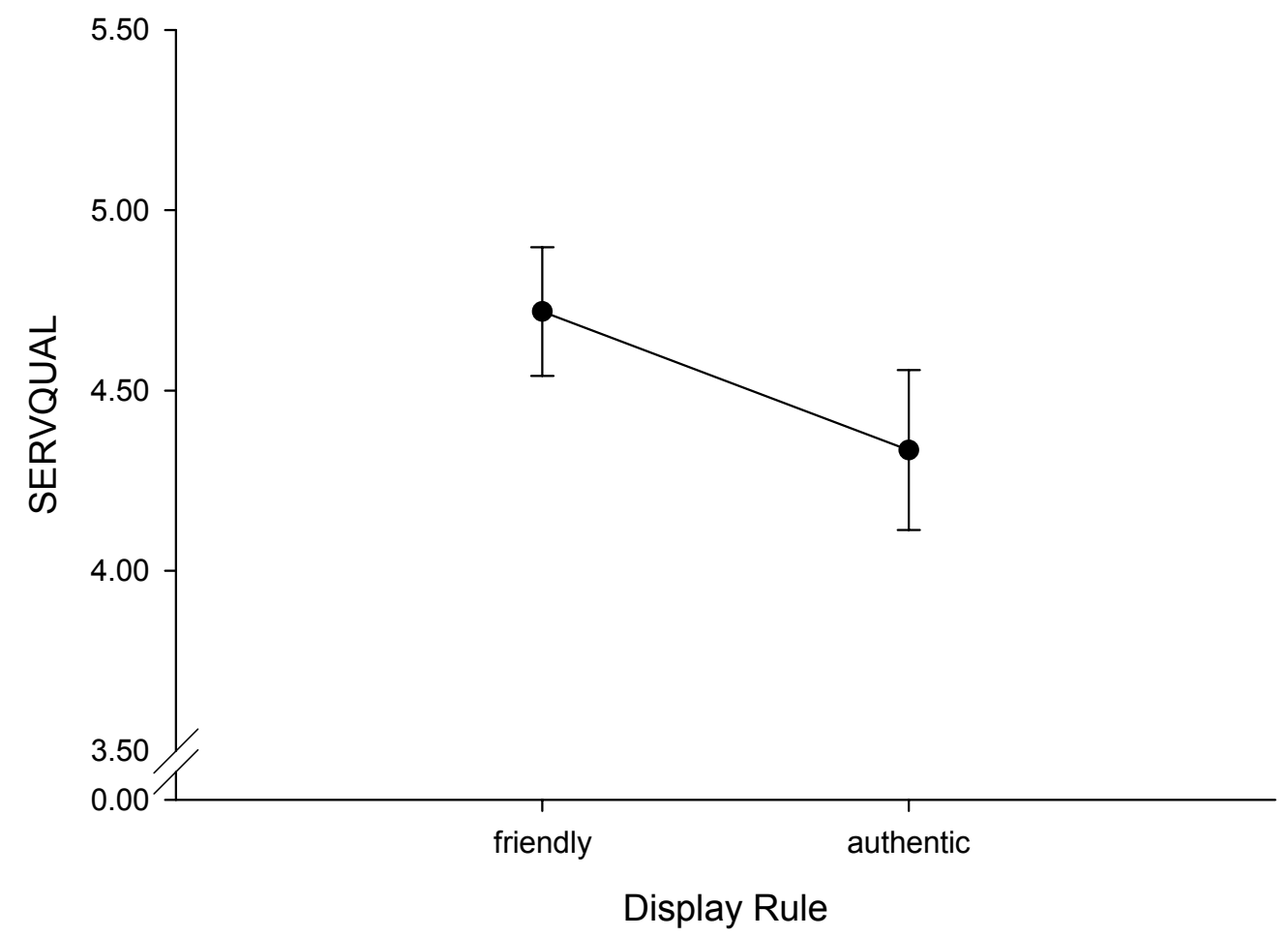

Figure 11. Effect of Display Rule on SERVQUAL in Experiment 3.

\subsubsection{Discussion-Experiment 3}

Experiment 3 (varying display rules combined with an intensely negative behaving customer defines the level of the external task emotional dissonance) results could not replicate the findings of Experiment 1 and 2 regarding 
emotional dissonance. Participants under the friendly display rule condition reported slightly more emotional dissonance in the situation with a negatively behaving customer than participants under the authentic display rule condition in an equivalent intensely negative behaving customer situation, but these findings reached no significance. This supports at least at a descriptive level Proposition 5 that emotional dissonance is an external task (Figure 4, p. 48), as well as Propositions 2 that inner-organizational determinants (organizational display rules), and Proposition 3 that customer event determinants (event quality and event intensity) affect external task definitions. Furthermore, the service quality (task behavior) under the friendly condition was evaluated by the observers as better than the service quality (task behavior) under the authentic condition. This finding supports Proposition 11 that external tasks affect task behavior (Figure 4, p. 48). As predicted, regardless of individual differences in redefinition and selfregulation, the experimental manipulation of organizational determinants (quality and intensity of the customer event and organizational display rule) affects the observed and evaluated task behavior.

Similar to Experiment 1 and in contrast to Experiment 2, Experiment 3 revealed small to mean effect sizes. This supports the assumption that greater effects can be expected if the experimental situation is closer to reality and smaller effects can be expected if the experimental situation is more standardized and controlled. This concerns the dilemma between internal and external validity, where strengthening one weakens the other.

The experimental instructions were intended to emulate an organizational socialization strategy (written material about the guiding belief of a company and what emotion display is required working for this company). In all three 
experiments, the hypothesized effects of the experimental socialization strategy were measured regarding defining emotional dissonance as an external task. It can be taken into question, however, if these results can apply to actual work situations as organizational socialization is a long-term and extremely complex process (Van Maanen \& Kunda, 1989). In particular, employees are typically not passive recipients of socialization strategies that companies, managers, instructors, and peer groups utilize to educate their human resources (Chatman, 1991; Frese, 1982), as were the participants in these experiments. Elements of the organizational socialization process contributed by the employee involve their active role in making vocational and organizational choices, becoming a member of the organization before the entry day, their own job experiences, explicit or implicit negotiations of rules with the other organizational members, their active personal job design, and their choice to leave the organization if they decide not to or fail to fit into patterns of shared values (Fischbach \& Zapf, 2003; Schneider, 1986, 1987; Semmer \& Schallberger, 1996). To show effects of communicating a display rule by a company (organizational socialization) on emotion work in actual work situations, this research question was integrated into a field study question regarding organizational socialization of display rules (hypothesized as an organizational determinant of emotion work external tasks) and a field study question regarding individual professional identity, which can be interpreted as self imposed display rules and personal consideration of and commitment to professional role expectations (hypothesized as a personal determinant in the redefinition of external tasks into internal tasks in the emotion work process) (Figure 2, p. 37, RS Model). 


\section{Redefinition Determinants of Emotion Work-Field Study}

\section{Part 2}

Investigation of redefinition processes proposed in the RS Model by Field Study Part 2. According to the external task-redefinition-internal task process illustrated in the RS Model (Figure 2, p. 37), redefinition is affected by the (a) external task and (b) personal determinants. The current Field Study Part 2 investigates that socialization strategies as an organizational external task determinant (Proposition 6); and professional identity as an personal redefinition determinant (Proposition 7) are pivotal variables in understanding how individuals redefine an external task into an internal task. Socialization strategies affect task understanding and therefore redefinition (Hackman, 1969, 1970). It is proposed that the more effective the socialization strategies are at communicating display rules, the more socialization strategies an employee perceives, and the greater influence the organizational display rules have in the emotion work task redefinition process (chapter 2). Professional identity affects task acceptance and therefore redefinition (Hackman). Professional identity is the personal consideration and commitment to professional role expectations. It is proposed that the more committed an employee is to certain display rules, the greater influence these particular display rules have in the task redefinition process 
(chapter 2). The simplified RS Model below (Figure 12) illustrates the proposed effects of socialization strategies and professional identity on task redefinition as investigated by Field Study Part 2.

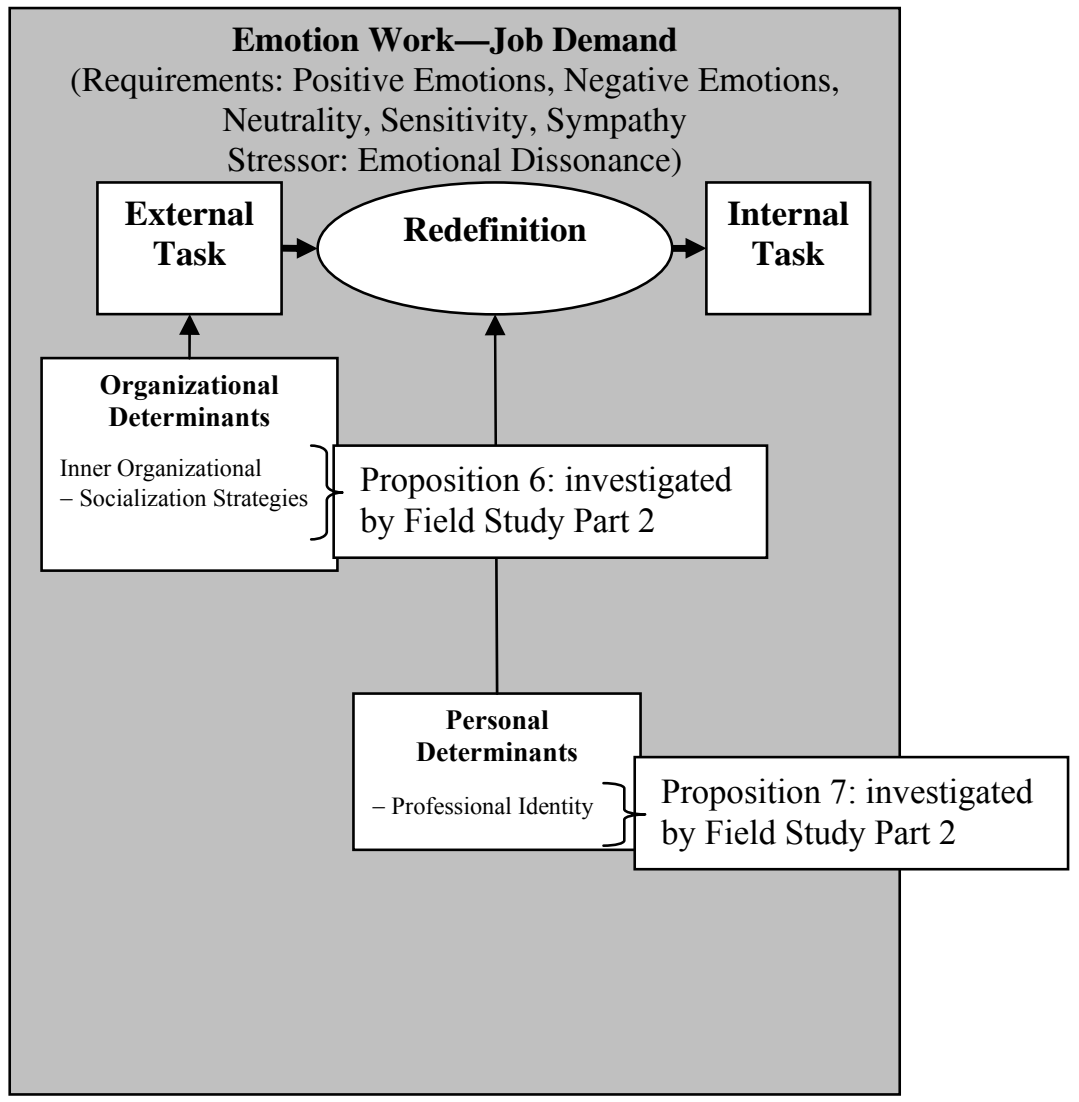

Figure 12. Simplified RS Model: Effects of External Tasks and Personal Determinants on Task Redefinition and Related Propositions 6 and 7.

In the Field Study Part 2 investigations of Propositions 6 and 7, organizational socialization and professional identity were treated as independent variables; and FEWS emotion work demands (positive and negative emotions, neutrality, sensitivity requirements, requirements to show sympathy, and 
emotional dissonance) were treated as dependent variables. It was proposed that variances of the reported FEWS emotion work job demands of the police and teacher surveys, as well as the predominant positive emotion display rule in the travel agent survey, can be explained by socialization strategies, and in turn by professional identity (Figure 12, p. 94). Regarding socialization strategies, it is hypothesized that:

Hypothesis 9: The diverse emotion work demands in police and teacher work, revealed in Field Study Part 1, are affected by socialization strategies.

Hypothesis 10: The predominant requirement of displaying positive emotions in travel agent work, revealed in Field Study Part 1, is affected by socialization strategies.

Regarding professional identity, it is hypothesized that:

Hypothesis 11: Emotion work demands in police, teacher and travel agent work, revealed in Field Study Part 1, are affected by individual differences in professional identity after controlling for socialization strategies.

\subsection{Method—Field Study Part 2}

Subjects-police, teachers, travel agents. The sample descriptions for this study can be found in chapter 3, External Task Determinants, pp. 56f. (police), 57f. (teachers), and 58f. (travel agents).

Instruments-FEWS. Emotion work job requirements and emotional dissonance for police were measured using the FEWS version 3.0 described in chapter 3. For the teacher and travel agent samples, FEWS version 4.0 was 
used - an enhanced version as a result of issues identified in the police survey and other previous studies. The FEWS version 4.0 improvements to linguistic concerns of version 3.0 were also described in chapter 3 . The FEWS version 4.0 included a sixth scale: requirement to show neutrality-five items measuring the frequency of requirement neither to show positive nor negative emotions toward clients (e.g., "How often are you required to display neither positive nor negative emotions towards clients [i.e., showing impartiality]?"). Furthermore, emotion terms (e.g., friendliness, anger, sympathy, neutrality/impartiality) were added to the positive, negative, sympathy, and neutrality requirement scales (e.g., "How often are you required to display sympathy?"). In FEWS 4.0, positive emotion was measured by ten items (measured by 3 items in version 3.0); negative emotion was measured by eight items (measured by 3 items in version 3.0); sensitivity requirement was measured by four items (measured by 3 items in version 3.0); requirement to show sympathy was measured by seven items (measured by 2 items in version 3.0); and emotional dissonance was measured by five items (measured by 4 items in version 3.0). An item analysis was applied to FEWS 4.0 and showed that five of the six scales in the teacher $(N=209)$ and travel agent $(N=202)$ samples reached coefficient alpha from .71 to .81 , falling comfortably above the recommended .70 minimum for reliability recommended by Nunnally and Bernstein (1994). The neutrality requirement scale in the teacher sample (coefficient alpha $=.68$ ) and the showing sympathy scale in the travel agent sample (coefficient alpha $=.65)$ fell under the .70 minimum for reliability.

Instruments-Organizational Socialization. Organizational socialization was measured by asking the subjects in all three samples if and how they learned 
about rules regulating how to deal with interactions with clients, and especially how to deal with the feelings of the clients as well as feelings of their own. The items were developed by Zapf et al. (1999). Seven items referred to how the participants received information about feelings and display rules relevant to their job. Using guidelines applied in other studies and theoretical papers (Bowen \& Schneider, 1988; Rafaeli \& Sutton, 1987; Semmer \& Schallberger, 1996; Sutton, 1991), the possible sources of information on feelings and display rules were identified as the supervisor, training, basic vocational education, organizational culture of the company, career success, guiding beliefs of the occupation, and social expectations at work. In the police survey, each item was rated on a scale with three response categories: I agree with [3], I partly agree with [2], and I disagree with [1]. For all three samples these items remained the same but for the teacher and travel agent surveys, the five-response category Likert-scale (I completely agree with [5], I mostly agree with [4], I partly agree with [3], I mostly disagree with [2], I completely disagree with [1]) was used with the expectation of improving scale properties. An example of the introduction, item and response format of an organizational socialization item is: In many jobs which demand interaction with clients, one has to deal with both one's own feelings as well as those of the clients in a very specific way in order to handle tasks of the job successfully. The way these interactions are regulated, however, differs from workplace to workplace. How is it where you work? These rules were conveyed in my vocational training: I agree with [3]... I disagree with [1] (for the police survey); I completely agree with [5]... I completely disagree with [1] (for the teacher and travel agent surveys). An organizational socialization index was computed by subjects mean scaled score of the seven 
items. High means are an index for stronger communication of display rules by organizational socialization; low means are an index for weaker communication of display rules by organizational socialization.

Instruments-Professional Identity. As far as is known, this study is among the first to validate measurements of professional identity. The intent of the study included measuring individual professional identity using self descriptions of their values and norms according to their professional role expectations. For the purpose of this study, several professional identity scales for the different professions (police, teacher, travel agent) were developed. For the police profession by means of critical incident interviews, 20 police- men and women were interviewed and asked a standardized list of questions about their understanding of police work and their self-concept concerning their role as a police officer. To get an empirically-grounded set of main dimensions of the police officer values and norms according to professional role expectations, their answers were recorded and the protocols were analyzed following the guidelines suggested by Silverman $(1997,2000)$. In an iterative process, three independent raters (the author and two research assistants) identified five categorical topics and assigned 47 statements to one of these five topics. These statements were then organized into item format, headed with the introductory statement: As a police officer, I personally consider... The five topics were: (a) interpersonal skills/awareness (e.g., communication skills; empathy); (b) citizen orientation (e.g., being available for citizen concerns; being a social worker in uniform); (c) police values (e.g., honesty and open-mindedness; abiding by the law); (d) role commitment (e.g., being policeman in private, setting examples); and (e) assertion style (e.g., ability to assert oneself, asserting law and order). Items were 
rated on a ten-point scale ranging from not important [1] to very important [10]. An example of the item and response format is: As a police officer, I personally consider my role regarding setting examples: unimportant [1] ...very important [10]. By means of exploratory factor analysis (PCA), a five-factor solution was calculated for the police data set $(N=221$; scree plot criteria). Items with high and with respect to content interpretable factor loadings (convergent validity criteria) and low factor loadings to the remaining factors (discriminant validity criteria) were selected. Items assigned to each of the five scales were analyzed and items with low item-scale correlation were deleted. The scales with the remaining items reached coefficient alpha from .71 to .86 and fell above the 0.70 minimum for reliability recommended by Nunnally and Bernstein (1994). For the teacher and travel agent professional identity scales, the police professional identity scales were emulated where possible, adapting 29 of the 47 items with only slight terminology changes (e.g., changing citizen to students or customers respectively). Eighteen items were found to be profession-specific to police work (e.g., asserting law and order) and non-adaptable to the teacher and travel agent professions. Similar to the police critical incident interviews, seven teacher and seven travel agents were interviewed and asked a standardized list of questions about their understanding of teaching or travel agents work and their self-concept concerning their role as a teacher or travel agent. Based on these interview results, 26 additional items were developed profession-specific to teachers (e.g., applying educational/pedagogical techniques) and 26 additional items were developed profession-specific to travel agents (e.g., ability to actualize client dream vacations). An example of how item and response format emulated the police survey is: As a teacher, I personally consider my role regarding taking 
student concerns seriously: unimportant [1] ...very important [10]. The teacher and travel agent data-sets were factorized to search for profession-specific replications of the five factor-structure of the police professional identity scales. By means of exploratory factor analysis (PCA), a six-factor solution was calculated for the teacher data set $(N=209)$ and a four-factor solution was calculated for the travel agent data set $(N=202$; scree plot criteria). Items with high and with respect to content-interpretable factor loadings (convergent validity criteria) and low factor loadings to the remaining factors (discriminant validity criteria) were selected. The professional identity scales for teachers with the remaining items reached coefficient alpha from .77 to .85 ; the professional identity scales for travel agents with the remaining items reached coefficient alpha from .81 to .87 -all falling above the 0.70 minimum for reliability recommended by Nunnally and Bernstein (1994).

In Table 4 (p. 103f.), the six professional identity scales and assigned items were specified for each of the three occupations. The professional identity scale termed interpersonal skills reflects an item-pattern of social competence skills that create a positive, social atmosphere. All seven items assigned to teacher interpersonal skills characterize generic skills regarding positive interactions with others (e.g., empathy; patience; and friendliness); whereas the six items assigned to travel agent interpersonal skills include profession-specific aspects (e.g., well-groomed appearance; smiling friendly at the client). In the police interpersonal skills, some of the seven assigned items also include aspects of self reflection (e.g., question one's actions) which are also considered conditions of social competence (Goleman, 1996). The professional identity scale termed as citizen/student/customer orientation reflects an item-pattern of 
taking care of the needs and wishes of those served, but the content and nature of service-providing issues naturally differ in these three occupations. The five items assigned to police citizen orientation focus on the helping aspect of police work (e.g., being a social worker in uniform). The four items assigned to teacher student orientation focus on providing an inspiring education (e.g., offering interesting classes with lots of variety). The nine items assigned to travel agent customer orientation focus on profession-specific helping and customer satisfaction aspects (e.g., taking client concerns seriously; valuing client satisfaction with the service). The professional identity scale termed as police values consists of four guiding beliefs in police work (e.g., honesty and openmindedness; sense of justice). By means of PCA, a complementary guiding belief factor was not found for the teacher or the travel agent professions. The professional identity scale termed as role commitment reflects an item-pattern of a strong personal identification with one's own profession (e.g., being policeman in private; being a teacher in private life as well; advising friends about vacations even away from work). Additionally, the after-hours, extra engagement aspect of several topics is included in the teacher profession (e.g., organizing extracurricular activities) and the travel agent profession (e.g., researching information about vacations even outside work). The professional identity scale termed as assertion style reflects an item-pattern of being an authority figure to those served-citizens in the police profession and students in the teaching profession. All of the four items assigned to police assertion style focus on an authoritative position relative to citizens (i.e., ability to assert oneself; profound professional knowledge; asserting law and order; and asserting sanctions consequently). The seven items assigned to teacher assertion style characterize 
authority in a softer, profession-specific style (e.g., ensuring discipline among students). By means of PCA, a complementary assertion style factor was not found for the travel agent profession. Consequently, the single travel agent assertion item (ability to assert oneself) was loaded onto the travel agent intrapersonal skills factor. By means of PCA, intrapersonal skills was found to be a separate factor for the teacher and travel professions, whereas for the police profession this aspect of professional identity was less discrete and therefore integrated into police interpersonal skills. The items assigned to teacher and travel agent intrapersonal skills correspond to self-management skills (e.g., ability to critically evaluate own actions; awareness of one's deficits). 
Table 4

Professional Identity Scales_-Police, Teacher, Travel Agent

\begin{tabular}{|c|c|c|}
\hline Police & Teacher & Travel Agent \\
\hline $\begin{array}{l}\text { Interpersonal Skills } \\
\text { (and Intrapersonal } \\
\text { Skills) } \\
\text { - empathy } \\
\text { - communication skills } \\
\text { - ability to understand } \\
\text { others } \\
\text { - psychological knowledge } \\
\text { - questioning one's actions } \\
\text { - awareness of one's deficits } \\
\text { one's actions }\end{array}$ & $\begin{array}{l}\text { Interpersonal Skills } \\
\text { - empathy } \\
\text { - ability to understand others } \\
\text { - being free of prejudices } \\
\text { - patience } \\
\text { - friendliness } \\
\text { - sense of justice/fairness } \\
\text { - taking students' concerns } \\
\text { seriously }\end{array}$ & $\begin{array}{l}\text { Interpersonal Skills (and } \\
\text { Appearance) } \\
\text { - politeness } \\
\text { - well-groomed appearance } \\
\text { - smiling friendly at the client } \\
\text { - friendliness } \\
\text { - punctuality } \\
\text { - patience }\end{array}$ \\
\hline $\begin{array}{l}\text { Citizen Orientation } \\
\text { - citizen-oriented } \\
\text { - being available for } \\
\text { citizens' concerns } \\
\text { - taking citizens' concerns } \\
\text { seriously } \\
\text { - being a social worker in } \\
\text { uniform } \\
\text { - helping citizens }\end{array}$ & $\begin{array}{l}\text { Student Orientation } \\
\text { - offering interesting classes } \\
\text { with lots of variety } \\
\text { - raising students' enthusiasm } \\
\text { for class subject } \\
\text { - creating positive feelings in } \\
\text { students (e.g., enjoying the } \\
\text { class) } \\
\text { - valuing students' satisfaction } \\
\text { with classes }\end{array}$ & $\begin{array}{l}\text { Customer Orientation } \\
\text { - valuing client satisfaction with } \\
\text { the service } \\
\text { - taking clients' concerns } \\
\text { seriously } \\
\text { - profound professional } \\
\text { knowledge } \\
\text { - enthusiasm/commitment to } \\
\text { - abk } \\
\text { - ability to grasp clients' wishes } \\
\text { - sense of responsibility } \\
\text { - ability to actualize clients' } \\
\text { dream vacations } \\
\text { - raising clients' enthusiasm for } \\
\text { the trip } \\
\text { - giving competent advice } \\
\end{array}$ \\
\hline $\begin{array}{l}\text { Police Values } \\
\text { - honesty and open- } \\
\text { mindedness } \\
\text { - abiding by the law } \\
\text { - tolerance } \\
\text { - sense of justice }\end{array}$ & no complimentary factor & no complimentary factor \\
\hline
\end{tabular}


Table 4 (continued)

\begin{tabular}{|c|c|c|}
\hline Police & Teacher & Travel Agent \\
\hline $\begin{array}{l}\text { Role Commitment } \\
\text { - being policeman in } \\
\text { private } \\
\text { - being proud of job } \\
\text { - setting examples } \\
\text { - avenging every offence }\end{array}$ & $\begin{array}{l}\text { Role Commitment } \\
\text { - available for students' and } \\
\text { parents' concerns } \\
\text { - counseling for problems } \\
\text { outside the school-context } \\
\text { - being a teacher in private life } \\
\text { as well } \\
\text { - dealing with professional } \\
\text { topics even at home } \\
\text { - organizing extra-curricular } \\
\text { activities } \\
\text { - always available to students } \\
\text { (in emergency, even outside } \\
\text { school hours) } \\
\text { - being proud of job } \\
\text { - applying } \\
\text { educational/pedagogical } \\
\text { techniques }\end{array}$ & $\begin{array}{l}\text { Role Commitment } \\
\text { - advising friends about } \\
\text { vacations even away from work } \\
\text { - dealing with professional topics } \\
\text { even at home } \\
\text { - being available for clients' } \\
\text { concerns } \\
\text { - researching information about } \\
\text { vacations even outside work } \\
\text { - working after hours to catch up } \\
\text { with paper work } \\
\text { - not pushing the client } \\
\text { - being proud of job }\end{array}$ \\
\hline $\begin{array}{l}\text { Assertion Style } \\
\text { - ability to assert oneself } \\
\text { - profound professional } \\
\text { knowledge } \\
\text { - asserting law and order } \\
\text { - asserting sanctions } \\
\text { consequently }\end{array}$ & $\begin{array}{l}\text { Assertion Style } \\
\text { - having an aura of authority } \\
\text { - being consequent } \\
\text { - keeping the appropriate } \\
\text { distance } \\
\text { - ensuring discipline among } \\
\text { - students } \\
\text { - putting students in their } \\
\text { place if necessary } \\
\text { - staying calm and never } \\
\text { losing temper in front of } \\
\text { class } \\
\text { - keeping everything under } \\
\text { control without the help of } \\
\text { others }\end{array}$ & $\begin{array}{l}\text { no separate factor, see } \\
\text { Intrapersonal Skills }\end{array}$ \\
\hline $\begin{array}{l}\text { no separate factor; see } \\
\text { Interpersonal Skills }\end{array}$ & $\begin{array}{l}\text { Intrapersonal Skills } \\
\text { - ability to critically evaluate } \\
\text { own actions } \\
\text { - able to accept criticism } \\
\text { - awareness of one's deficits } \\
\text { ability to deal with stress }\end{array}$ & $\begin{array}{l}\text { Intrapersonal Skills (and } \\
\text { Assertion Style) } \\
\text { - strong self-esteem } \\
\text { - ability to assert oneself } \\
\text { - ability to critically evaluate } \\
\text { own actions } \\
\text { - being free of prejudices } \\
\text { - awareness of one's deficits }\end{array}$ \\
\hline
\end{tabular}




\subsection{Results—Field Study Part 2}

For the purpose of analyzing the effects of socialization strategies and in turn professional identity on emotion work requirements and emotional dissonance within one occupation, separate hierarchical regression analyses were applied for each occupation. Reported organizational socialization (step 1) and reported organizational socialization and aspects of professional identity (step 2) were treated as independent variables, plus a dependent variable. For the police analysis, this depend variable was one of the four FEWS 3.0 requirement scales (positive emotions, negative emotions, sensitivity requirements, requirement to show sympathy) and emotional dissonance. For teacher and travel agent analyses, the dependent variable was one of the five FEWS 4.0 requirement scales (same four scales as for police, plus the neutrality requirement scale) and emotional dissonance as for police. The amount of variance in each of the FEWS requirement scales and emotional dissonance, accounted for by organizational socialization (step 1) and professional identity (step 2), was calculated by $\mathrm{R}^{2}$-type statistics. The descriptive data and correlations of all study variables are shown on the following page in Table 5. 


\section{Table 5}

Correlations among Study Variables and Descriptive Statistics for Police,

Teacher and Travel Agent Samples

\begin{tabular}{|c|c|c|c|c|c|c|c|c|c|c|c|c|c|c|c|c|c|}
\hline Variable name & Mean & S.D. & 1 & 2 & 3 & 4 & 5 & 6 & 7 & 8 & 9 & 10 & 11 & 12 & 13 & 14 & 15 \\
\hline \multicolumn{18}{|l|}{ 1. $\quad$ Age (years) } \\
\hline Police & 39.44 & 7.37 & - & & & & & & & & & & & & & & \\
\hline Teacher & 46.59 & 9.91 & - & & & & & & & & & & & & & & \\
\hline Travel Agent & 33.47 & 9.81 & - & & & & & & & & & & & & & & \\
\hline \multicolumn{18}{|c|}{ 2. Gender $(1=$ male $2=$ female $)$} \\
\hline Police & - & - & .33 & - & & & & & & & & & & & & & \\
\hline Teacher & - & - & -.19 & - & & & & & & & & & & & & & \\
\hline Travel Agent & - & - & -.23 & - & & & & & & & & & & & & & \\
\hline \multicolumn{18}{|c|}{ 3. Positive Emotions } \\
\hline Police & 2.10 & 0.77 & .00 & .01 & .57 & & & & & & & & & & & & \\
\hline Teacher & 3.84 & 0.52 & -.05 & .33 & .83 & & & & & & & & & & & & \\
\hline Travel Agent & 3.92 & 0.45 & -.05 & .16 & .71 & & & & & & & & & & & & \\
\hline \multicolumn{18}{|c|}{ 4. Negative Emotions } \\
\hline Police & 2.64 & 0.81 & -.21 & -.04 & .43 & .76 & & & & & & & & & & & \\
\hline Teacher & 2.74 & 0.54 & -.05 & .07 & .14 & .78 & & & & & & & & & & & \\
\hline Travel Agent & 1.57 & 0.46 & -.14 & -.12 & -.14 & .81 & & & & & & & & & & & \\
\hline \multicolumn{18}{|c|}{ 5. Neutrality Requirement } \\
\hline Teacher & 3.78 & 0.62 & -.15 & .09 & .09 & .24 & .68 & & & & & & & & & & \\
\hline Travel Agent & 3.45 & 0.71 & .10 & .00 & .08 & .12 & .74 & & & & & & & & & & \\
\hline \multicolumn{18}{|c|}{ 6. Sensitivity Requirement } \\
\hline Police & 3.19 & 0.88 & -.25 & -.08 & .47 & .47 & - & .89 & & & & & & & & & \\
\hline Teacher & 3.89 & 0.66 & .03 & .14 & .49 & -03 & .00 & .81 & & & & & & & & & \\
\hline Travel Agent & 3.74 & 0.68 & -.04 & .02 & .35 & -.16 & .12 & .77 & & & & & & & & & \\
\hline \multicolumn{18}{|c|}{ 7. Showing Sympathy } \\
\hline Police & 2.51 & 0.73 & -.20 & -.06 & .55 & .54 & - & .63 & .75 & & & & & & & & \\
\hline Teacher & 3.33 & 0.55 & .18 & .24 & .66 & .25 & .06 & .52 & .76 & & & & & & & & \\
\hline Travel Agent & 3.03 & 0.53 & -.06 & .06 & .42 & .15 & .16 & .47 & .65 & & & & & & & & \\
\hline \multicolumn{18}{|c|}{ 8. Emotional Dissonance } \\
\hline Police & 2.77 & 0.75 & -.23 & -.01 & .40 & .59 & - & .59 & .47 & .82 & & & & & & & \\
\hline Teacher & 2.62 & 0.70 & -.07 & .13 & .08 & .40 & .22 & -.03 & .17 & .80 & & & & & & & \\
\hline Travel Agent & 3.17 & 0.70 & -.15 & .05 & .13 & .09 & .27 & .21 & .36 & .78 & & & & & & & \\
\hline \multicolumn{18}{|c|}{ 9. Interpersonal Skills } \\
\hline Police & 8.22 & 1.00 & .19 & -.06 & .17 & .00 & - & .17 & .08 & .02 & .86 & & & & & & \\
\hline Teacher & 8.93 & 0.84 & .07 & .24 & .38 & -.04 & .07 & .29 & .37 & -.12 & .85 & & & & & & \\
\hline Travel Agent & 9.09 & 0.85 & -.02 & .07 & .22 & -.27 & .11 & .09 & .03 & -.05 & .85 & & & & & & \\
\hline \multicolumn{18}{|c|}{$\begin{array}{l}\text { 10. Citizen/Student/Customer } \\
\text { Orientation }\end{array}$} \\
\hline Police & 7.68 & 1.32 & .23 & .01 & .24 & -.09 & - & .12 & .14 & -.02 & .70 & .82 & & & & & \\
\hline Teacher & 8.35 & 1.18 & -.05 & .13 & .33 & -.12 & -.06 & .25 & .25 & -.23 & .59 & .85 & & & & & \\
\hline Travel Agent & 9.13 & 0.75 & .15 & .04 & .22 & -.21 & .06 & .10 & .01 & -.23 & .64 & .87 & & & & & \\
\hline \multicolumn{18}{|l|}{ 11. Police Values } \\
\hline Police & 9.10 & 0.79 & .23 & .00 & -.04 & -.17 & - & -.03 & -.01 & -.21 & .60 & .47 & .71 & & & & \\
\hline \multicolumn{18}{|c|}{ 12. Role Commitment } \\
\hline Police & 6.03 & 1.79 & .08 & .07 & .05 & .01 & - & -.08 & -.03 & -.03 & .37 & .37 & .28 & .71 & & & \\
\hline Teacher & 6.02 & 1.59 & .13 & .02 & .20 & -.01 & -.02 & .19 & .27 & -.13 & .46 & .52 & - & .85 & & & \\
\hline Travel Agent & 6.88 & 1.60 & .08 & .08 & .15 & .01 & .00 & .12 & .02 & -.15 & .40 & .49 & - & .84 & & & \\
\hline 13. Assertion Style & & & & & & & & & & & & & & & & & \\
\hline Police & 8.63 & 0.98 & .13 & .00 & .02 & .01 & - & .01 & -.01 & .02 & .62 & .36 & .62 & .50 & .72 & & \\
\hline Teacher & 7.70 & 1.27 & .01 & .15 & .04 & .19 & .18 & -.08 & .16 & .07 & .46 & .45 & - & .42 & .84 & & \\
\hline 14. Intrapersonal S & & & & & & & & & & & & & & & & & \\
\hline Teacher & 8.73 & 0.96 & .01 & .12 & 17 & .06 & .04 & .12 & .25 & -.02 & .52 & .45 & - & .41 & .46 & .77 & \\
\hline Travel Agent & 7.97 & 1.14 & .17 & -.02 & .10 & -.08 & .05 & .17 & .17 & -.10 & .44 & .50 & - & .46 & - & .81 & \\
\hline 15. Org. Socializati & & & & & & & & & & & & & & & & & \\
\hline Police & 2.08 & 0.39 & -.12 & -.10 & .19 & .28 & - & .27 & .23 & .28 & .05 & -.02 & .02 & .09 & .11 & - & - \\
\hline Teacher & 3.01 & 0.59 & -.04 & .00 & -.05 & .01 & -.06 & .01 & -.03 & -.06 & -.06 & .04 & - & -.08 & -.11 & -.01 & - \\
\hline Travel Agent & 3.51 & 0.60 & .11 & -.08 & .26 & -.13 & .04 & .09 & .11 & -.18 & .25 & .25 & - & .14 & - & .20 & - \\
\hline
\end{tabular}

Police: $N(210,219) ; p<.01$ at $\mathrm{r} \geq .18$; Teacher: $N(208,209) ; p<.01$ at $\mathrm{r} \geq .18$;

Travel Agent: $N(201,202) ; p<.01$ at $\mathrm{r} \geq .20$. Coefficient $\alpha$ in italic. 
The analysis revealed generally positive and mean to high first order correlations between professional identity aspects within the three professions (range of $r=$ .28 through .70). Organizational socialization and aspects of professional identity are not significantly correlated in the police and teacher profession but positive correlated in the travel agent profession (range of $r=.14$ through .25).

Results of hierarchical regression analyses are summarized below in Table 6.

\section{Table 6}

Organizational Socialization and Professional Identity as Determinants of Emotion Work (Police, Teacher, Travel Agent)

\begin{tabular}{|c|c|c|c|c|c|c|c|c|c|c|c|c|c|c|c|c|c|c|}
\hline & \multicolumn{3}{|c|}{$\begin{array}{l}\text { Positive } \\
\text { Emotions }\end{array}$} & \multicolumn{3}{|c|}{$\begin{array}{l}\text { Negative } \\
\text { Emotions }\end{array}$} & \multicolumn{3}{|c|}{$\begin{array}{l}\text { Neutrality } \\
\text { Requirements }\end{array}$} & \multicolumn{3}{|c|}{$\begin{array}{l}\text { Sensitivity } \\
\text { Requirements }\end{array}$} & \multicolumn{3}{|c|}{$\begin{array}{l}\text { Showing } \\
\text { sympathy }\end{array}$} & \multicolumn{3}{|c|}{$\begin{array}{l}\text { Emotional } \\
\text { Dissonance }\end{array}$} \\
\hline & $\beta$ & $\mathrm{R}^{2}$ & $\Delta \mathrm{R}^{2}$ & $\beta$ & $\mathrm{R}^{2}$ & $\Delta \mathrm{R}^{2}$ & $\beta$ & $\mathrm{R}^{2}$ & $\Delta \mathrm{R}^{2}$ & $\beta$ & $\mathrm{R}^{2}$ & $\Delta \mathrm{R}^{2}$ & $\beta$ & $\mathrm{R}^{2}$ & $\Delta \mathrm{R}^{2}$ & $\beta$ & $\mathrm{R}^{2}$ & $\Delta \mathrm{R}^{2}$ \\
\hline \multirow{2}{*}{\multicolumn{19}{|c|}{$\begin{array}{l}\text { Step } 1 \\
\text { Org. Determinant }\end{array}$}} \\
\hline & & & & & & & & & & & & & & & & & & \\
\hline Police & & $.03 * *$ & & & $.08^{* *}$ & & & & & & $.07^{* *}$ & & & $.05 * *$ & & & $.08 * *$ & \\
\hline Teacher & & .00 & & & .00 & & & .00 & & & .00 & & & .00 & & & .00 & \\
\hline Travel Agent & & $.07 * *$ & & & .02 & & & .00 & & & .01 & & & .01 & & & $.03 * *$ & \\
\hline \multicolumn{19}{|l|}{ Org. Socialization } \\
\hline Police & $.19^{* *}$ & & & $.28 * *$ & & & & & & $.27^{* *}$ & & & $.23 * *$ & & & $.28 * *$ & & \\
\hline Teacher & -.07 & & & -.02 & & & -.06 & & & .00 & & & -.03 & & & -.06 & & \\
\hline Travel Agent & $.26^{* *}$ & & & -.13 & & & .04 & & & .09 & & & .11 & & & $-.18 * *$ & & \\
\hline \multirow{2}{*}{\multicolumn{19}{|c|}{$\begin{array}{l}\text { Step } 2 \\
\text { Personal Determinant }\end{array}$}} \\
\hline & & & & & & & & & & & & & & & & & & \\
\hline Police & & $.13^{* *}$ & $.10^{* *}$ & & $.13 * *$ & $.05^{*}$ & & & & & $.16^{* *}$ & $.09 * *$ & & $.10^{* *}$ & .05 & & $.18^{* *}$ & $.10^{* *}$ \\
\hline Teacher & & $.21^{* *}$ & $.21 * *$ & & $.10^{* *}$ & $.10^{* *}$ & & $.07 *$ & $.07 *$ & & $.18^{* *}$ & $.18^{* *}$ & & $.18^{* *}$ & $.18^{* *}$ & & $.10^{* *}$ & $.10^{* *}$ \\
\hline Travel Agent & & $.10^{* *}$ & .03 & & $.11^{* *}$ & $.09 * *$ & & .02 & .02 & & .03 & .02 & & .05 & .04 & & $.10^{* *}$ & $.07^{*}$ \\
\hline \multicolumn{19}{|l|}{ Professional Identity } \\
\hline \multicolumn{19}{|l|}{ Interpersonal Skills } \\
\hline Police & .14 & & & .18 & & & - & & & $.28^{* *}$ & & & -.01 & & & .13 & & \\
\hline Teacher & $.36^{* *}$ & & & -.07 & & & .10 & & & $.29 * *$ & & & $.30^{* *}$ & & & -.06 & & \\
\hline Travel Agent & .11 & & & $-.26 * *$ & & & .13 & & & .00 & & & -.01 & & & $.20 *$ & & \\
\hline \multirow{2}{*}{\multicolumn{19}{|c|}{$\begin{array}{l}\text { Citizen/Student/Customer } \\
\text { Orientation }\end{array}$}} \\
\hline & & & & & & & & & & & & & & & & \multicolumn{2}{|c|}{ Orientation } & \\
\hline Police & $.29 * *$ & & & -.10 & & & - & & & .10 & & & $.26^{* *}$ & & & .07 & & \\
\hline Teacher & $.23^{* *}$ & & & $-.24 * *$ & & & $-.19 *$ & & & $.18^{*}$ & & & .01 & & & $-.29 * *$ & & \\
\hline Travel Agent & .10 & & & -.13 & & & -.02 & & & -.01 & & & -.10 & & & $-.30 * *$ & & \\
\hline \multicolumn{19}{|l|}{ Police Values } \\
\hline Police & $-.25 * *$ & & & $-.30 * *$ & & & - & & & $-.20 *$ & & & -.12 & & & $-.45 * *$ & & \\
\hline \multicolumn{19}{|l|}{ Role Commitment } \\
\hline Police & -.06 & & & -.01 & & & - & & & $-.19 *$ & & & -.13 & & & -.13 & & \\
\hline Teacher & .02 & & & -.01 & & & -.07 & & & -.11 & & & .13 & & & -.09 & & \\
\hline Travel Agent & .06 & & & $.17 *$ & & & -.06 & & & .05 & & & -.04 & & & -.07 & & \\
\hline \multicolumn{19}{|l|}{ Assertion Style } \\
\hline Police & .01 & & & .11 & & & & & & -.01 & & & .03 & & & $.24 *$ & & \\
\hline Teacher & $-.24 * *$ & & & $.31 * *$ & & & $.25 * *$ & & & $-.34 * *$ & & & -.08 & & & $.22 * *$ & & \\
\hline \multicolumn{19}{|l|}{ Intrapersonal Skills } \\
\hline Teacher & -.02 & & & .07 & & & -.01 & & & -.01 & & & .07 & & & .08 & & \\
\hline Travel Agent & -.07 & & & .04 & & & .03 & & & .14 & & & $.22 *$ & & & .03 & & \\
\hline
\end{tabular}

Police: $N(211,221)$; Teacher $N(206,207)$, Travel Agent: $N(200,201) ;{ }^{*} p<.05$; ** $p<.01$; 
Police sample results. Regarding Hypothesis 9, by means of hierarchical regression analyses, organizational socialization explained $3 \%$ to $8 \%$ (all $p<.01)$ of the variance in all emotion work demands. Organizational socialization was related positively to all aspects of emotion work $(\beta=.19$ for positive emotions, .28 for negative emotions, .27 for sensitivity requirements, .23 for requirements to show sympathy, and .28 for emotional dissonance, $p<.01$ )-supporting the tenets of Hypothesis 9 that the diverse emotion work demands in police work, revealed in Field Study Part 1, are affected by socialization strategies.

The personal determinant professional identity explained, after controlling for organizational socialization, $5 \%(p<.05$ for negative emotions; $p$ $>.05$ for showing sympathy) to $10 \%$ (all $p<.01$ ) of variance in frequencies of emotion work demands-supporting the tenets of Hypothesis 11. Overall, the variance in FEWS emotion work demands for the police sample could be explained by the external task determinant socialization strategies and the personal determinant professional identity (Figure 12, p. 94, Propositions 6 and 7). These two variables explained $13 \%(p<.01)$ of the variance in frequency of requirement to display positive emotions, $13 \%(p<.01)$ of the variance in frequency of requirement to display negative emotions, $16 \%(p<.01)$ of the variance in frequency of sensitivity requirements, $10 \%(p<.01)$ of the variance in requirements to show sympathy, and $18 \%(p<.01)$ of the variance in frequency of emotional dissonance.

The five aspects of police professional identity were related to FEWS version 3.0 five aspects of emotion work in identifiable patterns. A strong personal consideration of interpersonal skills was positively related to sensitivity requirements $(\beta=.28, p=<.01)$; a strong personal consideration of citizen 
orientation was positively related to both requirement to show positive emotions $(\beta=.29, p=<.01)$ and requirement to show sympathy $(\beta=.26, p=<.01)$; a strong personal consideration of certain police values was negatively related to all aspects of emotion work $(\beta=-.25, p<.01$ for FEWS 3.0 positive emotions; $\beta$ $=-.30, p<.01$ for FEWS 3.0 negative emotions; $\beta=-.20, p<.05$ for FEWS 3.0 sensitivity requirements; $\beta=-.12 ; p>.05, \mathrm{n}$. s. for FEWS 3.0 showing sympathy; and $\beta=-.45, p<.01$ for FEWS 3.0 emotional dissonance). A strong personal consideration of role commitment was negatively related to sensitivity requirements $(\beta=-.19, p<.05)$; and a strong personal consideration of asserting style was positively related to emotional dissonance $(\beta=.24, p<.05)$.

Teacher sample results. The organizational determinant organizational socialization explained no variance in frequencies of emotion work requirements at all, thus for the teacher sample Hypothesis 9 could not be supported by the data. However, the personal determinant professional identity explained $21 \%(p$ $<.01)$ of the variance in frequency of requirement to display positive emotions, $10 \%(p<.01)$ of the variance in frequency of requirement to display negative emotions, $7 \%(p<.05)$ of the variance in frequency of requirement to remain neutral, $18 \%(p<.01)$ of the variance in frequency of sensitivity requirements, $18 \%(\mathrm{p}<.01)$ of the variance in requirement to show sympathy, and $10 \%(\mathrm{p}<$ $.01)$ of the variance in frequency of emotional dissonance, supporting the tenets of Hypothesis 11. This suggests that emotion work demands in teacher work are strongly influenced by individual professional identity, a personal determinant influencing the task redefinition processes (Figure 12, p. 94, Proposition 7).

Three of the five aspects of teachers professional identity were related to the FEWS version 4.0 six aspects of emotion work in identifiable patterns. A 
strong personal consideration of interpersonal skills was positively related to requirement to show positive emotions $(\beta=.36, p=<.01)$; sensitivity requirements $(\beta=.29, p=<.01)$; and requirement to show sympathy $(\beta=.30, p$ $=<.01)$. A strong personal consideration of student orientation was negatively related to three aspects of emotion work: requirement to show negative emotions $(\beta=-.24, p=<.01)$, requirement to remain neutral $(\beta=-.19, p=<.05)$, and emotional dissonance $(\beta=-.23, p=<.01)$; and positively related to both requirement to show positive emotions $(\beta=.23, p=<.01))$ and sensitivity requirements $(\beta=.18, p=<.05)$. A strong personal consideration of asserting style was positively related to requirement to show negative emotions $(\beta=.31, p$ $=<.01)$, requirement to remain neutral $(\beta=.25, p=<.01)$, and emotional dissonance $(\beta=.22, p=<.01)$; and negatively related to both requirement to show positive emotions $(\beta=-.24, p=<.01)$ and sensitivity requirements $(\beta=$ $.34, p=<.05)$. Contrary to the assumptions of Hypothesis 11, two aspects of teacher professional identity were not related to the FEWS version 4.0 aspects of emotion work: role commitment and intrapersonal skills.

Travel Agent sample results. The organizational determinant organizational socialization explained $7 \%(\mathrm{p}<.01)$ of the variance in frequency of requirement to display positive emotions. This supports the tenets of Hypothesis 10 that the predominant requirement of positive emotion display in travel agent work is affected by socialization strategies. Organizational socialization was positively related to requirement to show positive emotions $(\beta$ $=.26, p<.01)$, negatively related to emotional dissonance $(\beta=-.18, p<.01)$, and not significantly related to the other FEWS version 4.0 aspects of emotion work. The personal determinant professional identity explained only $3 \%(p>.05, n . s$. 
of variance in frequency of positive emotion display, not supporting the tenets of Hypothesis 11. Furthermore the variance in frequency of requirement to display negative emotions was explained to $2 \%(p>.05, \mathrm{n}$. s.) by organizational socialization and to $9 \%(p<.01)$ by the personal determinant professional identity. After controlling for organizational socialization, the requirement of negative emotion display in travel agent work was still more influenced by professional identity (a personal determinant influencing the task redefinition processes), than by organizational socialization (an organizational determinant defining the external task). Moreover, $3 \%(p<.01)$ of the variance in frequencies of requirement to display emotional dissonance was explained by organizational socialization and $7 \%(p<.05)$ of this variance was explained by professional identity after controlling for organizational socialization. Overall, the model for the travel agent sample that the variance in FEWS emotion work demands could be explained by external task determinant socialization strategies and personal determinant professional identity (Figure 12, p. 94, Propositions 6 and 7) explained $10 \%(p<.01)$ of the variance in frequency of requirement to display positive emotions, $11 \%(p<.01)$ of the variance in frequency of requirement to display negative emotions, $2 \%(p>.05, \mathrm{n} . \mathrm{s}$. $)$ of the variance in frequency of neutrality requirements, $3 \%(p>.05, \mathrm{n}$. s.) of the variance in frequency of sensitivity requirements, $5 \%(p>.05$, n. s. $)$ of the variance in requirement to show sympathy, and $10 \%(p<.01)$ of the variance in frequency of emotional dissonance.

The four aspects of travel agent professional identity were related to FEWS version 4.0 six aspects of emotion work. A strong personal consideration of interpersonal skills was negatively related to requirement to show negative 
emotions $(\beta=-.26, p=<.01)$ and positively related to emotional dissonance $(\beta=$ $.20, p=<.05)$. A strong personal consideration of customer orientation was negatively related to emotional dissonance $(\beta=-.30, p=<.01)$; a strong personal consideration of role commitment was positively related to requirement to show negative emotions $(\beta=.17, p<.05)$; and a strong personal consideration of intrapersonal skills was positively related to requirement to show sympathy $(\beta=$ $.22, p<.05)$

\subsection{Discussion-Field Study Part 2}

The purpose of Field Study Part 2 was to show how organizational socialization as well as individual professional identity are determinants of emotion work and influence the task redefinition process, as proposed in the RS Model and related Propositions 6 and 7 (Figure 12, p. 94).The aim of this study was to investigate how imparted display rules acquired in the process of organizational socialization, together with aspects of professional identity, are involved in the task redefinition process. Effects of these determinants were different for the three occupations surveyed. Effects of organizational socialization and interpretable patterns of individual differences in professional identity were both shown for the police sample. However, no effects of organizational socialization yet interpretable patterns of individual differences in professional identity were shown for the teacher sample. Stronger effects of organizational socialization and weaker effects of professional identity on positive emotion requirements were shown for travel agents. One interpretation of this findings might be that regarding the discrete service- and interdependence characteristics of the three 
surveyed occupations-police, teacher and travel agent professions-and the empirical finding of Field Study Part 1, divergent importance between these professions of organizational socialization vs. professional identity for affecting reported emotion work requirements might be considered. The supposition is that police officers and teachers have more leeway for task redefinition than travel agents because the service characteristics for police and teacher are more complex (high intangibility and diverse inseparability for police; high inseparability for teacher-see Table 1, p. 52) than the service characteristics for travel agent work (diverse intangibility and low inseparability). In addition, the status and control of service-workers relative to customers can be considered higher for police and teachers than for travel agents, reinforcing redefinition processes (interindividual interpretations influencing what one ought to do regarding an assigned task) in police and teacher work; but inhibiting redefinition processes in travel agent work. Particularly for teachers, the interdependence characteristic of the teacher-student interactions, better described as relationships than encounters (Gutek, 1997; Holman, 2003; Zapf, Isic, Bechtoldt, \& Blau 2003) where authenticity and engagement are probable guiding pedagogic principles, it can expected that professional identity and task redefinition is more relevant in teacher work compared to the relevance of organizational socialization. Furthermore, the diversity of required emotions found for police and teacher work (positive as well as negative emotions, Field Study Part 1 results), contrasted with the predominance of requirement to display only positive emotions found for travel agents (Field Study Part 1 results), might be expected to reinforce task redefinition processes for police and teachers; but inhibit task redefinition processes for travel agents. 
The finding that organizational socialization and aspects of professional identity are not significantly correlated in the police and teacher profession but positive correlated in the travel agent profession lead to the interpretation that there may be high self imposed standards expected regardless of organizational socialization in both police and teacher work. This is in accordance with the interpretation of a higher leeway in task redefinition for police and teachers compared to travel agents.

There are possible alternative and/or additional interpretations of the results of this study. The high beta-weights might be a result of item overlap, as the supposition was that the applied scales measured discrete concepts. In both the 3.0 and 4.0 FEWS Scales, it is asked how often one has to display positive or negative emotions or how often one is required to show sympathy or how often there are sensitivity requirements or requirements of emotional dissonance in one's job. The items used for the professional identity scales ask what are one's personal considerations regarding professional role expectations. This most likely means that the FEWS questions relate to job requirements and emotional dissonance whereas the professional identity scales questions relate to attitudes and values. A concern of the study is the high inter-correlations within the professional identity scales. This could weight results, as one requirement of regression analysis is no high inter-correlation among independent variables. Nevertheless, the varying and interpretable patterns in the weights of the betacoefficients subject to the dependent variables lead to the conclusion that the results are by no means artifactual.

One limitation of these results might be that organizational socialization was measured by employee perceptions: perceiving that if the organization 
makes explicit and/or implicit efforts to communicate display rules, this means the organization sets standards regarding how to interact with clients (whether actually the case or not). It is conceivable that even the perception of organizational socialization is directly affected by implicit and/or explicit organization socialization. This could argue for the measurement of perceived job requirements and stressors by job analysts. Given the postulate that display rules are generally (at least in German organizations) more implicit than explicit and that rules governing how to interact with clients are seldom documented, there is greater leeway for employees to avoid implicit organizational socialization and argue that the organization has less-than-actual concern for display rules. Especially in the police sample where all subjects were members of the same organization, the probability was high that socialization strategies were similar for all organizational members-but there were still important individual differences in reported perceived socialization strategies. These results should be cross validated by, for instance, observation of organizational socialization, interviews with supervisors, document analysis, or analysis of money spend for training regarding emotion work. 


\section{General Discussion}

\subsection{How study findings relate to other emotion work research}

The Redefinition Self-Regulation Model of Emotion Work (Figure 2, p. 37) represents systematically derived propositions about antecedents and consequences of emotion work from emotion work literature and empirical findings, applying the Hackman input-strategy-outcome framework for assessing effects of tasks. Empirical findings of this study support that applying emotion work to Hackman's general concept of work behavior is useful for integrating several diverse emotion work conceptualizations and perspectivesdistinguishing emotional job demands, strategies in dealing with these job demands, and the consequences. This study focuses on how emotion work can be understood as a job demand, particularly how emotional dissonance can be understood as a job stressor, and variables that can be considered antecedents of emotion work.

Relating study findings regarding external task determinants. Several organizational variables regarded in the emotion work and service industry literature as defining or affecting emotion work were examined. Using the Frankfurt Emotion Work Scales (FEWS, Zapf et al., 1999; Zapf et al., 2000), a comparison of emotion work requirements (positive and negative emotions, 
sensitivity requirements, and requirements to show sympathy), and the emotion work stressor, emotional dissonance, was made among three highly diverse occupations: police, teachers, and travel agents. Results show that these occupations have predictable differences in emotion work job demands, interpreted as attributable to differences in major occupational tasks, occupational service characteristics (intangibility, heterogeneity, and inseparability); and interdependence characteristics (relationship vs. encounter interactions, customer demands, and status and control relative to customers). Furthermore, inner organizational determinants (display rules, socialization strategies, and corporate culture) and customer event determinants (frequency, intensity, duration, quality, and variety) were proposed to be more similar within and more dissimilar between occupations (Figure 3, p. 41). Drawing from reported data, these occupations can be profiled according to major tasks, service-, and interdependence characteristics. Regarding major tasks, police (danger- assessment and prevention) and teacher (education) work can be characterized as direct person related, whereas travel agent (travel sales) work can be characterized as indirect person related, combined with higher heterogeneity and inseparability of service delivery in police and teacher work compared to travel agent work. Regarding interdependence characteristics, teachers often become well acquainted with their students and have a shared history with them due to protracted time together, characterizing teacher service interactions more as relationship- than encounter. Students can have diverse needs and wishes (complex customer demands); and status and control for teachers relative to their students is high. Status and control is also high for police officers relative to their customer/clients (citizens, suspects or witnesses). 
Regarding travel agent interdependence characteristics, they often have service interactions which emulate relationships in order to commit customers to the agency but are actually interactions between strangers. The travel agent customer demands are high, and status and control relative to their customers is low. Travel agents report emotional demands dominated by the single emotion rule to display positive emotions. Police and teachers, on the other hand, report demands that can be characterized as more flexible, particularly the display of either positive or negative emotions toward clients. These dissimilarities in breadth of emotional demands, especially the allowance for display of negative emotion in the case of teachers and police but not for travel agents, imply that negative emotions are an accepted part of the work role for teachers and police but not for travel agents. This leads to a higher probability of emotional dissonance for travel agents than for police and teachers as it is inconceivable that travel agents feel only positive emotions in customer interactions at all times. These clearly distinguishable FEWS profiles for police, teacher and travel agent work support the assumption that the FEWS describes organizational job requirements and the stressor emotional dissonance independently of individual work descriptions. Several emotion work studies attempt to show burnout effects of occupations by classifying occupations as high vs. low people work, but thus far these studies have not been able to effectively predict burnout variables (Brotheridge \& Grandey, 2002; Hochschild, 1983; Schaubroeck \& Jones, 2000; Wharton, 1993; Wharton \& Erickson, 1995). Regarding differences in emotional dissonance between the three surveyed occupations (police, teachers, and travel agents), differences in burnout variables should theoretically be predictable (Abraham, 1998, Brotheridge \& Lee, 1998; Grandey, 1998; Kruml \& Geddes, 1998; Morris 
\& Feldman, 1997; Nerdinger \& Röper, 1999; Zapf et al., 1999; Zapf et al., 2001), but the scope of this study did not include a hypothesis dealing with burnout. A comparable proposition was empirically tested by Brotheridge and Grandey (2002) and the authors found differences between human service workers vs. sales workers in frequency, variety and duration of emotion work demands, particularly emotional dissonance, but were unable to distinguish significant occupational group differences in burnout variables. A conclusion of these authors is that individual perceptions of emotion work demands across jobs might be a better predictor for burnout than occupational categories, suggesting that interindividual differences in work perception are more relevant than job factors (Brotheridge \& Grandey, 2002; Brotheridge \& Lee, 2002). With regard to the broad and extended conceptualization of emotion work integrated into the RS Model, it is suggested that the reason for the lack of predictable effects of the variable occupation on emotion work consequences, particularly burnout, might be due to high intra-occupational variance in inner organizational and customer event variables, as well as organizational-specific characteristics of its employees due to personnel selection, training and other human resources management strategies. This makes the categorical variable occupation not distinguishable enough to detect the relationship of actual job characteristics and burnout. However, the conclusion that individual perceptions, regulation-strategies, and work behavior determine emotion work consequences and that therefore a worker-focused vs. an organization-focused perspective more adequately explains emotion work disregards occupational factors affecting and moderating emotion work consequences. Field Study Part 1 gives evidence that occupational determinants affect individual perceptions of job requirements and stressors. 
Without occupational determinants, there is no explanation for the empirically demonstrated occupational differences in the FEWS requirements and stressor scales.

Two organizational determinants (inner organizational display rules and customer event quality) were systematically manipulated in three experiments to show how these variables affect the magnitude of required emotional dissonance. Given intensely negative customer behavior (a customer related event quality) where an average person spontaneously feels disgust or anger, more emotional dissonance was predictably evoked by the display rule to be friendly; whereas the display rule to be authentic evoked less emotional dissonance. In all experiments, this paradigm of display rule and customer event manipulation leads to hypothesized consequences derivable from the RS Model of Emotion Work (Figure 4, p. 48). The friendly display rule leads to higher reported emotional dissonance, higher effort while dealing with tasks involving difficult clients/customers, higher quality in displayed customer orientation, and higher state negative affect. The measurable effects of emotional dissonance on several outcome variables are comparable to effects suggested and shown in the previous emotion work research cited above. However, the interpretation of emotional dissonance differs considerably from this cited research. Brotheridge and Grandey (2002) and Brotheridge and Lee (2002) conceptualize emotional dissonance as a choice of service workers to respond to job characteristics (defined as frequency, intensity, duration, quality, and variety of customer/client interactions combined with applicable display rules) with surface or deep acting strategies; and that the chosen emotion regulation strategy (surface or deep acting) is more relevant for predicting emotional dissonance than job 
characteristics. However, the manipulated organizational variables of the current study suggest that dynamics affecting emotional dissonance go beyond service worker perception of work demands and choice of emotion regulation strategy and that emotional dissonance is better understood as a job stressor with predictable job characteristics defining this stressor.

The conceptualization of emotion work as an external task entailing five possible emotion job requirements and the stressor, emotional dissonance (Figures 2, 3, and 4). The field study and experimental findings regarding these critical current study concepts show that independent from personal determinants and attendant individual approaches to external task redefinition, organizational determinants can lead to predictable consequences. The understanding of emotion work and particularly emotional dissonance as external tasks presented in this study broadens recent elaborated models of emotional self-regulation in emotion work (Brotheridge \& Grandey, 2002; Brotheridge \& Lee, 2002; Totterdell \& Holman, 2003). This conceptualization of emotion work goes beyond the understanding of emotion work simply in terms of demands and worker efforts to comply with these demands. In emotion work demand models, neither the direct effects of job characteristics nor the existence and effect of related display rules on burnout variables are accounted for nor demonstrated (Brotheridge \& Lee, 2002). In the Brotheridge and Grandey (2002) study, effects of high vs. low demanding occupations (frequency, variety and intensity of customer contact) on negative individual consequences (burnout) are hypothesized but could not be empirically demonstrated, and results argue against hypothesized positive effects (personal accomplishment) of demanding occupations. The interpretation of such findings hinges on understanding 
emotion work as a multidimensional construct, including emotional dissonance as a stressor (Zapf, 2002) leading to negative consequences, or a requirement fitting the ability and consequence of service workers-leading to positive individual as well as inner organizational and customer consequences (Zapf et al., 1999; Zapf et al., 2001). The mixed results regarding job-focused determinants on emotion work consequences in demand models might be a consequence of narrowed concepts and perspectives of work demands, which might be overcome by understanding emotion work and emotional dissonance as a job characteristic in a more encompassing work psychology framework (Hackman, 1969, 1970; Zapf, 2002).

Relating study findings regarding redefinition determinants. It was shown that socialization strategies (organizational socialization), considered an inner organizational determinant variable (service worker reported methods of how their organizations communicate their display rules), and professional identity, considered a personal determinant variable (service worker reported selfaccepted professional role expectations), are important variables in understanding emotion work as a job demand. By means of hierarchical regression analysis of police, teacher and travel agent surveys, organizational socialization and professional identity explained substantial variance in reported emotion work requirements and emotional dissonance. These findings support the conclusion of several studies that the questions of where display rules are acquired from and if service workers agree with and consider them personally important are essential in understanding phenomena of emotion work (Ashforth \& Humphrey, 1993; Ashforth \& Tomiuk, 2000; Blum \& Rosenberg, 1968; Brotheridge \& Lee, 2002; Rafaeli, 1989b; Sutton, 1991). Brotheridge and Lee 
(2002) found in their empirical test of an emotion work model that the social influence employees receive was positive related to reported communication of display rules, which was shown to affect in turn role characteristics and in turn frequency of performed surface and deep acting. As sources and strategies of display rule communication, this study considers social influence and the communication of display rules as organizational socialization strategies (Figure 2, p. 37, RS Model). In accordance with the Brotheridge and Lee model, these strategies and display rules define emotion work requirements (positive and negative emotions, neutrality, sensitivity, and sympathy) and the job stressor, emotional dissonance as it was shown in the police and travel agent samples. Both models propose similar assumptions and show similar effects of organizational socialization. They differ, however, regarding if and how authenticity and role identification enter the emotion work process. In the Brotheridge and Lee model, authenticity is considered a dependent variable affected by both the emotional strategy chosen by the service worker and high identification and commitment to job role. Brotheridge and Lee found authenticity reduced by the showing of emotions not actually felt (surface acting) and reinforced by a high identification and commitment to the job role. The current study considers authenticity and role identification as aspects of professional identity which in the proposed dynamic of task redefinition, affects emotion work strategies (Figure 2, p. 37, RS Model). In other words, authenticity and role commitment are presented in the current study as independent variables rather than dependent variables as in the Brotheridge and Lee model. According to findings in the present study, a strong commitment to display rules such as students/customer orientation in the teacher and travel agent samples and a 
strong commitment to police values in the police sample explain (holding other variables constant) reduced emotional dissonance. The current study findings which regard authenticity and role commitment as independent variables are reinforced by qualitative findings of Ashforth and Tomiuk (2000). In their study, professionals report that they "act" during customer/client interactions, yet at the same time describe their customer/client interactions as authentic reflectance of their true self. It is suggested that role commitment is more a question of how one defines his/her job rather than how the job affects the true self. Even though it was predicted in the three experiments of the current study that the friendly display rule would lead to more emotional dissonance than the authentic display rule, it was also expected, in line with the Ashforth and Tomiuk treatment of authenticity, that the display rule "be authentic" could still lead to a demand of emotional dissonance due to self-imposed (role commitment) conditions of "one should display emotions not actually felt in a service situation, no matter what." Treating role commitment and authenticity as independent variables, the results of this study suggest that even if one is authentic, this does not necessarily mean that one will not experience emotional dissonance as is suggested in the Brotheridge and Lee model. The present study decoupling of these variables suggests that emotional dissonance is a stressor whenever a person is required to show emotions not actually felt, whether that requirement is organizationally imposed or personally (role commitment) imposed. 


\subsection{Strength and limitations of the study}

This study has overall strengths and limitations. The scope of this dissertation was not to examine the entire structure of emotion work as presented in the Redefinition Self-Regulation Model of Emotion Work (Figure 2, p. 37) but rather to examine relevant predictor variables of emotion work job demands. One limitation is the possibility that important variables were not taken into account. The interpretation of occupational differences in emotion work requirements and emotional dissonance by means of occupational differences in major task, service characteristics, and interdependence characteristics were more derived from plausibility conclusions. These findings need cross validation by further research, including explicit measurements of postulated occupation-specific major tasks, service-, and interdependence characteristics. One might also argue that the directional interpretation of field study findings in a cross sequential design needs to be examined in a cross panel design by further research. However, applying causal interpretation of experimental effects and nomological interpretation of field study findings regarding if and how organizational determinants affect emotional work, it is postulated that characteristics of organizational determinants are involved in how: (a) major tasks and customer demands lead to organizational display rules, and in turn how different occupations have different emotion work display rules; (b) how these display rules in combination with customer events can affect emotion work requirements and emotional dissonance; (c) that display rules are part of the organizational culture and acquired by socialization strategies; and (d) that self-imposed role expectations are relevant in the task redefinition of emotion work. There are also 
validity and adequacy concerns regarding the research effort to explore determinants of emotion work using self description questionnaires. The FEWS (Zapf et al., 1999; Zapf et al., 2000) were applied, considered to be a behavior requirement approach in assessing job characteristics. It can be argued in support of this study that FEWS item scales are controlled for effects of individual characteristics and individual emotional and cognitive processing. The interpretation that hypothesized and revealed occupational differences in FEWS requirement scales and emotional dissonance are more affected by organizational determinants than by personal characteristics might be a somewhat cyclical interpretation. An alternative interpretation could be that idiosyncratic perceptions of job characteristics and strategies for dealing with demands vary systematically between occupations, influenced by personality-based decisions regarding work environments and voluntary turnover. This hypothesis was investigated in a study of effects of personality on emotion work, measured as job requirements and stressors with the FEWS (Fischbach \& Zapf, 2003). The analyses revealed only small effects of personality variables and demonstrated the postulated differences in emotion work requirements and emotional dissonance, even after controlling for personality. This supports the assumption of organizational determinants affecting the reported requirements and stressors in the FEWS scales. One further limitation of this study might concern the professional identity scales that were developed and the testing of hypothesized effects of professional identity in the redefinition process of emotion work within the same samples. These results need cross-validation with independent samples. However, it is expected that similar results can be shown in new samples due to the systematic and interpretable effects of professional identity scales among all 
three highly diverse occupations within scales that lead to comparable results (e.g., assertion style reinforcing emotional dissonance vs. citizen/student orientation diminishing emotional dissonance in the police as well as teacher sample). A strength of this study is the multimethod approach, combining field studies with job incumbents and experiments with student samples to support assumptions derived from the RS Model. However, experiment limitations include that findings are based on a sample of students rather than professionals and that the short-term and controlled conditions of an experiment have nothing in common with actual work processes. The opposite could be argued: that an experimental setting with assigned tasks given to students, accompanied by written instructions, is just another work setting and job requirement results are as valid in this setting as any so-called actual work setting. Nevertheless, transferability of results and conclusions to workforce might be taken into question. The three experiments presented in this study show comparable results, all supporting the assumptions postulated for each experiment and derived from the RS Model. These reliable results give no reason to believe that the students reacted to the experimental manipulation dishonestly. This speaks to the internal validity of the experiments. Moreover, the shown effects, although in an unnatural and short-term situation, give rise to the possibility that these effects (holding all other variables constant) might be overestimated for real work situations. In real work situations, service workers might in fact suffer less from a single negative customer event combined with a display rule to act friendly, such as students did in the presented experiments, because they might be familiar with such situations and have developed well-honed strategies to handle such customers compared to inexperienced students. This presumption supports that in 
real work life, the complexity of emotion work illustrated by the RS Model has to be taken into account in field research. The strength of this presented study was to separate hypotheses and show evidence of parts of the RS Model by reducing the complexity of emotion work. It is proposed that the empirically demonstrated experimental effects can be interpreted as starting points for efforts to understand emotion work and its complex dynamics in real work life.

To conclude, the results support the primary contention of this study-as proposed and illustrated in the RS Model — that emotion work and in particular the aspect of emotional dissonance can be viewed as an external task, entering the emotion work process independent of individual work behavior. It is proposed that the breadth of this concept of emotion work allows the examination of effects of several organizational consequences: positive as well as negative employee consequences, customer consequences, and inner organizational success consequences. The findings of this study speak to the benefits of mindful job design and redesign and managing emotion work organizational determinants to the extent possible, proactively preventing or minimizing individual negative consequences and enhancing individual positive consequences of emotion work (Zapf \& Semmer, in press).

\subsection{Job Design in Emotion Work}

The findings of this study speak to the benefits of managing emotion work organizational determinants and personal determinants - proactively minimizing negative consequences and enhancing positive consequences of emotion work. Ideally, positive organizational consequences should be maximized with regard 
to employees (e.g., health and well being); customers (e.g., service satisfaction); and pay-offs (e.g., organizational success). However, considering all three factors equally might lead to conflicting goals, because "there is no business without customers in service," yet customers can be the primary source of stressors for employees. According to action theory and its general suggestions for job design (Hacker, 1973, 1998; see also Frese \& Zapf, 1994; Zapf, 2002), job design should optimize emotion work job requirements (i.e., variability and complexity) so that they are in line with performance abilities of the individual (avoiding excessive and deficient demands), enhance emotion work job control (leeway in decision-making regarding how to deal with clients to fulfill the task), promote performance abilities of the individual by providing supervisor and coworker support, and diminish stressors (emotional dissonance). The optimal job design being difficult to achieve and it is conceivable that an enhancement of emotion work job control and/or a diminishment of emotional dissonance can be in conflict with customer demands. Providing customer oriented service at all times and under all conditions; or offering a benefit in personality enhancement and workplace health promotion; or increasing organization success by controlling human resource costs can all be seen to be in conflict- the first demanding maximum staffing, the second demanding costs for training classes on stress management, and the third entailing lower salaries, manpower reduction or a longer work week. However, it is strongly believed and possibly even quantifiable that organizational costs incurred from poor job design have employee, customer service, and organizational success consequences that outweigh any short-term gains. Setting up non-sustainable service expectations can bankrupt an organization; no attention to stress management needs of 
employees can lead to high turnover (impacting both customer service and organizational success), and poorly-compensated staff can make the organization vulnerable to strategic talent hiring on with competitors or employees being overworked to the point of inability to provide high standards of service. As proposed in several propositions derived from the RS Model (Figures 3 and 4), occupational determinants: major task, service- and interdependence characteristics - chapter 3; and redefinition determinants: the external task and professional identity-chapter 4; were found to affect emotion work requirements (Field Study Part 1); emotional dissonance (Field Study Part 1 and Experiments 1, 2, and 3); emotion work strategies (Experiments 1 and 3); and emotion work consequences (Experiments 1 and 2). The following section discusses how these empirical findings and interpretations of these findings can contribute to emotion work job designs to optimize external tasks and task redefinition.

Optimizing emotion work external tasks by customer demand management. One of the most effective starting points of proactive job design in service jobs seems to be managing the customer demands. In the three experiments it was shown that negative customer behavior was a primary contributor to the job stressor, emotional dissonance. It is suggested that proactive management of customer expectations, and therefore behavior, would diminish the probability for negative events for service workers and in turn diminish emotional dissonance without costs with regard to customer satisfaction. What level of service can a customer assume from a given organization? IKEA, the Swedish home furnishings firm, actively manages customer service demands and expectations. In their catalogue they explain that 
their long lines at the cash registers, the need for self transport, and their policy of product self-assembly is done in the interest of satisfying customers: long lines are the result of IKEA popularity, and both self-transport and self-assembly help keep prices as low as possible. This approach to managing customer service demands and expectations implies the basic assumption that customers are willing to adjust, they will accept self-service and self-assembly as long as they believe they benefit, and if they are informed about these rules, the rules will be better understood and accepted. IKEA customers understand IKEA culture and its service-providing policies because these aspects are explicitly, actively communicated via multiple means: catalog, television commercials, billboards, radio and internet ads, etc. No one is indignant that they have to return their tray in a McDonald's restaurant, but customers can be expected to complain if at a four star restaurant the table is not cleared and cleaned after the main course and before dessert. Another example of customer management is the Canadian Toronto police department with the slogan "to serve and protect" on every patrol car. This slogan is intended to communicate to citizens that the intention of Canadian Toronto police officers is to "to serve and protect" vs. intimidate, bully, or be an object of fear. An example of customer management in the teaching profession is when schools provide brochures explaining the pedagogy of the school, what type of student and parent support is offered by their teachers, channels of communication in place to voice concerns such as regularlyscheduled parent-teacher meetings, and rights and responsibilities of the students. It is assumed that these examples of explicit definition of service are part of customer management strategies because they control customer service expectations and therefore customer behavior. 
Optimizing emotion work external tasks by display rule management. In the three experiments of this study it was shown that, in addition to customer behavior, display rules another important contributor to the job stressor, emotional dissonance. The display rule instruction 'be authentic' lead to less emotional dissonance than the display rule 'be friendly' in a situation where a customer behaved in a very negative manner. It is suggested that the authentic display rule offers greater leeway regarding how to interact with the customers. It was demonstrated by observation that the authentic display rule lead to more interaction control for the service provider and in turn less emotional dissonance. In this study it is argued that police officers and teachers have greater social interaction control by virtue of their authority figure status and the dependence of their clients compared to travel agents whose success is more dependent on customers and sales (Nerdinger, 1994). The empirical findings of Field Study Part 1, higher emotional dissonance in the travel agent sample compared to lower reported emotional dissonance in the police and teacher samples, might be explained by differences in relative service worker-client status and control parameters among the three occupatins. These findings offer empirical support for the general aforementioned claim that interaction control leads to less emotional dissonance for the service worker. But the reinforcement of control might be problematic in emotion work because the reinforcement of control can lead to negative organizational consequences (less customer satisfaction and/or less organizational success). Police officers who are allowed to decide how they interact with clients might interact self-directedly in an organizationally-desired manner, but they also might not — and the same holds true for teachers. The findings of Field Study Part 1 also empirically demonstrated low emotional 
requirement variability for travel agents (dominant requirement being display of only positive emotion), and a higher variability in emotional requirements of police and teachers (requirement to display positive and negative emotions, neutrality, sensitivity, and sympathy). This was interpreted with regard to occupational determinants of service- and interdependence characteristics, particularly that travel agent success is dependent on customers and sales compared to success dependencies of teachers and police who are neither dependent on customer satisfaction as defined in the classic sense nor on sales (Nerdinger, 1994). The major task of travel agents (selling travel), coupled with their lower status and control relative to customers are proposed to affect the dominant display rule to show positive emotions toward customers and consequent relatively higher reported emotional dissonance compared to police and teacher samples. One proactive, management strategy for enhancing service worker job control might be to offer a personnel suggestion system, leading to discourse regarding what display rules in given situations are organizationallydesirable and promote both service worker health and organizational success. Organizations can become better informed regarding service worker customer challenges, have a forum for explicitly communicating display rules in line with various situational requirements, and have information with which to manage customer behavior and demands.

Optimizing emotion work redefinition processes by socialization strategies. In Field Study Part 2 with police, teachers and travel agents, it was empirically demonstrated that for police and somewhat for travel agents, perceived organizational socialization affected the redefinition process of emotion work. These findings might offer some suggestions for human resource 
management in emotion work. Organizations should attempt to explicitly define display rules that have proved successful and in line with the customer demands they target to serve, meeting major and primary tasks and minimizing negative consequences. Given emotion work external tasks designed and managed as mentioned above, the question becomes how personnel can be selected, trained and educated to comply with these demands. Display rules should be in line with the primary tasks and corporate culture and should be explicitly communicated by socialization strategies; e.g., personnel training and other education techniques such as documentation regarding which display rule is acceptable in which situation. Person-environment fit can be enhanced by explicitly communicating these display rules, especially during recruitment and selection. An example of display rule management during personnel selection is when the Niedersachsen police department decided in 2000 to add a broad social ability assessment center to their personnel selection test-battery (Fischbach, 2000). At the social ability assessment center they informed applicants that they are looking for service-oriented behavior as this is what is required in modern police work in addition to traditional police assertion skills. It seems optimal to make emotional competences part of personnel selection criteria, but it is probably possible to increase competences in incumbent service workers by providing targeted training, including perception of customer emotions, reframing strategies, detached concern strategies, and behavioral skills (Fischbach \& Zapf, 2002; Hochschild, 1983; Meichenbaum, 1991; Totterdell \& Holman, 2003; Zapf, 2002; Zapf, Isic, Fischbach, \& Dormann, 2003).

Optimizing emotion work redefinition processes by reinforcing aspects of professional identity. One of the suggestions of this study is that deliberated and 
clearly defined display rules (see above) be part of the corporate culture, and that display rules be communicated by explicit organizational socialization strategies. This approach to display rules would most likely reinforce commitment to display rules both by management in their definition and reasonableness and by employees in adherence and actual display (Frese, 1982; Semmer \& Schallberger, 1996). Personal commitment to certain display rules was shown in Field Study Part 2 to reinforce the redefinition of this display to an internal task. According to the organizational determinants depicted in the RS Model defining external tasks, this reinforcement of the redefinition of display rules to an internal task should also affect task behavior in an organizational-deliberated manner. In Field Study Part 2, citizen/student/customer orientation was particularly shown to reinforce the positive emotion display rule and diminish emotional dissonance in teacher and travel agent work. Commitment to police values was shown to diminish emotional dissonance in police work and a personal valuing of assertion styles reinforced emotional dissonance in the surveyed police and teacher samples. Given the predictable negative consequences of emotional dissonance, it is possible to build suggestions regarding which personnel values should be reinforced by organizational socialization in order to minimize negative consequences. 


\section{Summary}

Emotion work is an inherent part of service work, including organizationallydesired emotions regarding customer interactions and psychological strategies of service workers necessary to regulate these emotional demands. Several diverse conceptualizations and perspectives in emotion work research are integrated into a three-part Redefinition Self-Regulation Model of Emotion Work (RS Model) of job demand-strategy-consequences, emulating Hackman's $(1969,1970)$ threepart input-strategy-outcome framework for assessing the effects of work tasks. This study focuses on understanding emotion work as a job demand, including the five job requirements to display positive, negative, neutral, and/or sympathetic emotions and to be sensitive to customer emotions; and the one job stressor, emotional dissonance, which occurs when job-required emotions are not actually felt in a customer situation. The study attempts to extract from emotion work literature and empirical findings those variables that can be considered antecedents of emotion work job demands and strategies and those variables that can be considered consequences of emotion work job demands and strategies, integrates them in the proposed framework (RS Model), and elaborates upon them with 14 propositions. The first part of the RS Model conceptualizes emotion work demands in a dynamic of organizational determinants defining 
external tasks ("what one ought to do"); the task redefinition process ("how one perceives this ought-to-do task") leading from external tasks to internal tasks; and the internal task ("what one thinks one ought to do") resulting from external task-defining and redefining variables (variables affecting how the task is instructed to employees; and variables affecting how the task is received and perceived by the employees).

Propositions regarding external task determinants and predictable effects of these task determinants derived from the RS Model are examined by Field Study Part 1 with police $(N=221)$, teacher $(N=209)$ and travel agent samples $(N=202)$; and by three experiments (Experiment 1, $N=80$; Experiment 2, $N=$ 20; Experiment $3, N=30$ ) with student samples. Results of Field Study Part 1 show that the three highly diverse occupations have predictable differences in emotion work demands, measured by job descriptions of service workers in the Frankfurt Emotion Work Scales (FEWS, Zapf et. al., 1999; Zapf et al., 2000). Teachers report frequent requirements to display positive as well as negative emotions, police report less frequencies of requirements to display positive as well as negative emotions compared to teachers, whereas travel agents report predominantly high frequency of only positive emotion displays, in combination with a higher amount of emotional dissonance compared to teachers and police. Findings are interpreted regarding differences in occupation-specific external task determinants: major tasks, service-, and interdependence characteristics. The experiments include the development of an experimental paradigm to test the proposition that emotional dissonance is an external task. Emotional dissonance as an external task is presented as being particularly defined by, among other variables, display rules (organizationally-required expectations regarding how 
employees should behave emotionally while interacting with customers/clients) and customer events (frequency, intensity, duration, quality, and variety). Given rude customer behavior (intensely negative customer event) where an average person innately feels disgust or anger, emotional dissonance should predictably be evoked by the display rule to be friendly (be customer-oriented in all circumstances); whereas the display rule to be authentic (be natural and genuine in all circumstances) should evoke less emotional dissonance. In all three experiments, this experimental paradigm leads to hypothesized consequences of display rule manipulation. The friendly display rule, compared to the authentic display rule, leads to: higher reported emotional dissonance (effect of organizational determinants on the emotion work external task, shown in Experiments 2 and 3); higher effort while dealing with tasks involving difficult clients/customers (effect of the emotion work stressor on the emotion work strategy/process, shown in Experiment 1); higher quality in displayed customer orientation (effect of the emotion work stressor on task behavior, shown in Experiment 3); and a higher state negative affect after dealing with the task (effect of the emotion work stressor on emotion work consequences, shown in Experiments 1 and 2). Field Study Part 1 and Experiments 1 through 3 empirically demonstrate that emotion work requirements and particularly emotional dissonance are affected by external organizational variables which have predictable effects - independent of individual cognitions, emotional reactions, and actual task behavior.

Propositions regarding task redefinition determinants were examined in the second part of the field study with police, teacher and travel agents (Field Study Part 2). It is proposed that organizational socialization (how organizations 
communicate their display rules) as an external task determinant is the pivotal organizational determinant in task redefinition; and that professional identity (self-imposed professional role expectations) as a further redefinition determinant is the pivotal personal determinant in task redefinition. Emotional competence, personality, and gender are also proposed as important personal determinants in task redefinition, but are not investigated by this study. Results of Field Study Part 2 support the assumption that organizational socialization and professional identity are important variables in understanding emotion work requirements, the emotion work stressor, emotional dissonance, and external-tointernal task redefinition in service work. Reported organizational socialization strategies in the police sample reinforces all emotion work requirements and emotional dissonance; and personal commitment to customer-orientation norms and values diminish emotional dissonance in the teacher and travel agent sample.

The Redefinition Self-Regulation Model of Emotion work is a useful framework for integrating the emotion work literature and empirical findings, applying a more general work psychological framework that allows examination of external task effects under the question of how positive effects of emotion work can be reinforced and negative effects of emotion work can be diminished by job design and redesign. The findings of Field Study Part 1 and those of Experiments 1 through 3 lead to suggestions regarding optimizing emotion work external tasks by explicitly managing emotion work display rules and customer events. The findings of Field Study Part 2 lead to suggestions regarding optimizing redefinition processes through socialization strategies and reinforcing aspects of professional identity (e.g., customer orientation) to reinforce positive effects of emotion work and minimize negative effects of emotion work. 


\section{References}

Abraham, R. (1998). Emotional dissonance in organizations: Antecedents, consequences, and moderators. Genetic, Social \& General Psychology Monographs, 124, 229-246.

Adelmann, P. K. (1995). Emotional labor as a potential source of job stress. In S. L. Sauter \& L. R. Murphy (Eds.), Organizational risk factors for job stress (pp. 371-381). Washington, DC: American Psychological Association.

Ash, M. K. (1984). Mary Kay on people management. New York: Warner Brooks.

Ashforth, B. E., \& Humphrey, R. H. (1993). Emotional labor in service roles: The influence of identity. Academy of Management Review, 18, 88-115.

Ashforth, B. E., \& Humphrey, R. H. (1995). Emotion in the workplace: A reappraisal. Human Relations, 48, 97-125.

Ashforth, B. E., \& Tomiuk, M. A. (2000). Emotional labour and authenticity: Views from service agents. In S. Fineman (Ed.), Emotion in Organizations (pp. 184-203). London: Sage.

Bakan, D. (1966). The duality of human existence: An essay on psychology and religion. Chicago: Rand McNally.

Bandura, A. (1977). Social learning theory. Englewood Cliffs, NJ: Prentice-Hall.

Bandura, A. (1986). Social foundations of thought and action: A social cognitive theory. Englewood Cliffs, NJ: Prentice-Hall.

Bauer, T. N., Morrison, E. W., \& Callister, R. R. (1998). Organizational socialization: A review and directions for future research. In G. R. Ferris (Ed.), Research in personnel and human resources management, Vol. 16 (pp. 149-214). Greenwich: JAI Press.

Blum, A. F., \& Rosenberg, L. (1968). Some problems involved in professionalizing social interaction: The case of psychotherapeutic training. Journal of Health \& Social Behavior, 9, 72-85.

Bowen, D. E., \& Schneider, B. (1988). Services marketing and management: Implications for organizational behavior. Research in Organizational Behavior, 10, 43-80.

Briner, R. B. (1995, July). Emotional dissonance, emotional deviance, true feelings, and the self in organizational life. Paper presented at the 12th EGOS Colloqium, Istanbul. 
Brotheridge, C. M., \& Grandey, A. A. (2002). Emotional labor and burnout: Comparing two perspectives of "people work". Journal of Vocational Behavior, 60, 17-39.

Brotheridge, C. M., \& Lee, R. T. (1998, August). On the dimensionality of emotional labor: Development and validation of an emotional labor scale. Paper presented at the 1st Conference on Emotions in Organizational Life, San Diego, CA.

Brotheridge, C. M., \& Lee, R. T. (2002). Testing a conservation of resources model of the dynamics of emotional labor. Journal of Occupational Health Psychology, 7, 57-67.

Buessing, A., \& Glaser, J. (1999). Work stressors in nursing in the course of redesign: Implications for burnout and interactional stress. European Journal of Work \& Organizational Psychology, 8, 401-426.

Chatman, J. A. (1991). Matching people and organizations: Selection and socialization in public accounting firms. Administrative Science Quarterly, 36, 459-484.

Cohen, J. (1988). Statistical power analysis for the behavioral sciences. New York: Erlbaum.

Cooley, C. H. (1902). Human nature and the social order. New York: Scribner's.

Davies, M., Stankov, L., \& Roberts, R. D. (1998). Emotional intelligence: In search of an elusive construct. Journal of Personality \& Social Psychology, 75, 989-1015.

Dieckhoff, K., Freigang-Bauer, I., Schröter, W., \& Viereck, K. (2002). CCall Report 1. Branchenbild Call Center [Call centre branch overview]. Hamburg: Verwaltungs-Berufsgenossenschaft.

Dormann, C., Zapf, D., \& Isic, A. (2002). Emotionale Arbeitsanforderungen und ihre Konsequenzen bei Call Center-Arbeitsplätzen. [Emotional demands and consequences in call center work]. Zeitschrift für Arbeits- und Organisationspsychologie, 46, 201-215.

Eagly, A. H. (1987). Sex differences in social behavior. A social-role interpretation. Hillside, NJ: Erlbaum.

Erdfelder, E., Faul, F., \& Buchner, A. (1996). GPOWER: A general power analysis program. Behavior Research Methods, Instruments, and Computers, 28, 1-11.

Ekman, P., \& Friesen, W. V. (1975). Unmasking the face. Englewood Cliffs, NJ: Prentice Hall.

Faul, F., \& Erdfelder, E. (1992). GPOWER: A priori, post-hoc, and compromise power analyses for MS-DOS. Universität Bonn.

Fischbach, A. (2000). GöPA. Das Göttinger Polizei-Auswahlverfahren. (Handbuch für den Testleiter). [The Göttingen Police assessment for personnel selection; manual for test administrators]. Göttingen: GeorgAugust-Universität, Georg-Elias-Müller-Institut für Psychologie.

Fischbach, A., \& Zapf, D. (2002, September). Neutralität als emotionale Arbeitsanforderung. [Neutrality as an emotional job requirement]. Paper presented at the 43. Kongress der Deutschen Gesellschaft für Psychologie, Humboldt-Universität, Berlin.

Fischbach, A., \& Zapf, D. (2003). Role of personality in service sector emotion work-application of the Big Five personality dimensions. Unpublished manuscript, Georg-August-Universität, Göttingen. 
Foote, N. N. (1951). Identification as the basis for a theory of motivation. American Sociological Review, 16, 14-21.

Frese, M. (1982). Occupational socialization and psychological development: An underemphasized research perspective in industrial psychology. Journal of Occupational Psychology, 55, 209-224.

Frese, M., \& Zapf, D. (1988). Methodological issues in the study of work stress: Objective vs. subjective measurement of work stress and the question of longitudinal studies. In C. L. Cooper \& R. Payne (Eds.), Causes, coping and consequences of stress at work (pp. 375-411). Chichester: Wiley.

Frese, M., \& Zapf, D. (1994). Action as the core of work psychology: A German approach. In H. C. Triandis \& M. D. Dunnette (Eds.), Handbook of industrial and organizational psychology, Vol. 4 (2nd ed., pp. 271-340). Palo Alto, CA: Consulting Psychologists Press.

Frieling, E. (1977). Die Arbeitsplatzanalyse als Grundlage der Eignungsdiagnostik. [Job diagnoses as the basis for aptitude diagnoses] In J. K. Triebe \& E. Ulich (Eds.), Beiträge zur Eignungsdiagnostik (pp. 2090). Bern: Huber. [Contributions to aptitude diagnoses]

Goffman, E. (1959). The presentation of self in everyday life. New York: Doubleday Anchor.

Goleman, D. (1996). Emotional intelligence. New York: Bantam.

Grandey, A. A. (1998, August). Emotional labor: A concept and its correlates. Paper presented at the First Conference of Emotions in Organizational Life, San Diego, CA.

Grandey, A. A. (2000). Emotional regulation in the workplace: A new way to conceptualize emotional labor. Journal of Occupational Health Psychology, 5, 95-110.

Gross, P. (1983). Die Verheißungen der Dienstleistungsgesellschaft. [Prophecies of the service society]. Opladen: Westdeutscher Verlag.

Gutek, B. A. (1997). Dyadic interactions in organizations. In C. L. Cooper \& S. E. Jackson (Eds.), Creating tomorrows organizations today. Chichester: Wiley.

Hacker, W. (1973). Allgemeine Arbeits- und Ingenieurspsychologie [General work and engineering psychology]. Berlin: Deutscher Verlag der Wissenschaften.

Hacker, W. (1998). Allgemeine Arbeitspsychologie. Psychische Regulation von Arbeitstätigkeiten [General work psychology. Psychological regulation of work activity] (4th ed.). Bern: Huber.

Hackman, J. R. (1969). Toward understanding the role of tasks in behavioral research. Acta Psychologica, 31, 97-128.

Hackman, J. R. (1970). Tasks and task performance in research on stress. In J. E. McGrath (Ed.), Social and psychological factors in stress (pp. 202-237). New York: Holt, Rinehart \& Winston.

Hackman, J. R., \& Lawler, E. E. (1971). Employee reactions to job characteristics. Journal of Applied Psychology, 55, 259-286.

Hackman, J. R., \& Oldham, G. R. (1974). The job diagnostic survey: an instrument for the diagnosis of jobs and the evaluation of job redesign projects, Technical Report No 4. Yale University: Department of Administrative Sciences. 
Hager, W. (1987). Grundlagen einer Versuchsplanung zur Prüfung empirischer Hypothesen in der Psychologie. In G. Lüer (Ed.), Allgemeine experimentelle Psychologie (pp. 43-264). [General experimental psychology]. Stuttgart: Fischer.

Hochschild, A. R. (1983). The managed heart. Commercialization of Human Feeling. Berkeley: University of California Press.

Holman, D. J. (2003). Call centres. In D. J. Holman, T. D. Wall, C. W. Clegg, P. Sparrow, \& A. Howard (Eds.), The new workplace: A guide to the human impact of modern working practices. Chichester: Wiley.

James, N. (1989). Emotional labour: skill and work in the social regulation of feeling. Sociological Review, 37, 15-42.

James, N. (1992). Care = organization + physical labour + emotional labour. Sociology of Health and Illness, 14, 488-509.

Jex, S. M., \& Bliese, P. D. (1999). Efficacy beliefs as a moderator of the impact of work-related stressors: A multilevel study. Journal of Applied Psychology, 84, 349-361.

Jex, S. M., Bliese, P. D., Buzzell, S., \& Primeau, J. (2001). The impact of selfefficacy on stressor-strain relations: Coping style as an explanatory mechanism. Journal of Applied Psychology, 86, 401-409.

Kanfer, R. (1990). Motivation and individual differences in learning: An integration of developmental, differential and cognitive perspectives. Learning \& Individual Differences, 2, 221-239.

Karasek, R. A. (1979). Job demands, job decision latitude and mental strain: Implications for job redesign. Administrative Science Quarterly, 24, 385408.

Kasl, S. V. (1986). Stress and disease in the workplace: a methodological commentary on the accumulated evidence. In M. F. Cataldo \& T. J. Coates (Eds.), Health and industry. A behavioral medicine perspective (pp. 52-85). New York: Wiley.

Kruml, S. M., \& Geddes, D. (1998, August). Catching fire without burning out: is there an ideal way to perform emotion labor? Paper presented at the 1st Conference on Emotions in Organizational Life, San Diego, CA.

Kruml, S. M., \& Geddes, D. (2000). Catching fire without burning out: Is there an ideal way to perform emotion labor? In N. M. Ashkanasy \& C. E. Haertel (Eds.), Emotions in the workplace: Research, theory, and practice (pp. 177-188). Westport, CT: Quorum Books/Greenwood.

Lazarus, R. S., \& Folkmann, S. (1984). Stress, appraisal and coping. New York: Springer.

Maister, D. H. (1982). Balancing the Professional Service Firm. Sloan Management Review, 24, 15-29.

May, D. R., Schwoerer, C. E., Reed, K., \& Potter, P. (1997). Employee reactions to ergonomic job design: The moderating effects of health focus of control and self-efficacy. Journal of Occupational Health Psychology, 2, $11-24$.

Mead, G. H. (1934). Mind, self, and society. Chicago: University of Chicago.

Meichenbaum, D. (1991). Interventionen bei Stress. Anwendung und Wirkung des Stressimpfungstrainings. [Stress interventions. Application and effects of stress-immunization training]. Bern: Huber. 
Morris, J. A., \& Feldman, D. C. (1996). The dimensions, antecedents, and consequences of emotional labor. Academy of Management Review, 21, 986-1010.

Morris, J. A., \& Feldman, D. C. (1997). Managing emotions in the workplace. Journal of Managerial Issues, 9, 257-274.

Nerdinger, F. W. (1994). Zur Psychologie der Dienstleistung. Theoretische und empirische Studien zu einem wirtschaftspsychologischen

Forschungsgebiet. [Psychology of service] Stuttgart: Schäffer-Poeschel.

Nerdinger, F. W. (2001). Psychologie des persönlichen Verkaufs. [Psychology of personal sales]. München: Oldenbourg.

Nerdinger, F. W., \& Röper, M. (1999). Emotionale Dissonanz und Burnout. Eine empirische Untersuchung im Pflegebereich eines

Universitätskrankenhauses [Emotional dissonance and burnout. An empirical examination in the nursing sector of a university hospital]. Zeitschrift für Arbeitswissenschaft, 53, 187-193.

Nunnally, J. C., \& Bernstein, I. H. (1994). Psychometric theory (3rd ed.). New York: McGraw-Hill.

Oesterreich, R., \& Volpert, W. (Eds.). (1999). Psychologie gesundheitsgerechter Arbeitsbedingungen. [Psychology of healthy work conditions]. Bern: Huber.

Parasuraman, A., Zeithaml, V. A., \& Berry, L. L. (1988). SERVQUAL: A multiple-item scale for measuring consumer perceptions of service quality. Journal of Retailing, 64, 12-40.

Powell, G. N. (Ed.). (1999). Handbook of gender and work. Thousand Oaks, CA: Sage.

Rafaeli, A. (1989a). When cashiers meet customers: An analysis of the role of supermarket cashiers. Academy of Management Journal, 32, 245-273.

Rafaeli, A. (1989b). When clerks meet customers: A test of variables related to emotional expressions on the job. Journal of Applied Psychology, 74, 385-393.

Rafaeli, A., \& Sutton, R. I. (1987). Expression of emotion as part of the work role. Academy of Management Review, 12, 23-37.

Rafaeli, A., \& Sutton, R. I. (1990). Busy stores and demanding customers: How do they affect the display of positive emotion? Academy of Management Journal, 33, 623-637.

Rice, A. K. (1963). The enterprise and its environment. London: Travistock Publications.

Riggio, R. E. (1986). Assessment of basic social skills. Journal of Personality \& Social Psychology, 51, 649-660.

Rutter, D. R., \& Fielding, P. J. (1988). Sources of occupational stress: An examination of British prison officers. Work \& Stress, 2, 291-299.

Salovey, P., \& Mayer, J. D. (1989). Emotional intelligence. Imagination, Cognition \& Personality, 9, 185-211.

Schaubroeck, J., \& Jones, J. R. (2000). Antecedents of workplace emotional labor dimensions and moderators of their effects on physical symptoms. Journal of Organizational Behavior, 21, 163-183.

Schneider, B. (1986). When individual differences aren't. In K. Murphy (Ed.), Individual differences and behaviors in organizations (pp. 548-572). San Francisco: Jossey-Bass. 
Schneider, B. (1987). The people make the place. Personnel Psychology, 40, 437-453.

Schneider, B., \& Bowen, D. E. (1984). New services design, development, and implementation and the employee. In W. R. George \& C. E. Marshall (Eds.), Developing new services. Chicago: American Marketing Association.

Schuler, H. (2002). Emotionale Intelligenz - ein irreführender und unnötiger Begriff [Emotional intelligence - a misleading and unnecessary concept]. Zeitschrift für Personalpsychologie, 1, 138-140.

Schutte, N. S., Kenrick, D. T., \& Sadalla, E. K. (1985). The search for predictable settings: Situational prototypes, constraint, and behavioral variation. Journal of Personality \& Social Psychology, 49, 121-128.

Schutte, N. S., Malouff, J. M., Hall, L. E., Haggerty, D. J., Cooper, J. T., Golden, C. J. et al. (1998). Development and validation of a measure of emotional intelligence. Personality and Individual Differences, 25, 167-177.

Scott, W. G., Mitchell, T. R., \& Birnbaum, P. H. (1981). Organization theory: A structural and behavioral analysis. Homewood, IL: Richard D. Irwin.

Semmer, N. (1982). Stress at work, stress in private life, and psychological wellbeing. In W. Bachmann \& I. Udris (Eds.), Mental load and stress in activity (pp. 42-55). Amsterdam: North-Holland.

Semmer, N. (1992). One man's meat, another man's poison? Stressors and their cultural background. In M. v. Cranach, W. Doise, \& G. Dugny (Eds.), Social representations and the social basis of knowledge (pp. 153-158). Lewiston, NY: Hogrefe \& Huber.

Semmer, N., \& Schallberger, U. (1996). Selection, socialisation, and mutual adaptation: Resolving discrepancies between people and work. Applied Psychology: An International Review, 45, 263-288.

Silverman, D. (Ed.). (1997). Qualitative research: Theory, method and practice. Thousand Oaks, CA: Sage.

Silverman, D. (2000). Doing qualitative research. A Practical Handbook. London: Sage.

Spector, P. E. (1992). A consideration of the validity and meaning of self report measures of job conditions. In C. L. Cooper \& I. T. Robertson (Eds.), International review of industrial and organizational psychology 1992, Vol. 7 (pp. 123-151). Chichester: Wiley.

Stenross, B., \& Kleinman, S. (1989). The highs and lows of emotional labor. Detectives' encounters with criminals and victims. Journal of Contemporary Ethnography, 17, 435-452.

Stewart, G. L., Carson, K. P., \& Cardy, R. L. (1996). The joint effects of conscientiousness and self-leadership training on employee self-directed behavior in a service setting. Personnel Psychology, 49, 143-164.

Strauss, A., Farahaugh, S., Suczek, B., \& Wiener, C. (1980). Gefühlsarbeit. Ein Beitrag zur Arbeits- und Berufssoziologie [Sentimental work. A contribution to industrial and occupational sociology]. Kölner Zeitschrift für Soziologie und Sozialpsychologie, 32, 629-651.

Stryker, S. (1987). Identity theory: Developments and extensions. In K. Yardley \& T. Honess (Eds.), Self and identity: Psychosocial perspectives (pp. 89103). Chichester: Wiley. 
Sutton, R. I. (1991). Maintaining norms about expressed emotions: The case of bill collectors. Administrative Science Quarterly, 36, 245-268.

Totterdell, P., \& Holman, D. (2003). Emotion regulation in customer service roles: Testing a model of emotional labor. Journal of Occupational Health Psychology, 8, 55-73.

Tsai, W.-C. (2001). Determinants and consequences of employee displayed positive emotions. Journal of Management, 27, 497-512.

Van Maanen, J., \& Kunda, G. (1989). "Real feelings": Emotional expression and organizational culture. In L. L. Cummings \& B. M. Staw (Eds.), Research in organizational behaviour, Vol. 11 (pp. 43-103). Greenwich, CT: JAI Press.

Watson, D., Clark, L. A., \& Tellegen, A. (1988). Development and validation of brief measures of positive and negative affect: The PANAS scales. Journal of Personality \& Social Psychology, 54, 1063-1070.

Weiss, H. M., \& Cropanzano, R. (1996). Affective Events Theory: A theoretical discussion of the structure, causes and consequences of affective experiences at work. In B. M. Staw \& L. L. Cummings (Eds.), Research in organizational behavior: An annual series of analytical essays and critical reviews, Vol. 18 (pp. 1-74). Greenwich, CT: JAI Press.

Wharton, A. S. (1993). The affective consequences of service work: Managing emotions on the job. Work \& Occupations, 20, 205-232.

Wharton, A. S., \& Erickson, R. J. (1995). The consequences of caring: Exploring the links between women's job and family emotion work. Sociological Quarterly, 36, 273-296.

Zapf, D. (2002). Emotion work and psychological well-being: A review of the literature and some conceptual considerations. Human Resource Management Review, 12, 237-268.

Zapf, D., Isic, A., Bechtoldt, M., \& Blau, P. (2003). What is typical for call centre jobs? Job characteristics, and agent-customer interactions in different call centres. Unpublished manuscript, J. W. Goethe-Universität Frankfurt.

Zapf, D., Isic, A., Fischbach, A., \& Dormann, C. (2003). Emotionsarbeit in Dienstleistungsberufen. Das Konzept und seine Implikationen für die Personal- und Organisationsentwicklung. [Emotion work in service occupations. The concept and its implications for workforce and organizational development]. In K.-C. Hamborg \& H. Holling (Eds.), Innovative Ansätze der Personal- und Organisationsentwicklung. [Innovative approaches to workforce and organizational development]. Göttingen: Hogrefe.

Zapf, D., Mertini, H., Seifert, C., Vogt, C., Isic, A., \& Fischbach, A. (2000). FEWS (Frankfurt Emotion Work Scales, Frankfurter Skalen zur Emotionsarbeit). Version 4.0. Frankfurt am Main: Johann Wolfgang Goethe-Universität, Institut für Psychologie.

Zapf, D., Seifert, C., Schmutte, B., Mertini, H., \& Holz, M. (2001). Emotion work and job stressors and their effects on burnout. Psychology \& Health, $16,527-545$.

Zapf, D., \& Semmer, N. K. (in press). Stress und Gesundheit in Organisationen. In H. Schuler (Ed.), Enzyklopädie der Psychologie: Organisationspsychologie (Vol. D III 3). Göttingen: Hogrefe. 
Zapf, D., Vogt, C., Seifert, C., Mertini, H., \& Isic, A. (1999). Emotion work as a source of stress: The concept and development of an instrument. European Journal of Work \& Organizational Psychology, 8, 371-400.

Zeithaml, V. A., \& Bitner, M. J. (2000). Services marketing. Integrating customer focus across the firm (2nd ed.). Boston: McGraw-Hill.

Zerbe, W. J. (2000). Emotional dissonance and employee well-being. In N. M. Ashkanasy \& C. E. Haertel (Eds.), Emotions in the workplace: Research, theory, and practice (pp. 189-214). Westport, CT: Quorum Books/Greenwood.

Zerssen, D. v. (1970). Die Befindlichkeits-Skala. [Emotional condition scale]. Weinheim: Beltz. 


\section{Curriculum Vitae}

Geburtsdatum, -ort:

26.2.1969, Montabaur

Schule:

1975-1979 Grundschule, Heilberscheid/Westerwald

1979-1985 Realschule, Montabaur/Westerwald

(Abschluß: Mittlere Reife)

1988-1991 Ketteler Kolleg, Mainz (Abschluß: Abitur)

Universität:

1991-1999 Studium der Soziologie, Universität Frankfurt am Main (Abschluß: Vordiplom)

1992-1999 Studium der Psychologie, Universität Frankfurt am Main (Abschluß: Diplom)

Berufliche Ausbildung und Tätigkeiten:

1985-1988 Ausbildung zur Buchhändlerin in Limburg/Lahn (Abschluß: Prüfung vor der Industrie- und Handelskammer (IHK) Frankfurt am Main)

1991

Buchhändlerin in Limburg/Lahn und Frankfurt am Main

1991-1999

div. studentische Tätigkeiten

- $\quad$ Tutorin, wissenschaftliche Hilfskraft, Universität Frankfurt am Main

- Werkstudentin im Bereich Mediaforschung,"DAP Software Büro", Frankfurt am Main

- Vereinsvorstandsreferentin, Publik Forum, Oberursel/Taunus

- Werkstudentin im Bereich Personalberatung, Strametz \& Partner, Eschborn/Taunus

seit 1999

Wissenschaftliche Mitarbeiterin, Universität Göttingen 